\title{
Essays on Holiday Weight Gain, Meat Consumption and Dietary Structure, and Nutritional Outcome of Food Facility in China
}

\author{
Dissertation \\ to obtain the $\mathrm{Ph}$. D. degree \\ in the $\mathrm{Ph}$. D. Program for Agricultural Sciences \\ in Goettingen (PAG) \\ at the Faculty of Agricultural Sciences, \\ Georg-August-University Göttingen, Germany
}

presented by LUO, HENGRONG

born in Yibin, China

Göttingen, May 2020 


\section{D7}

1st supervisor: Prof. Xiaohua Yu, Ph.D.

2nd supervisor: Liangzhi You, Ph.D.

3rd supervisor: Prof. Dr. Yasemin Boztug

Date of dissertation: 15. 07. 2020 


\section{Contents}

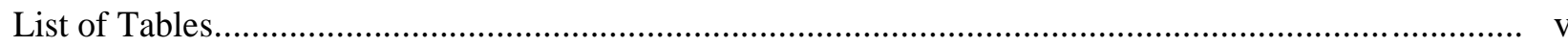

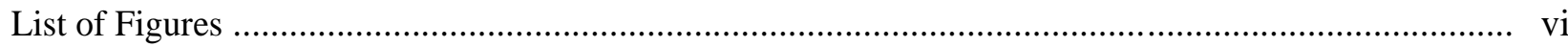

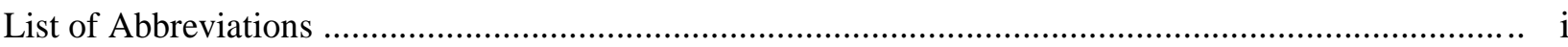

vi

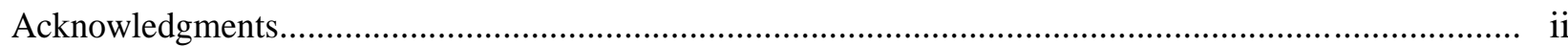

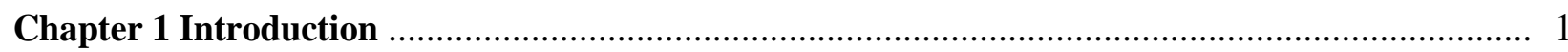

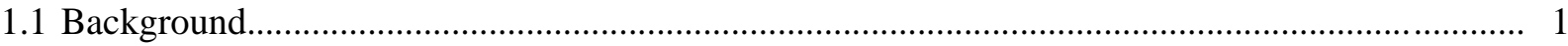

1.2 Motivation and problem statement

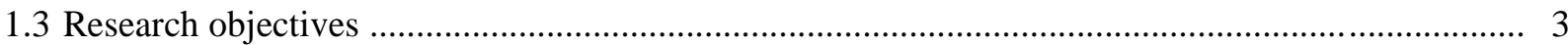

Chapter 2 Holiday and Weight Gain: Evidence from the National Day Holiday ........................... 6

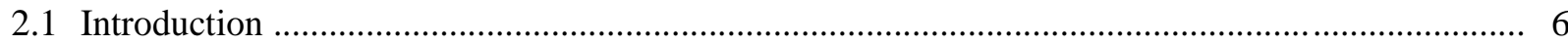

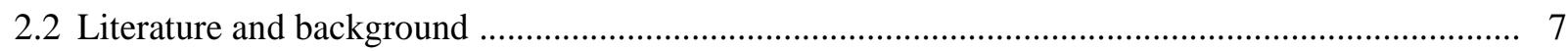

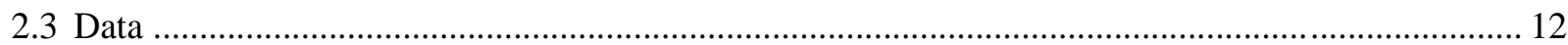

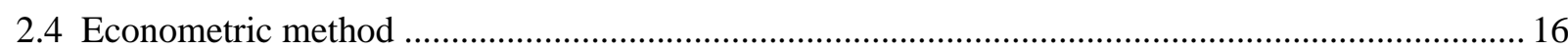

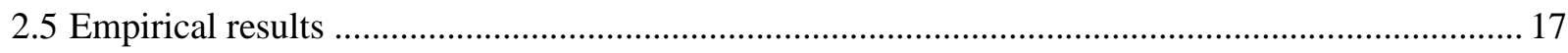

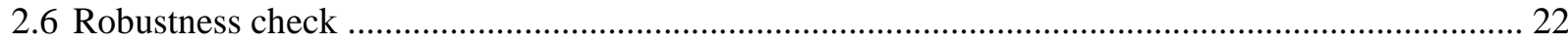

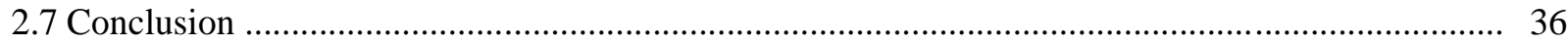

Chapter 3 Meat Consumption, Dietary Structure and Nutrition Transition in China ................... 38

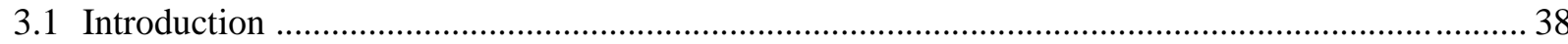

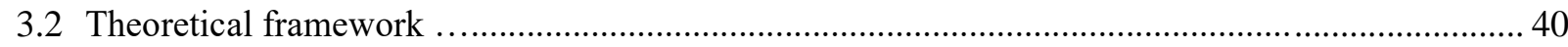

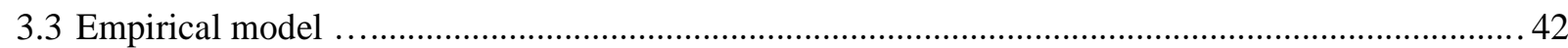

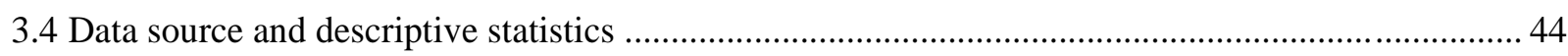

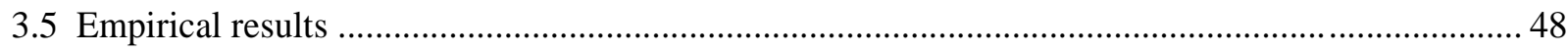

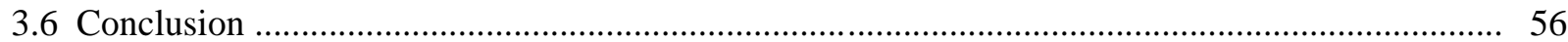

Chapter 4 Food Facility, Dietary Patterns, and Obesity in China ............................................... 58

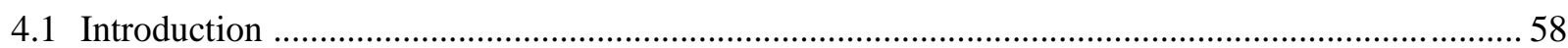




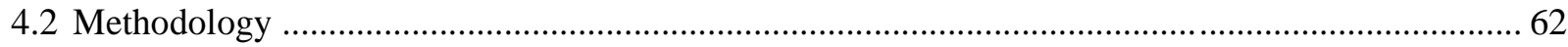

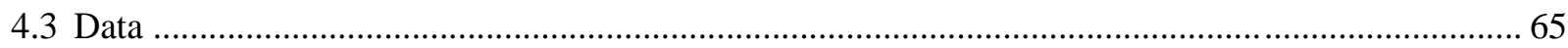

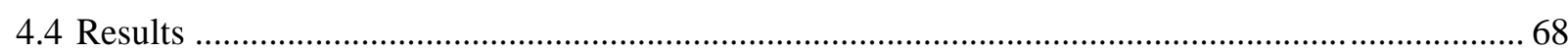

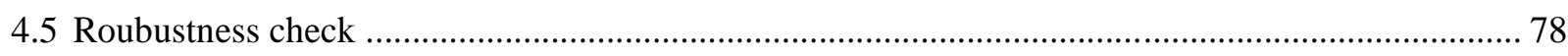

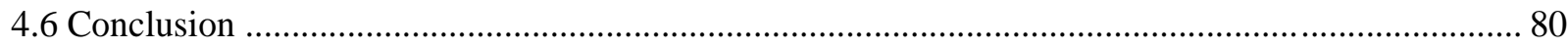

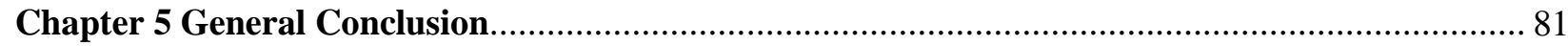

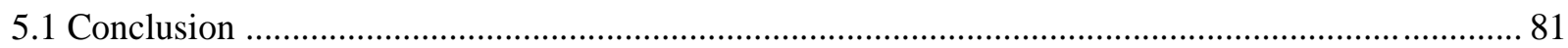

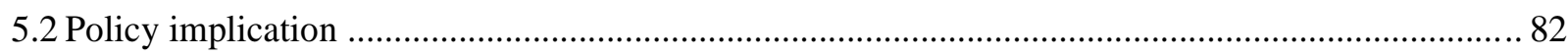

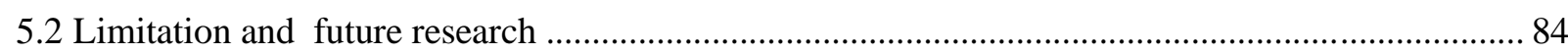

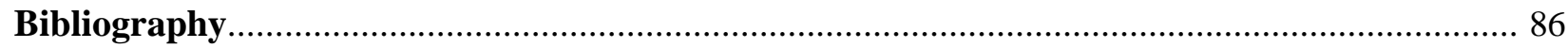

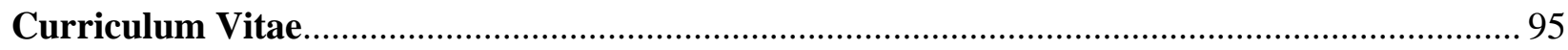


Essays on Holiday Weight Gain, Meat Consumption and Dietary Structure, and Nutritional Outcome of Food Facility in China 


\section{List of Tables}

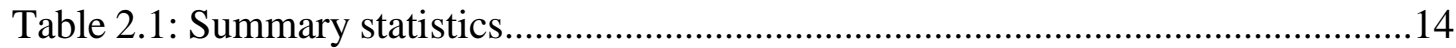

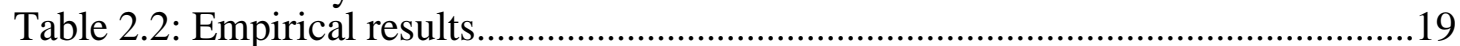

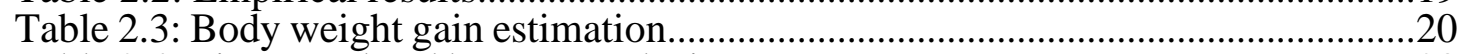

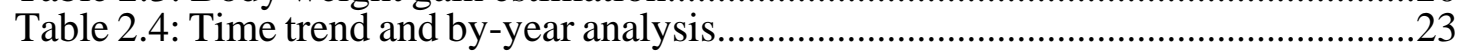

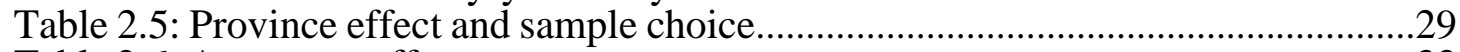

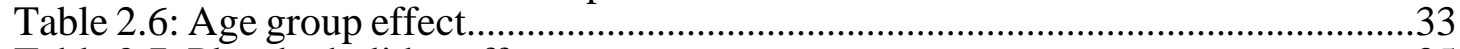

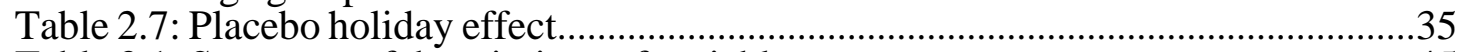

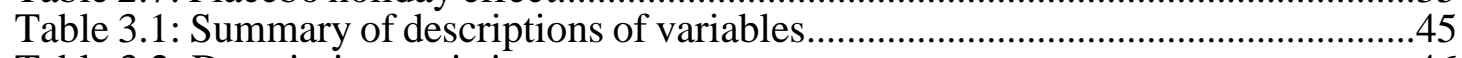

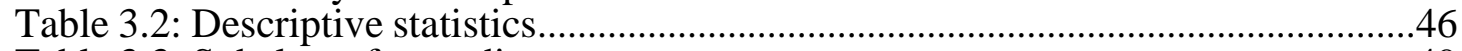

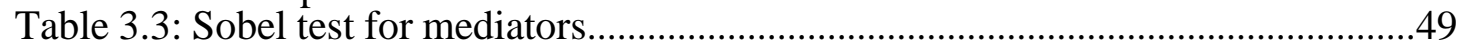

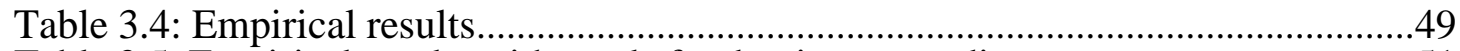

Table 3.5: Empirical results with staple food ratio as a mediator.................................51

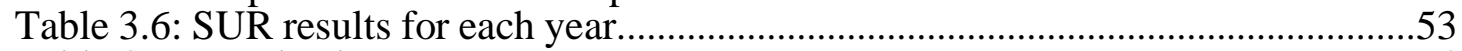

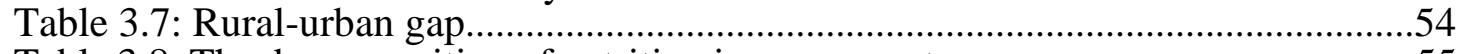

Table 3.8: The decomposition of nutrition improvement............................................55

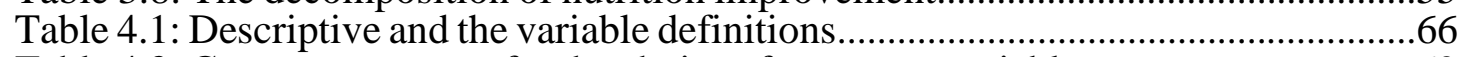

Table 4.2: Common supports for the choice of treatment variables................................69

Table 4.3: Propensity score function...........................................................................

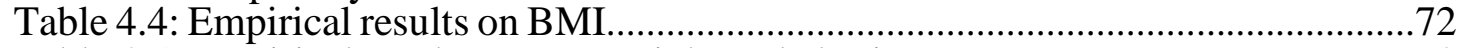

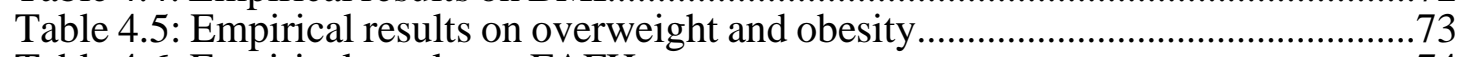

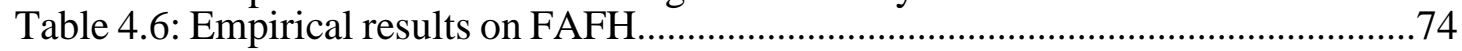

Table 4.7: Food facility on BMIunder multiple treatments framework ............................76

Table 4.8: Food facility on Obesity under multiple treatments framework.....................77

Table 4.9: Empirical results on SSB consumption.......................................................

Table 4.10: Instrumental variables regression for the nutritional outcome of Chinese

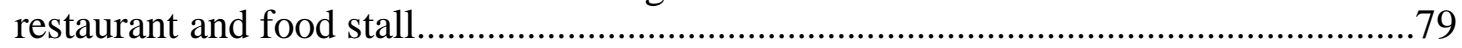




\section{List of Figures}

Figure 2.1 Duration of National Day holiday in China..................................................11

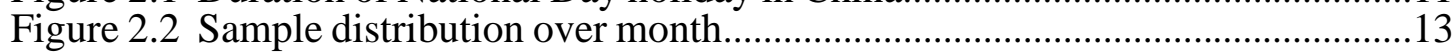

Figure 2.3 Distribution of time_lag...................................................................... 17

Figure 2.4 Distribution of BMIwith 7-7/14/30 windows...........................................21

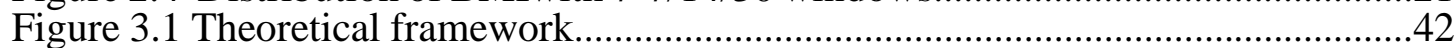

Figure 3.2 The fitted values of calorie consumption on income.....................................46

Figure 3.3 Meat consumption and income dynamics..................................................47

Figure 4.1 Balancing test for propensity scores on different treatment variables...........70 


\section{List of Abbreviations}

ATT: Average Treatment Effect on the Treated

BMI: Body Mass Index

CPI: Consumer Price Index

IFPRI: International Food Policy Research Institute

CHNS: China Health and Nutrition Survey

FAFH: Food-away-from-home

IV: Instrumental Variable

RDD: Regression Discontinuity Design

OLS: Ordinary Least Square Regression

NCDs: Non-Communicable Diseases

NIH: National Institute of Health

SSBs: Sugar-sweetened Beverages

US: The United States 


\section{Acknowledgment}

First of all, I would like to express my sincere gratitude to my supervisor, Prof. Xiaohua Yu, for his insightful guidance, continuous inspiration, and countless support during my entire period of Ph.D. study. I want to thank Dr. Liangzhi You, my second supervisor and counterpart at the International Food Policy Research Institute (IFPRI), who hosted me when I had the research stay at IFPRI in Washington, DC, and who cooperated with me and gave me constructive comments on my second paper. Further, I want to thank Prof. Yasemin Boztug and Prof. Bernhard Breummer for their valuable comments and wistful suggestions on the improvement of my dissertation. I also want to thank Dieter, Eva, Farah, Feifei, Tri, Yuquan, and all the other colleagues of Prof. Xiaohua Yu's chair for the innovative discussion and the analytical tools learning experience at the weekly group meeting. I want to thank Jana Nowakowsky, the secretary of our chair, for her heartful help in my work and life at Goettingen.

My Ph.D. study is sponsored by the Research Training Group (RTG) 1666 GlobalFood of the German Research Foundation (DFG). I would like to thank them for providing the financial support for my study and work in Germany. I want to express my special thanks to Prof. Matin Qaim, Dr. Melanie Grosse, Katrin Pape, AnnKathrin Fahlbusch, and all my colleagues in GlobalFood RTG. I appreciate the days working with colleagues from the different cultures at the GlobalFood RTG, the fruitful seminar discussion, and the heartwarming coffee break in a diverse working environment. Dela, Liza, and Sarah, thank you very much for the worthwhile discussion and friendship. 
Finally, I would like to thank my parents and my close friends. I cannot imagine how can I study abroad without their love and support. They are always on my side and encourage me when I feel down.

In addition, all three topics use the data from the China Health and Nutrition Survey (CHNS). We thank the National Institute for Nutrition and Health, China Center for Disease Control and Prevention, Carolina Population Center (P2C HD050924, T32 HD007168), the University of North Carolina at Chapel Hill, the NIH (R01-HD30880, DK056350, R24 HD050924, and R01-HD38700) and the NIH Fogarty International Center (D43 TW009077, D43 TW007709) for financial support for the CHNS data collection and analysis files from 1989 to 2015 and future surveys, and the China-Japan Friendship Hospital, Ministry of Health for support for CHNS 2009, Chinese National Human Genome Center at Shanghai since 2009, and Beijing Municipal Center for Disease Prevention and Control since 2011. 


\section{Chapter 1 Introduction}

\subsection{Background}

The global prevalence rate of adult overweight and obesity has reached $13.1 \%$ and $39 \%$ in 2016 respectively according to NCD risk factor collaboration. The Global Nutrition Report by IFPRI (2016) shows that the prevalence rates of both adult overweight and obesity are continuously increasing in recent years. As an emerging economy, China is no exception.

Along with the rapid economic growth, China has experienced a nutrition transition from deficiency to affluence. The food structure has been rapidly changing from a dietary dominated by cereals to one with more animal source foods (Yu and Abler, 2009; Tian and $\mathrm{Yu}, 2015)$. Consequently, China transfers from malnutrition to overweight and obesity rapidly, with the percentage of overweight adults almost tripled from 1991 to 2011(Gordon-Larsen et al., 2014).

Given the increasing prevalence rate of obesity in accompanying the acceleration of urbanization in the last two decades in China, it is straightforward to check the impact of dietary structural change on nutritional outcomes resulting from income growth. Besides the food patterns, lifestyle, and holiday arrangements also play a role in contributing to the prevalence of obesity (Yanovski et al., 2000). Particularly, there are more parties for family or friend's reunions during the holiday where more high-calorie foods and sugarsweetened beverages are consumed.

Eventually, it could lead to a body weight change. Once people eat more hearty food, participate in less physical activities, and thus gain weight during their holiday, there is 
little chance for them to fully recover to the normal weight during the working days (Whitney and Rolfes, 2016).

The location and the type of food facilities within a community influence the lifestyle of residence by imposing a higher chance to have food-away-from-home (FAFH). While FAFH enhances the prevalence of overweight and obesity in China (Zeng, 2018).

A general finding is that nutrition consumption first increases drastically, and then slows down until reaching a saturate point with income growth (Zhou and Yu, 2015; Tian and Yu, 2015; Shimokawa, 2009). Consequently, the income elasticity of nutrition would keep declining, and this is confirmed by a meta-analysis of Zhou and $\mathrm{Yu}$ (2015).

As discussed in a recent study (Pan et al., 2021), geographical location such as the existence of neighboring food facility, change in dietary patterns such as the upsurging animal-source food consumption, could be important determinants and risk factors for obesity.

\subsection{Motivation and problem statements}

There is quite a lot of literature on the nutrition transition in developing and emerging countries. However, the dynamics of dietary structure and nutrition as a result of income growth remain unclear.

In this dissertation, we explore three topics regarding the nutrition transition in an emerging economy like China. The short-run and middle-run holiday weight gain effect, the income growth on nutritional through the dynamic on food patterns and dietary structural change, and the nutritional outcome of the food facility. 
Concerning the econometric tools and empirical methodology, we utilize a regress discontinuity design (RDD) in the first topic with a check on the placebo effect of other public holiday arrangements. In the second topic, we propose a simple but novel framework to decompose the total income growth effect into the dietary structural change effect and the conditional income effect using mediation analysis. In the last topic, we use a propensity score matching (PSM) method to evaluate how food facilities formulate the food consumption patterns, food-away-from-home behavior, and the nutritional outcome for the residence in the community.

\subsection{Research objectives}

The three essays that make up this dissertation all focus on the body weight and calorie consumption of adults in rural and urban China. To be specific, we address the following research questions in this dissertation:

1. Does the lifestyle intervention by the central government, which is the public holiday schedule change, have to impact on the short run or long run body weight of adults in China?

2. Does the income growth increase non-staple food consumption and decrease staple food consumption for Chinese households?

3. Do the dynamics of dietary structure induce nutrition improvement?

4. Do any systematic disparities of food structural change that cannot be explained by the individual characteristics differences in rural and urban China? 
5. Does the location of food facilities and food availability affect the food patterns and therefore the nutritional outcome of Chinese adults?

In the first topic, we use the regression discontinuity design to study the body weight gain effect of the National Day holiday in China. We find that Chinese adults tend to gain $1.561 \mathrm{~kg}$ during the National Day holiday. The weight gain effect shrinks to an insignificant $0.967 \mathrm{~kg}$ or even $0.491 \mathrm{~kg}$ when we extend the time window from the oneweek level to the two-week level and the one-month level. This means that despite the reduction, short-term holiday weight gain may lead to long-term weight accumulation. Besides, the middle-aged group is the most fragile group to the holiday weight gain.

For the second topic, we propose a theoretical framework to disentangle the total income effect and check the impact of dietary structural change on the nutritional outcome. Using household survey data in China, we find that a $1 \%$ increment in income will boost per capita calorie consumption by $0.02 \%$ within a family. Meanwhile, 16 to $21 \%$ of the increase is due to dietary structural change, while the rest part is attributed to the conditional income effect. In addition, the dietary structural change effect is more prominent in the rural region, which implies a rural-urban gap in the diet. Rural China has more room to improve dietary quality and food diversity.

For the third topic, we estimate the impact of the type and the location of the food facility on food patterns and nutritional outcomes of adults in China. Based on the household and individual survey, we find that the existence of the food facility leads to a higher frequency of FAFH. Food facility plays a role in explaining the obesity of community residence. Different from intuition, compared to Western food facilities, Chinese restaurants have a greater influence on weight and obesity. 
All three papers above contribute to the literature by broadening the scope of nutrition transition in an emerging economy. The general conclusion and policy implications are summarized below: first, the golden week policy for the National Day holiday has a prominent short-run unfavored body weight gain effect and it tends to partly remain in the long run. Second, the dietary structural change caused by income growth plays an important role in explaining the increase in calorie expenditure in rural and urban China. Third, the location and the type of food facility, especially the Chinese restaurant within a $5 \mathrm{~km}$ radius, have a direct impact on the choice of food patterns and the nutritional results of residents. It is possible for the government to raise awareness of the nutritional consequences of dietary choices and dietary changes to the public to curb the prevalence of obesity. 


\section{Chapter 2 Holiday and Weight Gain: Evidence from the}

\section{National Day Holiday in China}

We use the regression discontinuity model and CHNS (China Health and Nutrition Survey) data, to study the body weight gain effect of the week-long National Day holiday in China. We find that Chinese adults tend to significantly gain $1.56 \mathrm{~kg}$ of body weight during the National Day holiday, and males have a larger effect. However, the effect will be smaller and insignificant in 2 weeks. It verifies the Chinese saying: People gain $1.5 \mathrm{~kg}$ body weight for a good holiday (mei feng jia jie pang san jin), only in the short-run. Besides, the middle-age group is the most fragile group to the holiday weight gain.

\subsection{Introduction}

Obesity is now regarded as an "epidemiology" globally: the prevalence rate of adult overweight globally reached $39 \%$ in 2015(IFPRI 2016). As an emerging economy, China is no exception. China transfers from malnutrition to overweight and obesity rapidly, with the percentage of overweight adults almost tripled from 1991 to 2011(Gordon-Larsen et al. 2014). In company with rapid economic growth, China has experienced a nutrition transition from deficiency to affluence. The food structure has been rapidly changing, changing from a dietary dominated by cereals to one with more animal products (Yu and Abler 2009; Tian and Yu 2015). Nutrition knowledge, lifestyles, and holiday arrangements are also believed to be related to increasing overweight and obesity (Zhao and Yu 2019; Zeng and Yu 2019), but they are under-researched. The current literature on the linkage between holiday arranges and obesity is inconclusive (Roberts 2000; Helander et al. 2016; Hull et al. 2006; Wagner et al. 2012; Yanovski et al. 2000; Schoeller, 2014). 
In addition to food structure and dietary change, lifestyles and holiday arrangements are believed to be related to increasing overweight and obesity. Notwithstanding, the latter has not been well examined in the literature. Particularly, it has been observed that the average working hours annually are globally shrinking while leisure time and holidays become longer. For instance, people can arrange more parties, family unions, and tourism activities, and consume more food and drinks. One can speculate that such behavior can lead to body weight increment (Wagner et al., 2012).

\subsection{Literature and background}

There was a popular point of view on the holiday weight gain that adults tend to gain 2-5 kg weight in the US during the winter holiday which started from Thanksgiving Day and ended on New Year's Day in the US. Newspapers and fashion magazines enforced a deep impression, so that folks accepted the assertion, although it was not true (Wagner et al. 2012). However, situations are different in other countries. Specifically, it is widely convinced that Chinese adults tend to gain $1.5 \mathrm{~kg}$ during the week-long National Day holiday and the Spring Festival holiday individually in the social media in China (Mei Feng Jia Jie Pang San Jin). Though quite a few scientific studies on holiday weight gain have been conducted, the study on China is only conducted in a limited way.

Few studies have been conducted based on all year round. Yanovski et al. (2000) conducted an early study on holiday weight gain with use of the data of 195 adult subjects recruited from the employees of the National Institute of Health in the US and found that people tend to have an average net weight gain of $0.48 \mathrm{~kg}$ in the three months. Roberts (2000) proposed a review for the NIH (National Institute of Health) study in the same year, 
arguing that the representative samples and clear channels for the disproportionate seasonal distribution of weight gain are needed for further study.

Hull et al. (2006) later used the data of 94 college student subjects who reported their height and weight at the laboratory in the University of Oklahoma and find that people who are classified as overweight or obese tended to gain more weight $(1.0 \mathrm{~kg})$ than those who are classified as normal $(0.2 \mathrm{~kg})$ during the two-week-long holiday. Furthermore, Wagner et al. (2012) used both the BMI(body mass index) and body composition of 34 nonuniversity student subjects from North Utah as indicators and found no significant holiday weight gain although the participants held the belief that they gain weight a lot during the winter holiday. All these studies focused on the winter holiday from Thanksgiving Day to New Year's Day in the US. After that, a review by Schoeller (2014) concluded that winter holiday tends to accompany a body weight gain of 0.4 to $0.7 \mathrm{~kg}$ in the United States.

Limited studies show interest in the holiday weight of citizens from Europe or Asia. Recently, through daily body weight data of 2924 wireless users from the US, German, and Japan, Helander et al. (2016) showed that people tend to gain weight during holidays despite the cultural and environmental differences between these three countries. Although the volume of weight gain varies, the weight gain that happened on the holiday of Christmas and New Year was significant in all three countries. In summary, they observed weight gain during the Easter in the US and German, as well as during the "Golden Week" in Japan. However, the holiday weight gain in an emerging country, such as in China, is still worth further investigation.

The effect of holiday weight gain is not conclusive. Some literature found that there indeed exist the phenomena of holiday weight gain, although the amount was lower than 
the media claimed (Yanovski et al. 2000 and Helander et al. 2016). While some other researchers believed that there was no significant evidence of the holiday weight gain (Hull et al. 2006 and Wagner et al. 2012). One possible argument that leads to the mixed results is that cultural convention and environment, such as the temperature, in those destinations are different.

Many explanations of holiday weight gain already exist in the literature. One explanation is that people will react to the seasonal cycles and temperature change during the winter holiday. However, it cannot fully explain those increases in BMIin South Africa and Japan during summertime holiday (Sturm et al. 2016, Helander et al. 2016). Thus, the traditional culture of having big meals in those long-term holidays serves as the main factor which contributes to weight gain. That is, the changes in lifestyle in the longtime holiday are linked to weight gain. Besides, even if people do not gain a big amount of weight gain during the holiday, such the holiday weight gain has the potential to incur a substantial effect on the yearly weight gain. Thus, when people eat more, participate in less physical activities, temporarily change lifestyles, and thus gain weight during their holiday, there is little chance for them to fully recover to the normal weight during the working days (Whitney and Rolfes, 2016).

Compared to the previous studies, whose samples are either recruited from an institute on health research or those rich, highly educated and health conscientious users with a passion for losing weight and tracking their body weight records, we use a large-scale survey data, which is more representative. Another problem that could occur in the previous studies is that the samples, whether college students or non-college students, are needed to take health exams both before and after the holiday. Once the subjects were taken 
the health exam before the holiday, they fully realized that they had to give another report about their body weight and health conditions after the holiday. Thus, the participants have a chance to form the consciousness on their health condition and have incentives to keep their body weight during the whole holiday intendedly or unintendedly. While our study only requires subjects to report their health exam results once in the survey year. With the consideration of the average holiday weight gain, our sample avoids those potential endogeneity issues on the reaction of subjects to the other upcoming health exams. Besides, compared with past studies using small samples, our research using a relatively large sample with 38,180 observations can better reveal the nutritional dynamics in China.

Since 2000, the Chinese government has implemented a policy to shift the working calendar, and then the National Day holiday which starts from the first day of October has been enlarged from legally three days to seven days to create a "Golden Week" for "Tourism Promotion". Usually, two-weekend breaks around October 1 are shifted to form the holiday. The National Day Holiday arrangements are shown in Figure 2.1.

It is noticeable that there are exceptions in 2009, 2012 and 2017. In those years the National Day holiday lasted for 8 days because the government had combined the National Day holiday with the Mid-Autumn Festival holiday. In the rest years, the National day holiday only lasted for 7 days. 


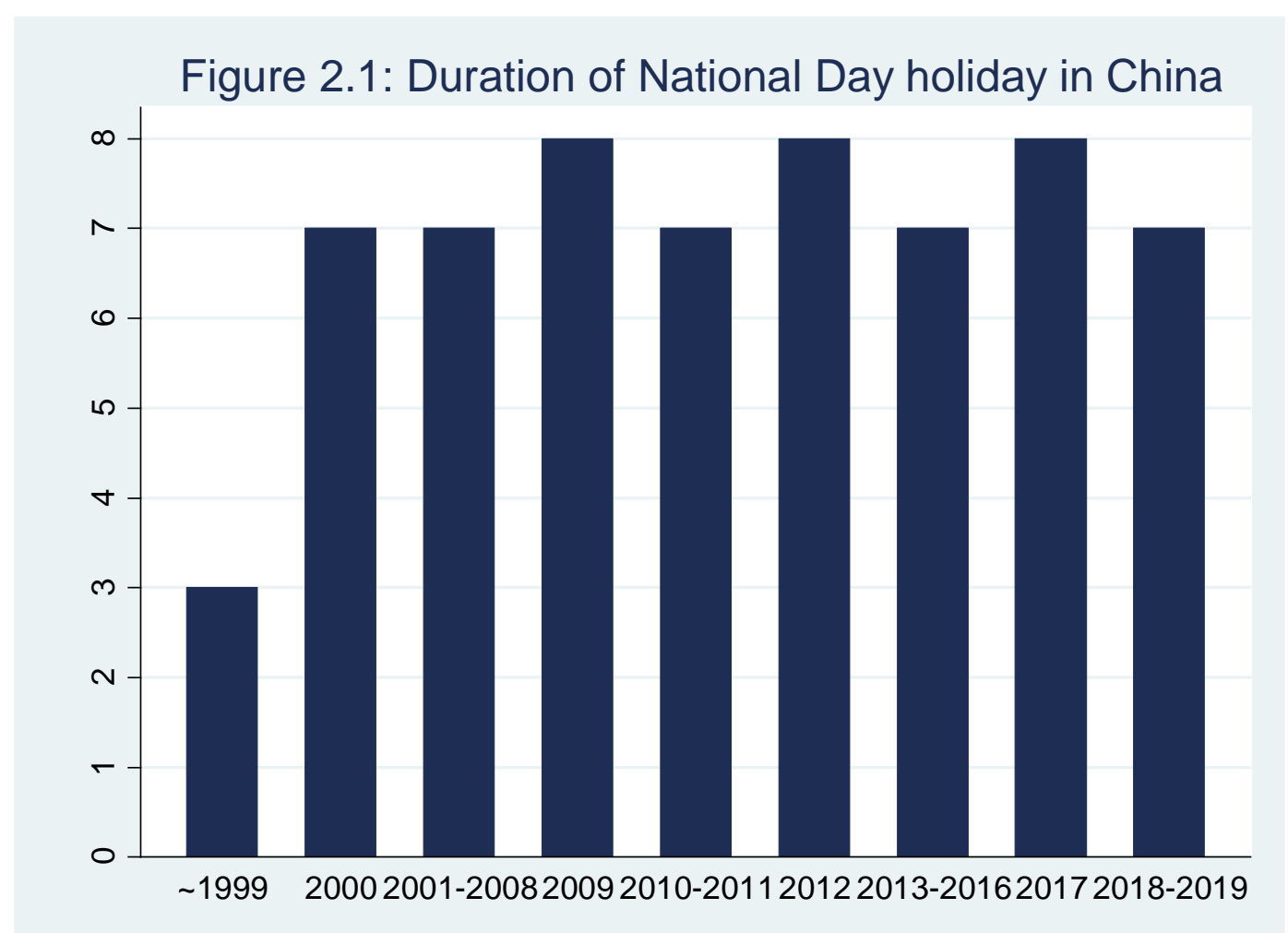

Note: From 2000 to 2019, the National Day Holidays all start on November 1 and end on November 7, except for 4 exceptions: in 2008, the National Day Holiday starts on September 29 and ends on November 5; in 2009, the National Day Holiday starts on November 1 and ends on November 8; in 2012, the National Day Holiday starts on September 30 and ends on November 7; in 2017, the National Day Holiday starts on November 1 and ends on November 8.

The rearrangement of the National Day holiday could change biological clocks, people's lifestyle and consumption patterns. Particularly, there are more parties for family or friend's reunion during the holiday where more food and drinking are consumed. Some people may prefer travelling in group during the holiday which could lead to higher energy expenditure due to the higher density of physical activities. Eventually, the National Day holiday could lead to the body weight change, but whether it is weight gain or weight loss is not determined. The paper aims to analyze the dynamics of nutritional status before and after the National Day holiday in China, and after some side health effects for the holiday. This may help the policymakers to rethink the holiday arrangement from the perspective of health and nutrtition. 


\subsection{Data}

The data used in this project is the secondary data from the CHNS (China Health and Nutrition Survey). CHNS is a long-term investigation project conducted by three institutes: Carolina Population Center of the University of North Carolina at Chapel Hill, the National Institute of Nutrition and Food Safety, and the Chinese Center for Disease Control and Prevention. This project focuses on the transformation of the socioeconomic and nutritional status of the Chinese Society. More than 4300 households are randomly chosen from more than 200 communities covering nine provinces. The data used in this research cover 2000, 2004, 2006, 2009, and 2011. In each survey round, each individual provides physical exam results only once, which means the daily or monthly tracking data of body weight are not available for any individual. The data has been widely used in the literature for different research (Zeng and Yu 2019). As shown in Figure 2.2, the majority of health examinations in CHNS occurred in the second half of the year and analyzing the weight-gain effect of the National Day holiday is straightforward. In the setting of regression discontinuity design, the treatment variable is a dummy variable that describes whether the health exam was conducted before or after the holiday ${ }^{1}$.

\footnotetext{
${ }^{1}$ Only two subjects reported their health condition in the first half year.
} 


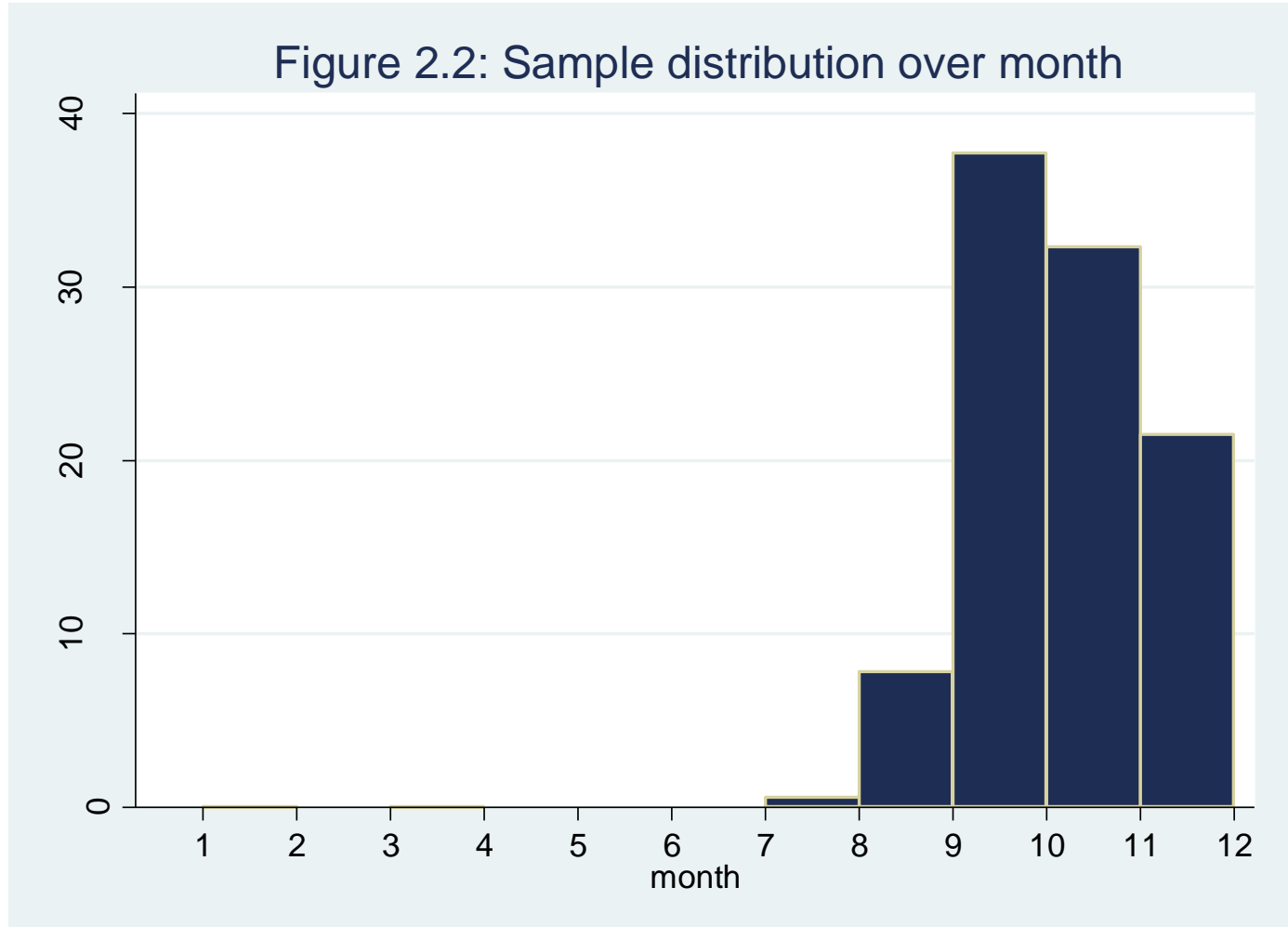

Note: this figure is based on the dataset after eliminating the observations with missing values. In the first half of all the survey years, there are only two subjects who take physical examinations. Thus, we eliminate this observation for our analysis since we treat them as outliners.

We take the BMI(body mass index) as the dependent variable, which is constructed by dividing body weight (in $\mathrm{kg}$ ) by the square of height (in meters). The natural logarithms of per capita annual income, gender, age, the quadratic term of age and year dummy of 2009 are treated as control variables. The national holiday in 2009 lasted for 8 days. Besides, we construct an assignment variable timelag. It measures the number of days between the health exam date and the National Day holiday period, which helps to describe (potential) time trend of the $B M I$.

To remove outliers, all the samples whose BMIis less than 14 or more than 40 are excluded from the sample. Neither extremely underweighted people nor extremely obese people are considered. Besides, we only care about adults who are at working age, those 
whose age is less than 18 or greater than 65 are excluded as well. Since the very limited number of samples got health exams during the National Day holiday, we exclude all those observations.

\section{Table 2.1: Descriptive statistics}

\begin{tabular}{|c|c|c|c|c|c|}
\hline \multirow[t]{2}{*}{ Variable } & \multirow[t]{2}{*}{ Definition } & \multirow[t]{2}{*}{ Unit } & \multicolumn{3}{|l|}{ Mean } \\
\hline & & & $\begin{array}{l}\text { Full } \\
\text { sample }\end{array}$ & $\begin{array}{l}\text { Sample } \\
\text { before } \\
\text { holiday }\end{array}$ & $\begin{array}{l}\text { Sample } \\
\text { after } \\
\text { holiday }\end{array}$ \\
\hline weight & body weight & kilogram & 61.221 & 61.105 & 61.321 \\
\hline height & height & centimeter & 161.750 & 161.656 & 161.830 \\
\hline \multicolumn{6}{|c|}{ Dependent variable } \\
\hline BMI & body weight Index & $\mathrm{kg} / \mathrm{m}^{2}$ & 23.323 & 23.311 & 23.334 \\
\hline \multicolumn{6}{|c|}{ Treatment variable } \\
\hline treat & $\begin{array}{l}\text { survey date bofore or after } \\
\text { the National Day holiday }\end{array}$ & binary & 0.538 & & \\
\hline \multicolumn{6}{|c|}{ Assignment variable } \\
\hline time_lag & $\begin{array}{l}\text { survey date-the nearest } \\
\text { Holiday date }\end{array}$ & day & 4.397 & -19.356 & 24.814 \\
\hline \multicolumn{6}{|c|}{ Control variables } \\
\hline age & age & year & 44.830 & 44.829 & 44.830 \\
\hline agesqr & squred term of age & year^$^{\wedge} 2$ & 2148.677 & 2146.688 & 2150.386 \\
\hline eight_days & dummy of year 2009 & binary & 0.188 & 0.212 & 0.167 \\
\hline interaction & $\begin{array}{l}\text { interaction term of } \\
\text { time_lag and treat }\end{array}$ & day & 13.344 & 8.305 & 24.814 \\
\hline lincome & logarithm of income & $\mathrm{CNY}$ & 8.381 & 0.484 & 8.446 \\
\hline $\operatorname{sex}$ & gender, male $=1$, female $=0$ & binary & 0.485 & & 0.486 \\
\hline Obs. & & & 38180 & 20532 & 17648 \\
\hline
\end{tabular}

Note: The full sample is composed of all observations that neither have missing value nor are extremely overweight/underweight. The age of observations is constrained to the interval from 18 to 65 . We use the National Day Holiday as the rule to divide the full sample into the before-holiday sample and the after-holiday sample.

As shown above in Table 2.1, the total number of observations in the full sample is 38,180 , in which 20,532 had health exams after the holiday and 17,648 before the holiday. 
Their average heights are $161.83 \mathrm{~cm}$ and $161.656 \mathrm{~cm}$ respectively, while the average weights are $61.321 \mathrm{~kg}$ and $61.105 \mathrm{~kg}$ respectively before and after the holiday.

The independent variable sex is a dummy for gender ( 0 for females and 1 for males). In our sample, $48.5 \%$ are males, and $51.5 \%$ females. The variable age denotes the age of the subject when the survey was conducted. In the sample of interest, the average age of subjects is 44.5 years old. Similarly, age_sqr stands for the quadratic term of age. And the variable interaction stands for the interaction term between treat and time_lag, which describes the different influence of timelag before and after the holiday weight gain. As mentioned above, treat is a variable whether the health exam occurred before or after the National Day holiday. Its average is 0.538 , indicating the sample is distributed evenly before and after the National Day holiday.

After the holiday, we take three different time windows, specifically, 7 days, 14 days, and 30 days, which respectively could capture short-run, medium-run, and long-run effects, though 14 days might be the best one by the Newey-West 's Rule of Thumb. We choose the maximum lags by facilitating the rule of thumb in Newey-West standard error lag length $T=N^{1 / 4}$, and $14 \approx 38180^{\frac{1}{4}}$, where 38180 is the total number of observations. Alternatively, we also use 30 days length and 7 days length for a comparison of robust check.

Our main analysis focuses on the estimated holiday weight gain under three time window specifications: 7 days window, 14 days window and 30 days window before and after the National Day holiday in China. Specifically, 7 days and 30 days could capture short-run and long-run effects, in addition to the time window of 14 days. 


\subsection{Econometric Model}

The regression discontinuity method (Lee and Lemieuxa 2010) is adopted to judge if there is any jump in weight before and after the National Day holiday. We find two advantages of regression discontinuity design: first, the regression discontinuity design is equivalent to a local random trail around the breakpoint (7-days-holiday); second, a recent study shows (Imbens and Lemieux, 2008), a well-behaved regression discontinuity does not need any control variables, so this design could eliminate the omitted-variable bias. Using the pooled setting, we ignore the potential structural change of BMIfrom 2000 to 2011. BMI(body mass index) is the dependent variable, and the demographics are included as the control variables. Because of the limitation of the data source, we evaluate only the average holiday weight gain over the whole weight gain individually. sample, but not able to trace and identify the weight gain individually. However, we use the demographic variables to control for the individual heterogeneities. The model is specified as follows:

$$
B M I_{i}=x_{i}^{\prime} \beta_{1}+\beta_{2} \text { treat }_{i}+\beta_{3} \text { time_lag }_{i}+\beta_{4} \text { treat }_{i} * \text { time_lag }_{i}+e_{i},
$$

where $e_{i}$ is an error term with a zero mean normal distribution. $x_{i}$ is the vector of all control variables: $a g e_{i}, a g e_{-} s q r_{i}$, eight_days $_{i}$ and lincome $_{i}, \beta_{1}$ is the vector of the corresponding coefficients. As mentioned in the data section, treat $_{i}$ is the treatment variable. The coefficient of the variable treat ${ }_{i}, \beta_{2}$, is the coefficient of interest because it describes the holiday weight gain before and after the holiday. Both the variable time_lag $g_{i}$ and the interaction treat $*$ time_lag $_{i}$ are important for controlling the time trend. $\beta_{3}$ denotes the symmetric time trend effect on $B M I$ of an additional day while $\beta_{4}$ represents the asymmetric time trend. 


\subsection{Empirical results}

- Model specification

Before we start our analysis on the results, it is important to take the distribution of time_lag into consideration. The results of the histogram graph and the line chart are depicted in Figure 2.3. It is worth mentioning that both the distribution of time_lag of males and females are very close to the whole sample case, thus we do not report their results separately.

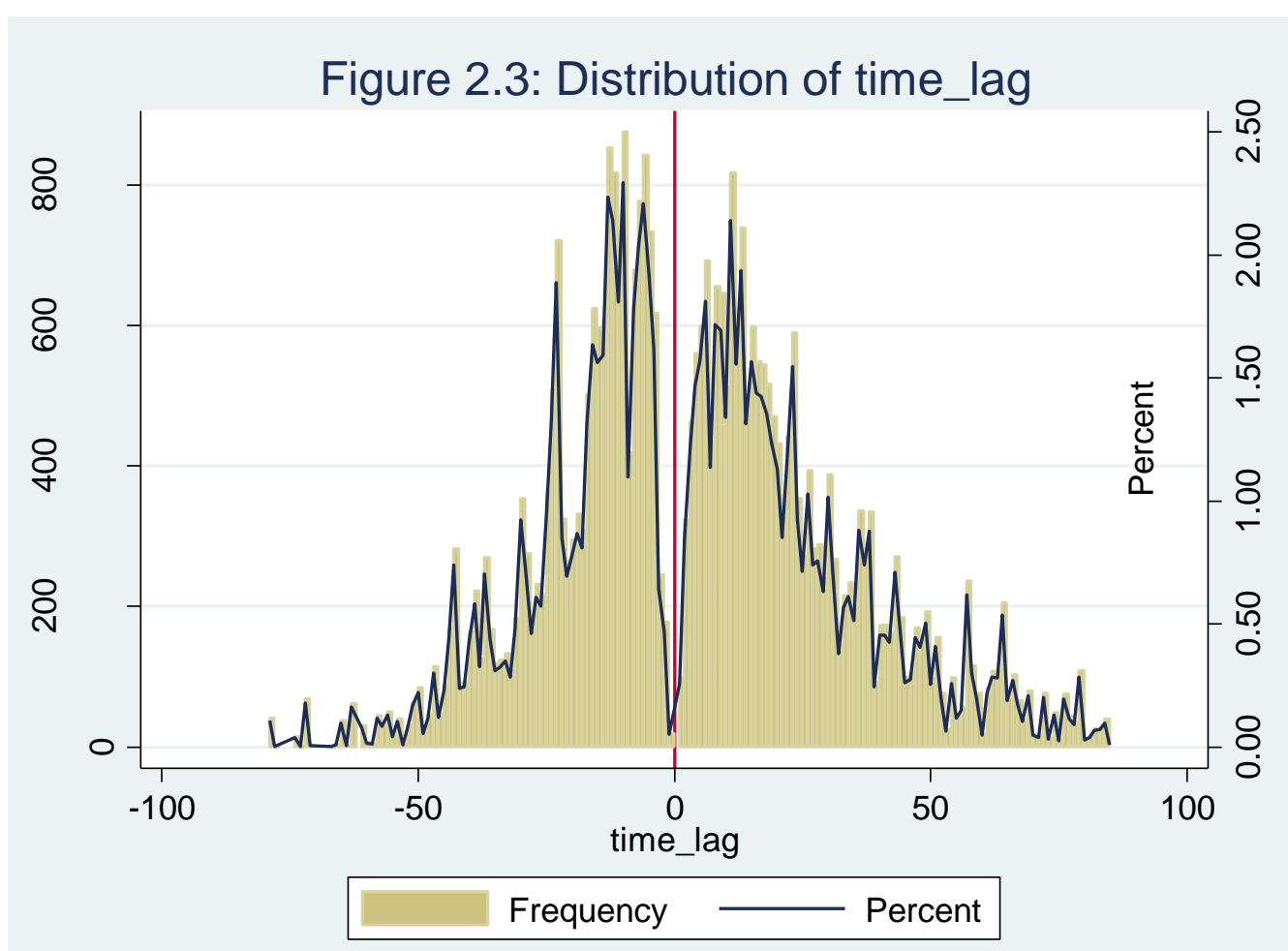

The low frequency around the point time_lag=0 happens because we exclude a few samples whose health exams were taken during the National Day holiday. In terms of time_lag distribution, our sample does not violate the random sampling assumption. Some dates are given a larger weight than the average, while other parts are given a smaller 
weight when we run the regression. Meanwhile, the sample shows no big jump of the assignment variable at the cutoff. We can hardly imagine the subjects intentionally manipulated the date of the health exams. Thus, there is no support for the existence of assignment variable manipulation both theoretically and practically.

In order to reduce the measurement errors caused by seasonality, we take a strategy of asymmetric time windows before and after the holiday. For the samples before the holiday, we only use a time window of 7 days, because a longer time window may entail more measurement errors. After the holiday, we take three different time windows, specifically, 7 days, 14 days, and 30 days, which respectively could capture short-run, medium-run, and long-run effects, though 14 days might be the best one by the NeweyWest 's Rule of Thumb. Our design follows a typical RDiT (regression discountinuity in time) framework (Hausman and Rapson, 2018) since we use a time related variable time_lag as the running variable.

- Result discussion

All the regression results under these three different window lengths are reported in Table 2.2.

As we can see, the estimated coefficient of the treatment variable treat is statistically significant only for the 7-7 window, while it is not significant for 7-14 window and 7-30 window anymore. Their coefficients are $0.593,0.369$, and 0.187 respectively. The magnitudes for the coefficients decline with the expansion of time windows as well. 
Essays on Holiday Weight Gain, Meat Consumption and Dietary Structure, and Nutritional Outcome of Food Facility in China

Table 2.2: Empirical results

\begin{tabular}{|c|c|c|c|c|}
\hline \multirow[b]{2}{*}{ Dependent Variable } & \multicolumn{4}{|l|}{ Time Windows } \\
\hline & (1) & (2) & (3) & (4) \\
\hline BMI & Whole sample & 7-7 Window & 7-14 Window & 7-30 Window \\
\hline \multirow[t]{2}{*}{ treat } & 0.0353 & $0.593 * *$ & 0.369 & 0.187 \\
\hline & $(0.0566)$ & $(0.266)$ & $(0.225)$ & $(0.211)$ \\
\hline \multirow[t]{2}{*}{ sex } & 0.0395 & $0.190 * *$ & $0.131 * *$ & $0.111 * *$ \\
\hline & $(0.0332)$ & $(0.0803)$ & $(0.0619)$ & $(0.0485)$ \\
\hline \multirow[t]{2}{*}{ age } & $0.291 * * *$ & $0.260 * * *$ & $0.281 * * *$ & $0.296 * * *$ \\
\hline & $(0.00989)$ & $(0.0237)$ & $(0.0184)$ & $(0.0146)$ \\
\hline \multirow[t]{2}{*}{ agesqr } & $-0.00283 * * *$ & $-0.00236 * * *$ & $-0.00266 * * *$ & $-0.00287 * * *$ \\
\hline & $(0.000113)$ & $(0.000270)$ & $(0.000210)$ & $(0.000165)$ \\
\hline \multirow[t]{2}{*}{ lincome } & $0.183 * * *$ & $0.196 * * *$ & $0.171 * * *$ & $0.167 * * *$ \\
\hline & $(0.0133)$ & $(0.0334)$ & $(0.0253)$ & $(0.0194)$ \\
\hline \multirow[t]{2}{*}{ time_lag } & $0.00645 * * *$ & 0.00757 & 0.00633 & 0.00538 \\
\hline & $(0.00179)$ & $(0.0380)$ & $(0.0379)$ & $(0.0376)$ \\
\hline \multirow[t]{2}{*}{ interaction } & $-0.0126 * * *$ & $-0.0916^{*}$ & -0.0336 & -0.0125 \\
\hline & $(0.00217)$ & $(0.0514)$ & $(0.0392)$ & $(0.0378)$ \\
\hline \multirow[t]{2}{*}{ eight_days } & 0.0317 & 0.0596 & 0.0172 & 0.0264 \\
\hline & $(0.0430)$ & $(0.0970)$ & $(0.0767)$ & $(0.0592)$ \\
\hline \multirow[t]{2}{*}{ _cons } & $14.92 * * *$ & $15.02 * * *$ & $14.95 * * *$ & $14.75 * * *$ \\
\hline & $(0.242)$ & $(0.620)$ & $(0.493)$ & $(0.407)$ \\
\hline Obs. & 38180 & 6582 & 11047 & 17731 \\
\hline adj.R-square & 0.047 & 0.054 & 0.049 & 0.047 \\
\hline
\end{tabular}

Note: For each explanatory variable, the upper part is the coefficient estimation value, the lower part is the standard error, $* * *, * *, *$ means significant at $1 \%, 5 \%$, and $10 \%$ respectively. lincome is the natural logarithm of total individual income (inflated to the 2009 price level). 
To calculate the average weight gain, we use the quadratic of the root mean square (RMS) times the estimated coefficient of variable treat to obtain the estimated average body weight gain for the National Day Holiday. The details of all time windows are shown below in Table 2.3 .

Table 2.3: Body weight gain estimation

\begin{tabular}{|c|c|c|c|c|c|c|c|}
\hline Samples & & Total & & Male & & Female & \\
\hline $\begin{array}{l}\text { Indicators } \\
\text { windows }\end{array}$ & $\begin{array}{ll} & \text { Time }\end{array}$ & $\begin{array}{l}\text { RMS of } \\
\text { height }\end{array}$ & $\begin{array}{l}\text { Average } \\
\text { WG }\end{array}$ & $\begin{array}{l}\text { RMS of } \\
\text { height }\end{array}$ & $\begin{array}{l}\text { Average } \\
\text { WG }\end{array}$ & $\begin{array}{l}\text { RMS of } \\
\text { height }\end{array}$ & $\begin{array}{l}\text { Average } \\
\text { WG }\end{array}$ \\
\hline 7-7 window & & 162.271 & 1.561 & 167.683 & 1.667 & 157.030 & 1.462 \\
\hline 7-14 window & & 161.961 & 0.967 & 167.446 & 1.035 & 156.631 & 0.905 \\
\hline 7-30 window & & 162.036 & 0.491 & 167.495 & 0.525 & 156.661 & 0.459 \\
\hline
\end{tabular}

Note: RMS means root mean square. The values of height are calculated in centimeter, while the values of weight are calculated in a kilogram. WG means weight gain.

We take advantage of the root mean square of height, under the 7-7 time window, the expected weight gain is $1.561 \mathrm{~kg} .{ }^{2}$ Based on the coefficients in Table 2.2 and Table 2.3, males on average gain more weight compared with females, from the perspectives of both BMIand body weight, during the National Day Holiday. In summary, it shows that the result is consistent with the Chinese saying: Each holiday people gain $1.5 \mathrm{~kg}$ body weight, only in the short run.

As for the time trend, in most cases, either symmetric or asymmetric time trend is not significant. The control variables age and age_sqr both are statistically significant at $1 \%$ level under various window lengths, showing older people have higher chances to gain weight during the National Day Holiday, perhaps due to low metabolism. Another control

\footnotetext{
${ }^{2}$ For the 7-7 time window, the average weight gain of the whole subsample is: $0.593 *\left(\mathrm{MRS}^{\wedge} 2\right)=1.561$ $\mathrm{kg}$,where MRS is the root mean square of height in corresponding subsample, and 0.593 is the estimated coefficient of treatment variable treat reported in Table 2.2; similarly, for the other time windows, we can estimate the weight gain by multiplying estimated coefficient with the corresponding MRS. We can also calculate body weight gain per capita the for males and females based on the same rationale.
} 
variable, sex, seems a little bit controversial. Although not always significant, the male tends to gain more weight compared with female. One possible rationale is the male gains more holiday weight in a short period, but they recover to ordinary weight at a faster pace than the female. Richer people are more prone to high body weight as well.

\section{Figure 2.4: Distribution of BMI with 7-7/14/30 windows}
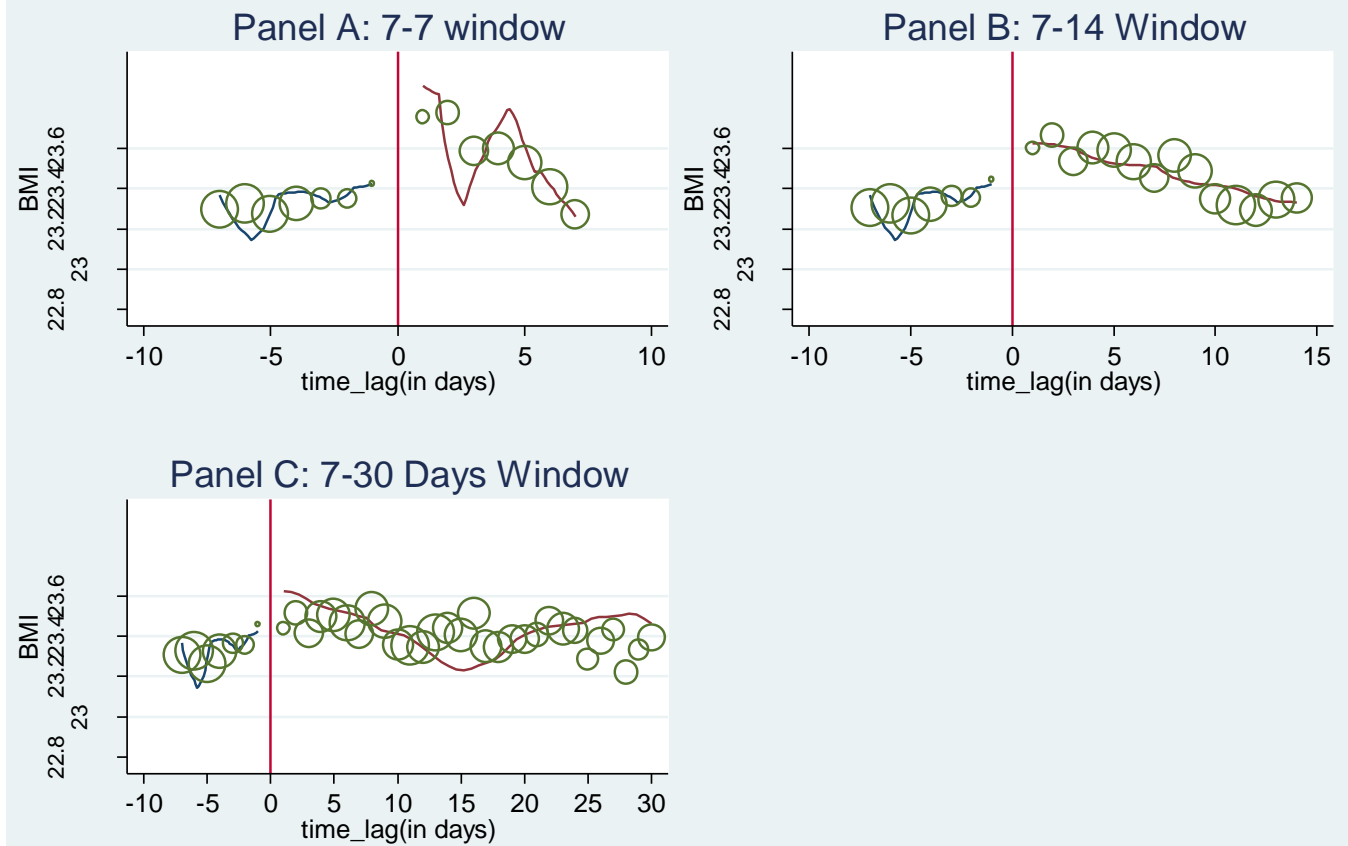

Note: The polyline represents the local polynomial smooth plots before and after the National Day holiday. The hollow circle represents the fitted mean from the regression. The size of hollow circles represents the density of the sample distribution over time_lag.

Another point of view to investigate the treatment effect of the National Day holiday is to draw graphs to visualize the jump of BMIat the cutoff, which is shown in Figure 2.4. Both the local polynomial smooth plot and the fitted values from the regression discontinuity method are reported. We find the graphs are conformed to the results discussed above: the holiday weight gain exists in the 7 days window and no gap window, but it undergoes a reduction in the 14 days window and the 30 days window. 


\subsection{Robustness check}

So far, our analysis is restricted to holiday weight gain effect using a pooled regression, without considering the potential time trend and geographic effects. Thus, with controlling for the time trend and province effect, we additionally include more samples by imposing no restrictions on weight and age of subjects for robustness check.

First, we add an extra time trend indicator $y e a r_{i}$ to equation (1), which leads to equation (2) for estimation:

$$
B M I_{i}=x_{i}^{\prime} \beta_{1}+\beta_{2} \text { treat }_{i}+\beta_{3} \text { time_lag }_{i}+\beta_{4} \text { treat }_{i} * \text { time_lag }_{i}+\beta_{5} \text { year }_{i}+e_{i},
$$

In year specific regression, we simply run the same regression based on equation (1) but limit the subjects to a specific year. Which is equivalent to equation (3) as below:

$$
B M I_{i t}=x_{i t}^{\prime} \beta_{1 t}+\beta_{2 t} \text { treat }_{i t}+\beta_{3 t} \text { time }_{-} \text {lag }_{i t}+\beta_{4 t} \text { treat }_{i t} * \text { time }_{-} \text {lag }_{i t}+e_{i t},
$$

As shown in Table 2.4, the time trend can partly explain the holiday weight gain effect. Except for the first year of holiday length expansion that happened in 2000, we observe a positive holiday weight gain effect. 


\section{Table 2.4: Time trend and by-year analysis}

\begin{tabular}{|c|c|c|c|c|c|c|}
\hline \multirow[b]{3}{*}{$\begin{array}{l}\text { Dependent } \\
\text { variable }\end{array}$} & \multicolumn{6}{|c|}{ Time windows } \\
\hline & \multicolumn{3}{|l|}{ Time trend } & \multicolumn{3}{|l|}{2000} \\
\hline & (1) & (2) & (3) & (4) & (5) & (6) \\
\hline \multirow[t]{2}{*}{ BMI } & & $7-14$ & $7-30$ & $7-7$ & $7-14$ & $7-30$ \\
\hline & 7-7 window & window & window & window & window & window \\
\hline \multirow[t]{2}{*}{ treat } & $0.500^{*}$ & 0.199 & 0.046 & -0.500 & $-1.034 * *$ & $-1.378 * * *$ \\
\hline & $(0.266)$ & $(0.225)$ & $(0.211)$ & $(0.488)$ & $(0.426)$ & $(0.396)$ \\
\hline \multirow[t]{2}{*}{$\operatorname{sex}$} & $0.199 * *$ & $0.142 * *$ & $0.119 * *$ & 0.035 & -0.031 & -0.067 \\
\hline & $(0.080)$ & $(0.062)$ & $(0.048)$ & $(0.167)$ & $(0.129)$ & $(0.104)$ \\
\hline \multirow[t]{2}{*}{ age } & $0.250 * * *$ & $0.271 * * *$ & $0.288 * * *$ & $0.189 * * *$ & $0.201 * * *$ & $0.244 * * *$ \\
\hline & $(0.024)$ & $(0.018)$ & $(0.015)$ & $(0.047)$ & $(0.036)$ & $(0.029)$ \\
\hline \multirow[t]{2}{*}{ agesqr } & $-0.002 * * *$ & $-0.003 * * *$ & $-0.003 * * *$ & $-0.002 * * *$ & $-0.002 * * *$ & $-0.002 * * *$ \\
\hline & $(0.000)$ & $(0.000)$ & $(0.000)$ & $(0.001)$ & $(0.000)$ & $(0.000)$ \\
\hline \multirow[t]{2}{*}{ lincome } & $0.150 * * *$ & $0.127 * * *$ & $0.128 * * *$ & 0.046 & 0.011 & 0.018 \\
\hline & $(0.034)$ & $(0.026)$ & $(0.020)$ & $(0.078)$ & $(0.058)$ & $(0.045)$ \\
\hline \multirow[t]{2}{*}{ time_lag } & 0.041 & 0.040 & 0.035 & $0.321 * * *$ & $0.326^{* * *}$ & $0.321 * * *$ \\
\hline & $(0.038)$ & $(0.038)$ & $(0.038)$ & $(0.077)$ & $(0.075)$ & $(0.074)$ \\
\hline \multirow[t]{2}{*}{ interaction } & $-0.139 * * *$ & $-0.065 *$ & -0.042 & $-0.519 * * *$ & $-0.366^{* * *} *$ & $-0.320 * * *$ \\
\hline & $(0.052)$ & (0.039) & $(0.038)$ & $(0.100)$ & $(0.078)$ & $(0.074)$ \\
\hline \multirow[t]{2}{*}{ eight_days } & $-0.244 * *$ & $-0.292 * * *$ & $-0.238 * * *$ & & & \\
\hline & $(0.106)$ & $(0.084)$ & $(0.065)$ & & & \\
\hline \multirow[t]{2}{*}{ year } & $0.081 * * *$ & $0.082 * * *$ & $0.071 * * *$ & & & \\
\hline & $(0.011)$ & $(0.009)$ & $(0.007)$ & & & \\
\hline \multirow{3}{*}{ _cons } & - & - & - & & & \\
\hline & $147.193 * * *$ & $147.917 * * *$ & $127.235 * * *$ & $19.290 * * *$ & $19.442 * * *$ & $18.615^{* * *}$ \\
\hline & $(22.739)$ & $(17.802)$ & $(14.220)$ & $(1.280)$ & $(0.981)$ & $(0.814)$ \\
\hline Obs. & 6582 & 11047 & 17731 & 1482 & 2388 & 3564 \\
\hline adj.R-square & 0.061 & 0.056 & 0.052 & 0.051 & 0.045 & 0.042 \\
\hline
\end{tabular}




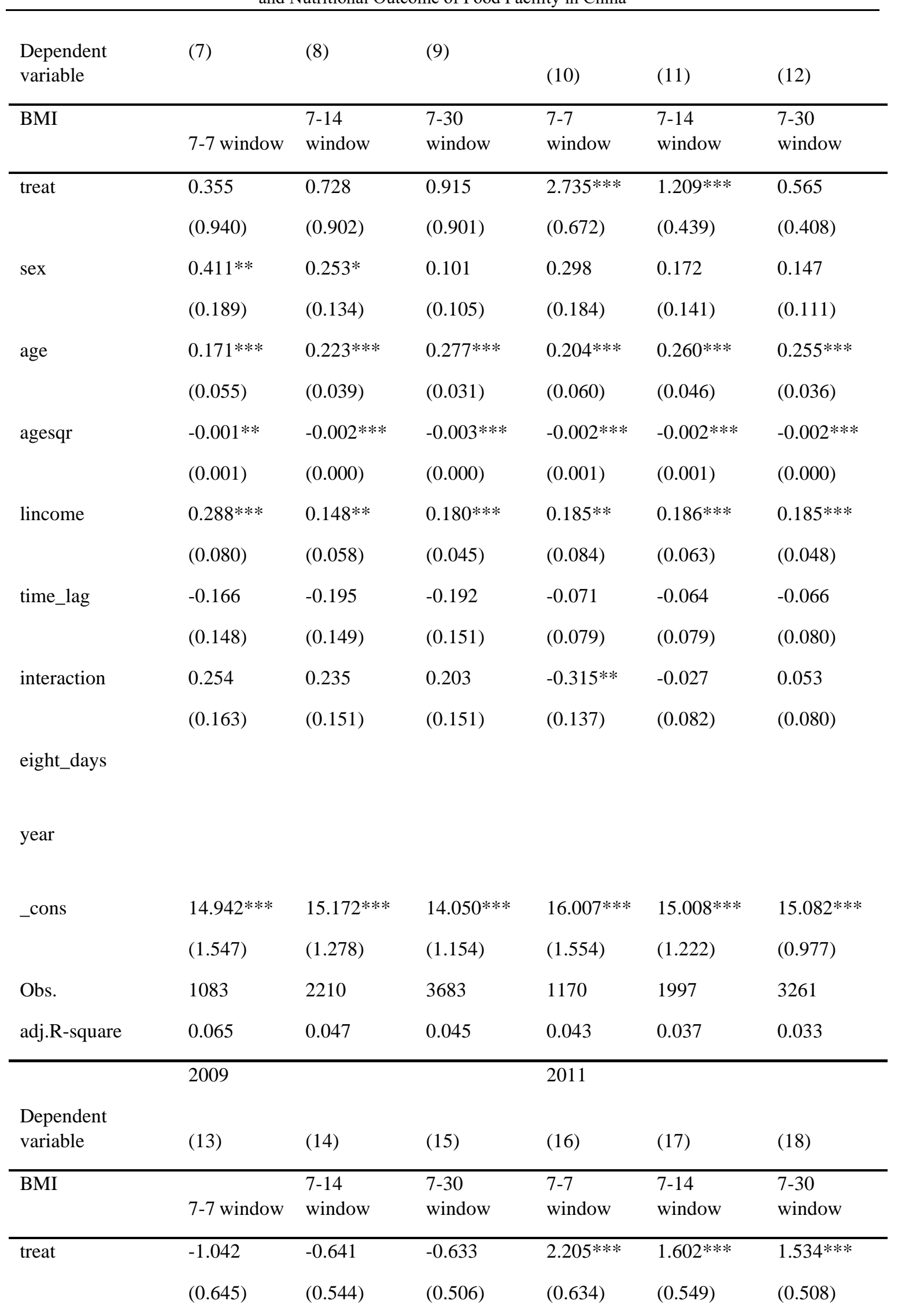


Essays on Holiday Weight Gain, Meat Consumption and Dietary Structure, and Nutritional Outcome of Food Facility in China

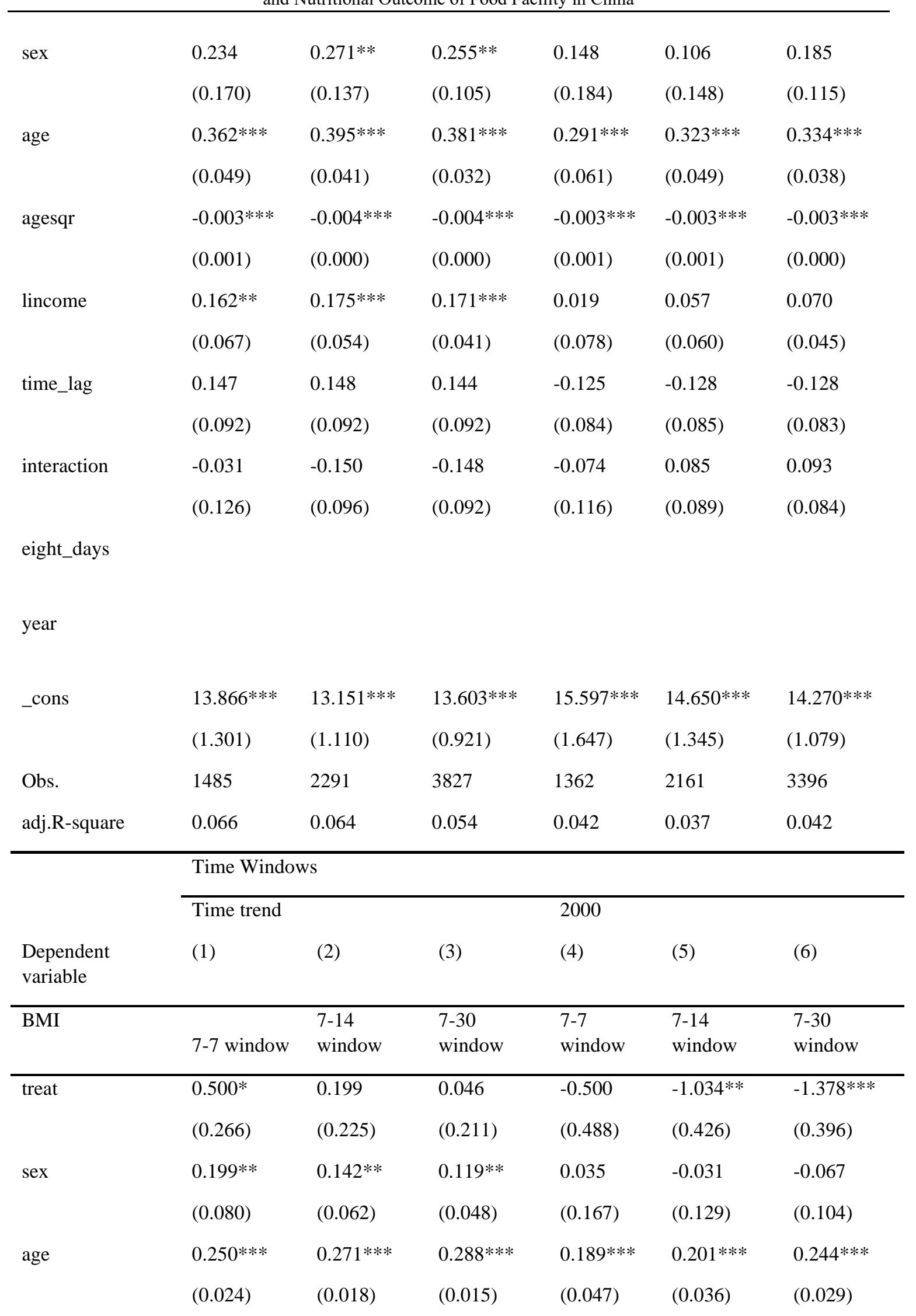


Essays on Holiday Weight Gain, Meat Consumption and Dietary Structure, and Nutritional Outcome of Food Facility in China

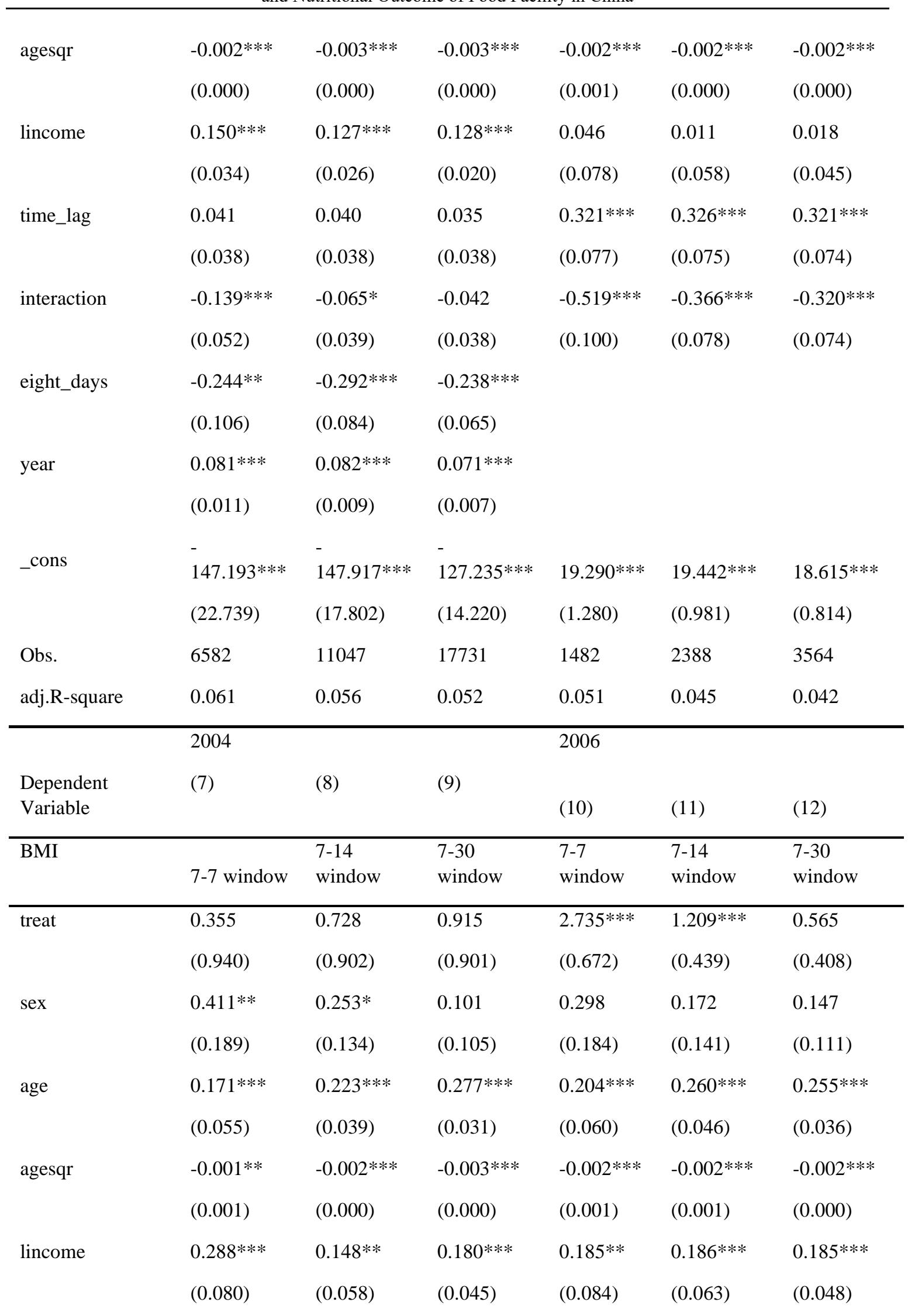


Essays on Holiday Weight Gain, Meat Consumption and Dietary Structure, and Nutritional Outcome of Food Facility in China

\begin{tabular}{lllllll}
\hline \multirow{2}{*}{ time_lag } & -0.166 & -0.195 & -0.192 & -0.071 & -0.064 & -0.066 \\
\multirow{2}{*}{ interaction } & $(0.148)$ & $(0.149)$ & $(0.151)$ & $(0.079)$ & $(0.079)$ & $(0.080)$ \\
& 0.254 & 0.235 & 0.203 & $-0.315^{* *}$ & -0.027 & 0.053 \\
& $(0.163)$ & $(0.151)$ & $(0.151)$ & $(0.137)$ & $(0.082)$ & $(0.080)$
\end{tabular}

eight_days

year

\begin{tabular}{lllllll} 
_cons & $14.942 * * *$ & $15.172 * * *$ & $14.050 * * *$ & $16.007 * * *$ & $15.008 * * *$ & $15.082 * * *$ \\
& $(1.547)$ & $(1.278)$ & $(1.154)$ & $(1.554)$ & $(1.222)$ & $(0.977)$ \\
Obs. & 1083 & 2210 & 3683 & 1170 & 1997 & 3261 \\
adj.R-square & 0.065 & 0.047 & 0.045 & 0.043 & 0.037 & 0.033 \\
\hline
\end{tabular}

$2009 \quad 2011$

Dependent

Variable

(13)

(14)

(15)

(16)

(17)

(18)

\begin{tabular}{lllllll}
\hline BMI & $7-7$ window & $\begin{array}{l}7-14 \\
\text { window }\end{array}$ & $\begin{array}{l}7-30 \\
\text { window }\end{array}$ & $\begin{array}{l}7-7 \\
\text { window }\end{array}$ & $\begin{array}{l}7-14 \\
\text { window }\end{array}$ & $\begin{array}{l}7-30 \\
\text { window }\end{array}$ \\
\hline treat & -1.042 & -0.641 & -0.633 & $2.205^{* * *}$ & $1.602 * * *$ & $1.534 * * *$ \\
sex & $(0.645)$ & $(0.544)$ & $(0.506)$ & $(0.634)$ & $(0.549)$ & $(0.508)$ \\
& 0.234 & $0.271^{* *}$ & $0.255^{* *}$ & 0.148 & 0.106 & 0.185 \\
age & $(0.170)$ & $(0.137)$ & $(0.105)$ & $(0.184)$ & $(0.148)$ & $(0.115)$ \\
& $0.362^{* * *}$ & $0.395^{* * *}$ & $0.381^{* * *}$ & $0.291^{* * *}$ & $0.323^{* * *}$ & $0.334 * * *$ \\
agesqr & $(0.049)$ & $(0.041)$ & $(0.032)$ & $(0.061)$ & $(0.049)$ & $(0.038)$ \\
& $-0.003 * * *$ & $-0.004 * * *$ & $-0.004 * * *$ & $-0.003 * * *$ & $-0.003 * * *$ & $-0.003 * * *$ \\
lincome & $(0.001)$ & $(0.000)$ & $(0.000)$ & $(0.001)$ & $(0.001)$ & $(0.000)$ \\
& $0.162 * *$ & $0.175^{* * *}$ & $0.171^{* * *}$ & 0.019 & 0.057 & 0.070 \\
time_lag & $(0.067)$ & $(0.054)$ & $(0.041)$ & $(0.078)$ & $(0.060)$ & $(0.045)$ \\
& 0.147 & 0.148 & 0.144 & -0.125 & -0.128 & -0.128 \\
& $(0.092)$ & $(0.092)$ & $(0.092)$ & $(0.084)$ & $(0.085)$ & $(0.083)$ \\
interaction & -0.031 & -0.150 & -0.148 & -0.074 & 0.085 & 0.093 \\
& $(0.126)$ & $(0.096)$ & $(0.092)$ & $(0.116)$ & $(0.089)$ & $(0.084)$
\end{tabular}

eight_days 


$\begin{array}{lllllll}\text { year } & & & & & \\ \text { _cons } & 13.866^{* * *} & 13.151^{* * *} & 13.603^{* * *} & 15.597 * * * & 14.650^{* * * *} & 14.270^{* * *} \\ & (1.301) & (1.110) & (0.921) & (1.647) & (1.345) & (1.079) \\ \text { Obs. } & 1485 & 2291 & 3827 & 1362 & 2161 & 3396 \\ \text { adj.R-square } & 0.066 & 0.064 & 0.054 & 0.042 & 0.037 & 0.042\end{array}$

Note: For each explanatory variable, the upper part is the coefficient estimation value, the lower part is the standard error, $* * *, * *, *$ means significant at $1 \%, 5 \%$, and $10 \%$ respectively. lincome is the natural logarithm of total individual income (inflated to the 2009 price level).

Furthermore, if we want to know the difference of treatment effect evaluation induced by outsiders, we use reports the regression results based on equation (1) but without excluding the hyper overweight or underweight subjects and without excluding the kids and old people. Noticeable that Province Effect is equivalent to the below:

$$
B M I_{i}=x_{i}{ }^{\prime} \beta_{1}+\beta_{2} \text { treat }_{i}+\beta_{3} \text { time_lag }_{i}+\beta_{4} \text { treat }_{i} * \text { time_lag }_{i}+p v_{i}^{\prime} \beta_{5}+e_{i},(4)
$$

Where $p v_{i}$ is the vector of all dummies for each province and municipality (except Beijing, which is treated as the reference). As we argue in Table 2.5, the province of subjects contributes to the holiday weight gain to some extent. While the sample size choice does not change our conclusion. Notice that variable $p v_{-} s h_{i}$ is excluded from our analysis since all the subjects in Shanghai report their health exam other than the nearest 14 days window. 


\section{Table 2.5: Province effect and sample choice}

\begin{tabular}{|c|c|c|c|}
\hline \multirow{3}{*}{$\begin{array}{l}\text { Dependent } \\
\text { variable }\end{array}$} & \multicolumn{3}{|c|}{ Time windows } \\
\hline & \multicolumn{3}{|c|}{ Province effect } \\
\hline & (1) & (2) & (3) \\
\hline BMI & 7-7 window & 7-14 window & 7-30 window \\
\hline \multirow[t]{2}{*}{ treat } & 0.038 & -0.083 & -0.056 \\
\hline & $(0.265)$ & $(0.224)$ & $(0.208)$ \\
\hline \multirow[t]{2}{*}{$\operatorname{sex}$} & $0.203 * * *$ & $0.144 * *$ & $0.121 * *$ \\
\hline & $(0.078)$ & $(0.060)$ & $(0.047)$ \\
\hline \multirow[t]{2}{*}{ age } & $0.264 * * *$ & $0.274 * * *$ & $0.288 * * *$ \\
\hline & $(0.023)$ & $(0.018)$ & $(0.014)$ \\
\hline \multirow[t]{2}{*}{ agesqr } & $-0.002 * * *$ & $-0.003 * * *$ & $-0.003 * * *$ \\
\hline & $(0.000)$ & $(0.000)$ & $(0.000)$ \\
\hline \multirow[t]{2}{*}{ lincome } & $0.149 * * *$ & $0.107 * * *$ & $0.106^{* * *}$ \\
\hline & $(0.034)$ & $(0.026)$ & $(0.020)$ \\
\hline \multirow[t]{2}{*}{ time_lag } & 0.031 & 0.028 & 0.031 \\
\hline & $(0.038)$ & $(0.037)$ & $(0.037)$ \\
\hline \multirow[t]{2}{*}{ inter1 } & -0.054 & -0.017 & -0.029 \\
\hline & $(0.051)$ & $(0.039)$ & $(0.037)$ \\
\hline \multirow[t]{2}{*}{ eight_days } & $0.198 * *$ & $0.209 * * *$ & $0.226^{* * *}$ \\
\hline & (0.099) & $(0.077)$ & $(0.059)$ \\
\hline \multirow[t]{2}{*}{ pv_ln } & 0.149 & -0.408 & $-0.554 * * *$ \\
\hline & $(0.349)$ & $(0.249)$ & $(0.187)$ \\
\hline \multirow[t]{2}{*}{ pv_hlj } & 0.189 & $-0.464 *$ & $-0.741 * * *$ \\
\hline & $(0.349)$ & $(0.248)$ & $(0.191)$ \\
\hline \multirow[t]{2}{*}{ pv_sh } & 0.000 & 0.000 & 0.000 \\
\hline & $()$. & (.) & (.) \\
\hline \multirow[t]{2}{*}{$p v_{j}$ js } & -0.503 & $-1.001 * * *$ & $-1.207 * * *$ \\
\hline & $(0.345)$ & $(0.240)$ & $(0.178)$ \\
\hline pv_sd & $0.960 * * *$ & 0.306 & 0.072 \\
\hline
\end{tabular}


Essays on Holiday Weight Gain, Meat Consumption and Dietary Structure, and Nutritional Outcome of Food Facility in China

\begin{tabular}{llll} 
& $(0.345)$ & $(0.241)$ & $(0.179)$ \\
pv_hen & 0.343 & -0.267 & $-0.547 * * *$ \\
& $(0.358)$ & $(0.247)$ & $(0.181)$ \\
pv_hb & -0.522 & $-1.076 * * *$ & $-1.225 * * *$ \\
& $(0.352)$ & $(0.243)$ & $(0.184)$ \\
pv_hun & $-1.474 * * *$ & $-1.957 * * *$ & $-1.897 * * *$ \\
& $(0.360)$ & $(0.251)$ & $(0.182)$ \\
pv_gx & $-1.990 * * *$ & $-2.398 * * *$ & $-2.502 * * *$ \\
& $(0.373)$ & $(0.255)$ & $(0.185)$ \\
pv_gz & $-1.556 * * *$ & $-2.093 * * *$ & $-2.105 * * *$ \\
& $(0.355)$ & $(0.250)$ & $(0.188)$ \\
pv_cq & 0.203 & $-0.641 * *$ & $-0.814 * * *$ \\
& $(0.425)$ & $(0.300)$ & $(0.222)$ \\
_cons & $15.823 * * *$ & $16.654 * * *$ & $16.659 * * *$ \\
N & $(0.717)$ & $(0.556)$ & $(0.448)$ \\
adj. R-sq & 6582 & 11047 & 17731 \\
\hline
\end{tabular}

Dependent Including extreme weight samples variable

(4) (5) (6)

\begin{tabular}{llll}
\hline BMI & $7-7$ window & $7-14$ window & $7-30$ window \\
\hline treat & $0.745^{* *}$ & $0.488^{* *}$ & 0.293 \\
& $(0.295)$ & $(0.243)$ & $(0.234)$ \\
sex & $0.264^{* * *}$ & $0.156^{* *}$ & $0.127^{* *}$ \\
& $(0.089)$ & $(0.067)$ & $(0.054)$ \\
age & $0.265^{* * *}$ & $0.284 * * *$ & $0.306^{* * *}$ \\
& $(0.028)$ & $(0.021)$ & $(0.017)$ \\
agesqr & $-0.002^{* * *}$ & $-0.003^{* * * *}$ & $-0.003^{* * *}$ \\
& $(0.000)$ & $(0.000)$ & $(0.000)$ \\
lincome & $0.218^{* * *}$ & $0.180^{* * *}$ & $0.165^{* * *}$ \\
& $(0.037)$ & $(0.028)$ & $(0.022)$ \\
time_lag & -0.008 & -0.008 & -0.009
\end{tabular}


Essays on Holiday Weight Gain, Meat Consumption and Dietary Structure, and Nutritional Outcome of Food Facility in China

\begin{tabular}{|c|c|c|c|}
\hline & $(0.042)$ & $(0.041)$ & $(0.042)$ \\
\hline \multirow[t]{2}{*}{ inter1 } & -0.087 & -0.023 & 0.001 \\
\hline & $(0.057)$ & $(0.042)$ & $(0.042)$ \\
\hline \multirow[t]{2}{*}{ eight_days } & 0.025 & -0.015 & -0.014 \\
\hline & $(0.108)$ & $(0.083)$ & $(0.066)$ \\
\hline \multirow[t]{2}{*}{ _cons } & $14.634 * * *$ & $14.731 * * *$ & $14.477 * * *$ \\
\hline & $(0.721)$ & $(0.558)$ & $(0.470)$ \\
\hline $\mathrm{N}$ & 6430 & 10796 & 17344 \\
\hline adj. R-sq & 0.045 & 0.043 & 0.039 \\
\hline \multirow{2}{*}{$\begin{array}{l}\text { Dependent } \\
\text { variable }\end{array}$} & \multicolumn{3}{|c|}{ Including kids and senior citizens } \\
\hline & $(7)$ & $(8)$ & (9) \\
\hline BMI & 7-7 window & 7-14 window & $7-30$ window \\
\hline \multirow[t]{2}{*}{ treat } & $0.677 * * *$ & $0.445^{* *}$ & $0.768 * * *$ \\
\hline & $(0.246)$ & $(0.208)$ & $(0.182)$ \\
\hline \multirow[t]{2}{*}{$\operatorname{sex}$} & 0.106 & 0.043 & -0.029 \\
\hline & $(0.073)$ & $(0.056)$ & $(0.056)$ \\
\hline \multirow[t]{2}{*}{ age } & $0.310 * * *$ & $0.313 * * *$ & $0.299 * * *$ \\
\hline & $(0.011)$ & $(0.008)$ & $(0.009)$ \\
\hline \multirow[t]{2}{*}{ agesqr } & $-0.003 * * *$ & $-0.003 * * *$ & $-0.003 * * *$ \\
\hline & $(0.000)$ & $(0.000)$ & $(0.000)$ \\
\hline \multirow[t]{2}{*}{ lincome } & $0.239 * * *$ & $0.206^{* * *}$ & $0.256 * * *$ \\
\hline & $(0.029)$ & $(0.022)$ & $(0.022)$ \\
\hline \multirow[t]{2}{*}{ time_lag } & -0.013 & -0.013 & $-0.023 * *$ \\
\hline & $(0.035)$ & $(0.035)$ & $(0.010)$ \\
\hline \multirow[t]{2}{*}{ inter1 } & -0.067 & -0.012 & $-0.056^{*}$ \\
\hline & $(0.047)$ & $(0.036)$ & $(0.034)$ \\
\hline \multirow[t]{2}{*}{ eight_days } & 0.025 & -0.032 & 0.041 \\
\hline & $(0.088)$ & $(0.069)$ & $(0.066)$ \\
\hline \multirow[t]{2}{*}{ _cons } & $13.377 * * *$ & $13.666 * * *$ & $13.399 * * *$ \\
\hline & $(0.398)$ & $(0.318)$ & $(0.278)$ \\
\hline $\mathrm{N}$ & 8003 & 13518 & 13906 \\
\hline
\end{tabular}



adj. R-sq
0.111
0.117
0.108

Note: For each explanatory variable, the upper part is the coefficient estimation value, the lower part is the standard error, $* * *, * *, *$ means significant at $1 \%, 5 \%$, and $10 \%$ respectively. lincome is the natural logarithm of total individual income (inflated to the 2009 price level). Here, we use the residences in Beijing as a reference. Dummy variables pv_ln, pv_hlj, pv_sh, pv_js, pv_sd, pv_hen, pv_hb, pv_hun, pv_gx, pv_gz, and pv_cq represents the subjects who live in the community which is located in Liaoning Province, Heilongjiang Province, Shanghai, Jiangsu Province, Shandong Province, Henan Province, Hubei Province, Hunan Province, Guangxi Province, Guizhou Province, and Chongqing respectively.

For the potential age group disparities, we use Table 2.6 to indicate that the most fragile group to the holiday weight gain is the middle-aged group. Not surprisingly, compared with the female at the same age group, young and middle-aged male has a higher BMI. But males have a lower BMIwhen they getting old.

Until now, we cannot reject the possibility that any other period that is near to but other than the National Day holiday may lead to a hypothetical "holiday weight gain". We further check the placebo effect of holiday weight gain to show that it is not the case. Under such circumstance, we assume hypothetical holidays which happens at other dates other than National Day Holiday. If the holiday weight gain effect still holds for those hypothetical holidays, the National Day holiday weight gain would be skeptical. 
Table 2.6: Age group effect

\begin{tabular}{|c|c|c|c|}
\hline \multirow{3}{*}{ Age Group } & \multicolumn{3}{|l|}{$\begin{array}{l}\text { Time } \\
\text { Windows }\end{array}$} \\
\hline & \multicolumn{3}{|l|}{$18-29$} \\
\hline & (1) & (2) & (3) \\
\hline BMI & 7-7 Window & 7-14 Window & 7-30 Window \\
\hline \multirow[t]{2}{*}{ treat } & -0.129 & 0.193 & 0.215 \\
\hline & $(0.729)$ & $(0.614)$ & $(0.596)$ \\
\hline \multirow{2}{*}{ sex } & $1.209 * * *$ & $1.095 * * *$ & $0.912 * * *$ \\
\hline & $(0.217)$ & $(0.164)$ & $(0.134)$ \\
\hline \multirow{2}{*}{ age } & $1.407 * * *$ & $1.030 * * *$ & $0.868 * * *$ \\
\hline & $(0.504)$ & $(0.385)$ & $(0.317)$ \\
\hline \multirow[t]{2}{*}{ agesqr } & $-0.027 * *$ & $-0.018 * *$ & $-0.015^{* *}$ \\
\hline & $(0.011)$ & $(0.008)$ & $(0.007)$ \\
\hline \multirow[t]{2}{*}{ lincome } & 0.073 & $0.097 *$ & 0.033 \\
\hline & $(0.078)$ & $(0.056)$ & $(0.046)$ \\
\hline \multirow[t]{2}{*}{ time_lag } & 0.003 & -0.009 & -0.020 \\
\hline & $(0.105)$ & $(0.104)$ & $(0.107)$ \\
\hline \multirow[t]{2}{*}{ interaction } & 0.060 & 0.017 & 0.028 \\
\hline & $(0.140)$ & $(0.108)$ & $(0.107)$ \\
\hline \multirow[t]{2}{*}{ eight_days } & -0.426 & $-0.483 * *$ & -0.230 \\
\hline & $(0.279)$ & $(0.223)$ & $(0.180)$ \\
\hline \multirow[t]{2}{*}{ _cons } & 2.364 & 6.162 & $8.479 * *$ \\
\hline & $(5.942)$ & (4.589) & (3.798) \\
\hline $\mathrm{N}$ & 773 & 1331 & 2072 \\
\hline adj. R-sq & 0.058 & 0.064 & 0.052 \\
\hline \multirow[t]{2}{*}{ Age Group } & $30-45$ & & \\
\hline & (4) & $(5)$ & (6) \\
\hline BMI & 7-7 Window & 7-14 Window & 7-30 Window \\
\hline \multirow[t]{2}{*}{ treat } & $0.784 *$ & 0.301 & 0.135 \\
\hline & $(0.421)$ & $(0.351)$ & $(0.329)$ \\
\hline \multirow{2}{*}{ sex } & $0.421 * * *$ & $0.454 * * *$ & $0.536 * * *$ \\
\hline & $(0.130)$ & (0.099) & $(0.078)$ \\
\hline \multirow{2}{*}{ age } & 0.076 & 0.143 & 0.157 \\
\hline & $(0.270)$ & $(0.204)$ & $(0.162)$ \\
\hline \multirow[t]{2}{*}{ agesqr } & 0.000 & -0.001 & -0.001 \\
\hline & $(0.004)$ & $(0.003)$ & $(0.002)$ \\
\hline \multirow[t]{2}{*}{ lincome } & $0.245 * * *$ & $0.165^{* * *}$ & $0.139 * * *$ \\
\hline & $(0.053)$ & (0.039) & $(0.030)$ \\
\hline \multirow[t]{2}{*}{ time_lag } & 0.042 & 0.042 & 0.042 \\
\hline & $(0.060)$ & $(0.059)$ & $(0.059)$ \\
\hline
\end{tabular}


Essays on Holiday Weight Gain, Meat Consumption and Dietary Structure, and Nutritional Outcome of Food Facility in China

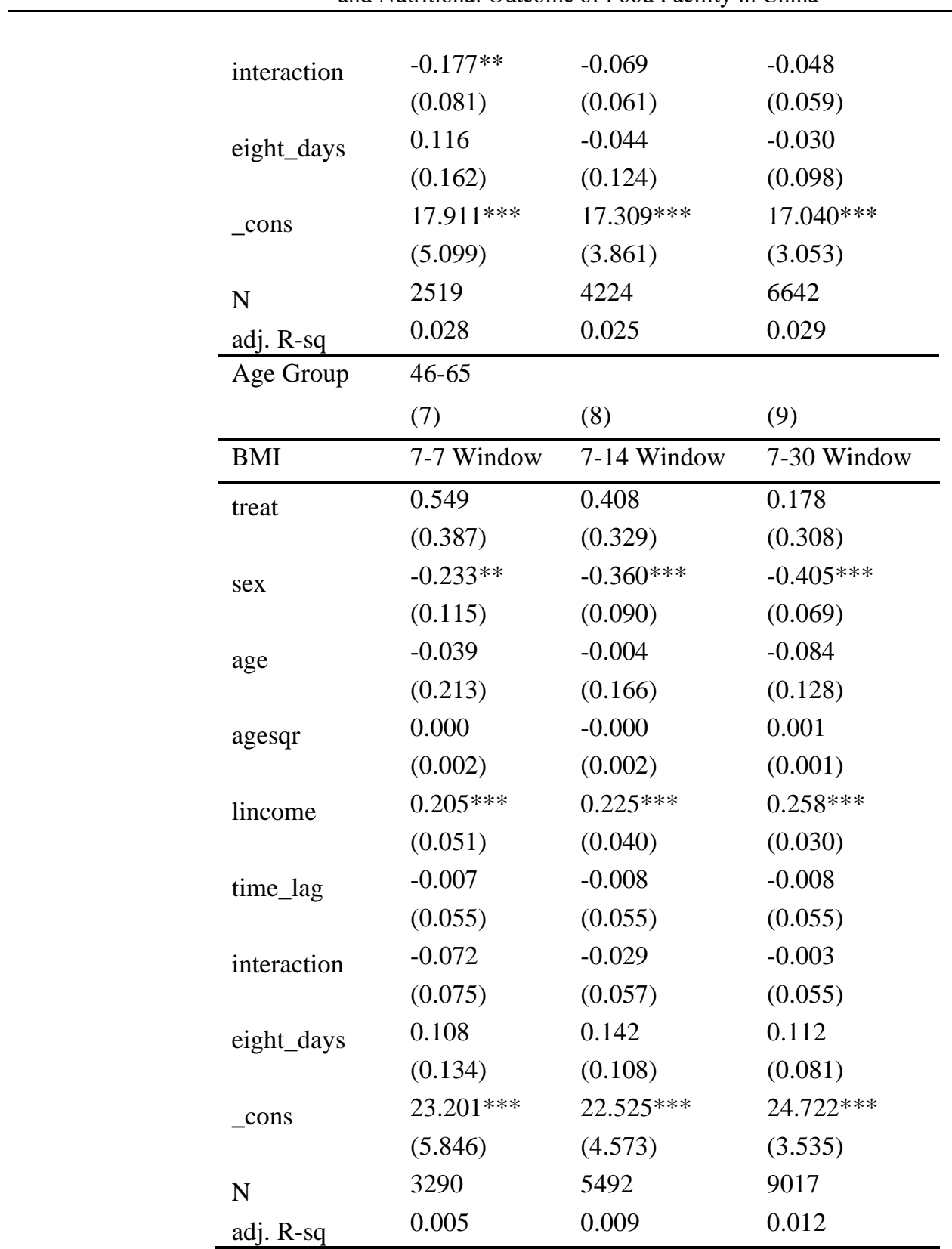

Note: For each explanatory variable, the upper part is the coefficient estimation value, the lower part is the standard error, $* * *, * *, *$ means significant at $1 \%, 5 \%$, and $10 \%$ respectively.

However, whether the National Day holiday rather than other periods around September or October keeps the status of the driver for weight gain still needs further exploration. 


\section{Table 2.7: Placebo holiday effect}

\begin{tabular}{|c|c|c|c|c|}
\hline \multirow[b]{2}{*}{ treat } & \multicolumn{4}{|c|}{ Time Windows } \\
\hline & (1) & (2) & (3) & (4) \\
\hline Date & $\begin{array}{l}\text { Whole } \\
\text { sample }\end{array}$ & $\begin{array}{l}7-7 \\
\text { Window }\end{array}$ & $\begin{array}{l}7-14 \\
\text { Window }\end{array}$ & $\begin{array}{l}7-30 \\
\text { Window }\end{array}$ \\
\hline \multirow[t]{2}{*}{$09.26-10.02$} & 0.023 & 0.724 & 0.377 & 0.152 \\
\hline & -0.060 & -1.500 & -0.270 & -0.161 \\
\hline \multirow[t]{2}{*}{$09.27-10.03$} & 0.075 & $3.144 * * *$ & $0.557 * * *$ & $0.370 * * *$ \\
\hline & -0.057 & -0.874 & -0.215 & -0.126 \\
\hline \multirow[t]{2}{*}{ 09.28-10.04 } & 0.067 & 0.308 & $0.631 * * *$ & $0.371 * * *$ \\
\hline & -0.057 & -0.531 & -0.185 & -0.127 \\
\hline \multirow[t]{2}{*}{ 09.29-10.05 } & 0.061 & $0.664 *$ & $0.526 * * *$ & $0.274 *$ \\
\hline & -0.056 & -0.363 & -0.183 & -0.147 \\
\hline \multirow[t]{2}{*}{ 09.30-10.06 } & 0.050 & 0.343 & 0.155 & -0.018 \\
\hline & -0.056 & -0.273 & -0.185 & -0.163 \\
\hline \multirow[t]{2}{*}{$10.02-10.08$} & 0.010 & -0.209 & -0.187 & -0.389 \\
\hline & -0.057 & -0.299 & -0.280 & -0.271 \\
\hline \multirow[t]{2}{*}{$10.03-10.09$} & -0.010 & 0.132 & 0.215 & 0.026 \\
\hline & -0.058 & -0.413 & -0.400 & -0.393 \\
\hline \multirow[t]{2}{*}{$10.04-10.10$} & -0.019 & 0.311 & 0.269 & 0.056 \\
\hline & -0.059 & -0.603 & -0.592 & -0.588 \\
\hline \multirow[t]{2}{*}{$10.05-10.11$} & -0.059 & -0.245 & -0.153 & -0.274 \\
\hline & -0.061 & -0.978 & -0.966 & -0.966 \\
\hline \multirow[t]{2}{*}{$10.06-10.12$} & -0.067 & 0.002 & -0.020 & -0.114 \\
\hline & -0.062 & -1.448 & -1.439 & -1.440 \\
\hline
\end{tabular}

Note: For each explanatory variable, the upper part is the coefficient estimation value, the lower part is the standard error, $* * *, * *, *$ means significant at $1 \%, 5 \%$, and $10 \%$ respectively.

As listed in Table 2.7, if we assume that the week-long holiday is changed from the real starting date to hypothetically ten nearest dates, that is, from September 26th, September 27th up to October 6th, we find that the hypothetical holidays under any window 
give us no significant results, except for the placebo holiday starting from September 27th, September 28th and September 29th. One possible explanation is that some people go traveling in advance and return home early for their National Day holiday plan, which makes the real holiday that they spare slightly ahead. Thus, putting the hypothetical starting date slightly in advance is consistent with those people's behavior.

\subsection{Conclusion}

Our study uses the regression discontinuity model and CHNS (China Health and Nutrition Survey) data, to study the weight gain effect of the National Day holiday in China. We find that Chinese adults tend to gain $1.561 \mathrm{~kg}$ during the National Day holiday in China. The effect could remain for about one or weeks and disappear in one month. It implies that holiday weight gain could be reduced in one month and has no long-run health and nutrition effects. The Golden Week policy is not that health unfriendly in terms of weight gain risks. Besides, richer people and older people have a significantly higher chance to gain weight during the National Day Holiday.

Compared to previous research with no more than 200 subjects, data used in this study is a relatively large survey. We find that people increase body weight on average by 1.56 $\mathrm{kg}$ although the length of the holiday is only set up to 7 days. With the assumption of random sampling held, we estimate the average weight gain of the National Day holiday in China. Also, the time trend effect, the influence of the control variable, and the problem of window specification are all considered. Our study will help shed light on holiday weight gain and further nutritional dynamics in the emerging country. In conclusion, we argue that although people will gain body weight shortly after the holiday. Meanwhile, in the long 
run (in one month), we observe the gained weight will only be kept partly. Thus, the 7days-long National Day Holiday imposes a significant short-term but rather a small longterm effect on body weight. By classifying our sample to three age groups, we find that middle-aged residents suffer most in terms of holiday weight gain risk. 


\section{Chapter 3 Meat Consumption, Dietary Structure and Nutrition Transition in China}

Nutrition improvement, as a facet of nutrition transition, is driven by quantity increase and structural change in food consumption. This study proposes a simple but innovative framework to decompose the total income effect on nutrition improvement into direct income effect and structural change effect. With the use of the China Health and Nutrition Survey (CHNS) data, we find that a $1 \%$ increment in income will boost per capita calorie consumption by $0.02 \%$ within a family. When considering the calorie consumption increment led by the income growth, $16 \%$ to $21 \%$ of the total effect is due to changes in the diet structure, while the rest is attributed to the conditional income effect. In addition, in rural areas, the impact of changes in diet structure is more prominent, which means that the existence of a gap in the dietary structure between urban and rural China. It is expected that the consumption of meat in rural China will increase in the future.

\subsection{Introduction}

Increasing specific nutrients intake and calorie consumption, in coincidence with rapid economic growth and fierce social change, occurs in developing and emerging economies. (Guo et al., 2000; Du et al., 2002; Popkin et al., 2002; Jensen \& Miller, 2010; Tian and Yu, 2015). Early studies (Popkin, 1999; Subramanian \& Deaton, 1996) focus on the relationship between income and energy intake, under a static framework, especially for the income elasticity of calorie intake. Lifestyle change that induces a reduction in physical activity levels, people's preference towards processed food and sugar-sweetened beverages, and food patterns change like the popularity of having food away from home also contributes to the prevalence of obesity and obesity-related non-communicable disease 
in emerging and developing countries. (Popkin et al., 2012). A general finding is that nutrition consumption first increases drastically, and then slows down until reaching to a saturate point with income growth (Zhou and Yu 2015; Tian and Yu, 2015; Shimokawa, 2010). Consequently, the income elasticity of nutrition would keep declining, and this is confirmed by a meta-analysis of Zhou and Yu (2015).

Income does not only increase the food quantity but also food quality (Yu and Abler 2009). Food quality is measured by dietary structure. Some recent researchers start to shed light on dietary structural change in the nutrition transition. (Jensen \& Miller, 2010) use the share of calories from staple food as an index to measure the level of undernutrition, as it first maintains at a high level and then decreases drastically when income reaches a certain level. Min et al. (2020) find that the effect of dietary knowledge is heterogeneous for food and calories loss with household features and income.

Tian and $\mathrm{Yu}$ (2015) used semi-parametric methods and demonstrated that dietary structure changes over income in China. A typical phenomenon is that traditional diets dominated by fiber and staples are being replaced by meat consumption in recent decades (Yu \& Abler, 2009 \& 2014; Tian \& Yu,2013; Zhou et al., 2015). This is confirmed by a large volume of literature on food demand analysis in China. Chen et al. (2016) and Zhou et al. (2017) conducted meta-analyses for the demand elasticities in China. As income still grows, meat consumption is expected to increase in a mid-term. Zhou et al. (2017) projected that meat consumption will increase by about 50\% from 2015 to 2030 .

In addition to income, many other factors have been taken into account in the literature of nutrition analysis, such as household structure, gender, and other socioeconomic variables (Tian and $\mathrm{Yu}, 2015)$. For instance, intrahousehold calorie allocation responds 
asymmetrically to expected declines and increases in household food availability in China (Shimokawa, 2010). However, the linkage between dietary structural change and nutrition improvement has not been thoroughly examined quantitatively. Low level of overall economic development other than low income could be the main cause of insufficient calorie consumption in development countries (Dawson, 2007). The meat itself as a food category has some unique attributes such as the high environmental and ecological burdens, compared with cereals, fruits, and vegetables (Shimokawa, 2015; Yu, 2015). Democracy levels of countries could also correlate with meat consumption as a democratic government has the incentive to reach food security and ensure sufficient meat supply (Hasiner and $\mathrm{Yu}$, 2016). Other than nutrient intake, cooking style, and food patterns in China have changed drastically as the snacking and fried food are limited in traditional Chinese daily meals (Wang et al., 2008).

In order to fill in the research gap, this paper will propose a simple but innovative framework to decompose the total income effect on nutrition improvement into direct income effect and structural effect. Specifically, the dietary structure is measured by meat consumption.

The rest of this paper is organized as follows: Section 2 and 3 describe the theoretical framework and the empirical model. Section 4 introduces the data source and descriptive statistics. Section 5 discusses the empirical results, followed by Section 6 of the conclusion.

\subsection{Theoretical framework}

We assume nutrition consumption $C$ (e.g. Calories) is a function of income $(X)$ and dietary structure $(S)$. Following Jensen \& Miller (2010) and Tian \& Yu (2015), the dietary 
structure can be measured by the calories share of meat products $\left(S_{c}\right)$, or the expenditure on meat expenditure in total food expenditure $S_{e}$.

$$
C=F(X, S)
$$

However, if we assume income is exogenous, food structure can be driven by income growth, as is observed in the literature. That is, $S$ is also a function of $X$. That is,

$$
C=F[X, S(X)]
$$

The relationship between income, food structural change, and nutrition transition can be demonstrated in Figure 3.1. That is, income has two channels to impact nutrition consumption: expansion of food consumption and change of food structure. Taking total differentiation for (2) with respect to $X$, we have

$$
\frac{d \ln C}{d \ln X}=\left.\frac{\partial \ln C}{\partial \ln X}\right|_{\text {Constant } S}+\frac{\partial \ln C}{\partial S} \frac{\partial S}{\partial \ln X}
$$

where $\frac{d \ln C}{d \ln X}$ is the unconditional income elasticity of calorie consumption, measuring the total income effect. That is equation (3) decompose the total income effect into two terms : $\frac{\partial \ln C}{\partial \ln X}$ and $\frac{\partial \ln C}{\partial S} \frac{\partial \ln S}{\partial \ln X}$.

$\frac{\partial \ln C}{\partial \ln X}$ is the direct income effect after controlling for the dietary structure. From an economic perspective, this term measures the direct income effect, mainly driven by the food quantity expansion with the assumption of fixed food structural change. While the second term $\frac{\partial \ln C}{\partial S} \frac{\partial \ln S}{\partial \ln X}$ measures the effect of dietary change on total calorie consumption. 
If we use the calories share of meat or expenditure share of meat as the measure of dietary structure, we have a hypothesis that $\frac{\partial \ln C}{\partial S}>0$ and $\frac{\partial S}{\partial \ln X}>0$, as income increases meat consumption generally in developing and emerging economies. Hence, we have

$$
\frac{d \ln C}{d \ln X}>\left.\frac{\partial \ln C}{\partial \ln X}\right|_{\text {Constant } S}
$$

It implies that direct (conditional) income effect on nutrition consumption is often lower than the total effect. It is our common wisdom that dietary quality increase also could enhance nutrition consumption. However, to what extent the dietary structural change affect nutrition improvement is an empirical problem. This will be studied in the next section.

The channel for the impact of income growth on nutrition improvement is summarized below in Figure 3.1.

\section{Figure 3.1: Theoretical framework}

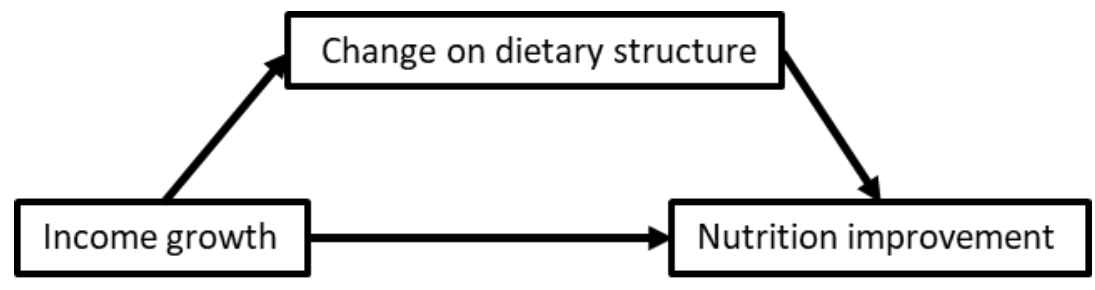

\subsection{Empirical model}

Following the above theoretical framework, we assume equation (1) is a linear function, and have the following specifications:

$$
\begin{aligned}
& \ln C_{i}=\alpha_{0}+\alpha_{1} * \ln X_{i}+\alpha_{2} * S_{i}+z_{i}{ }^{\prime} \alpha_{3}+e_{i} \\
& S_{i}=\theta_{0}+\theta_{1} * \ln X_{i}+z_{i}{ }^{\prime} \theta_{2}+\varepsilon_{i}
\end{aligned}
$$


Where $\alpha_{r}(\mathrm{r}=0,1,2,3)$ and $\theta_{t}(\mathrm{t}=0,1)$ are parameters to be estimated. $z_{i}$ is a vector of control variables. $e_{i}$ and $\varepsilon_{i}$ are error terms following normal distribution $\mathrm{N}\left(0, \sigma_{e}^{2}\right)$ and $\mathrm{N}(0$, $\left.\sigma_{\varepsilon}^{2}\right)$ respectively.

However, the current literate often has the following conventional model without considering dietary structural change,

$$
\ln C_{i}=\tilde{\alpha}_{0}+\tilde{\alpha}_{1} * \ln X_{i}+z_{i}^{\prime} \tilde{\alpha}_{2}+\tilde{e}_{i}
$$

Where similarly, $\tilde{\alpha}_{0}, \tilde{\alpha}_{1}, \tilde{\alpha}_{3}$ are parameters to be estimated, while $\tilde{e}_{i}$ is the error term.

Compare equation (6) with equations (4) and (5), we could easily obtain,

$$
\begin{aligned}
\tilde{\alpha}_{1}= & \frac{d \ln C}{\operatorname{dln} X} \\
= & \left.\frac{\partial \ln C}{\partial \ln X}\right|_{S \text { is controlled }}+\frac{\partial \ln C}{\partial S} \frac{\partial S}{\partial \ln X} \\
& =\alpha_{1}+\alpha_{2} * \theta_{1}
\end{aligned}
$$

Equation (7) empirically decompose the total income effect into a conditional income effect and a structural change effect, consistent with the Equation (3) in the theoretical framework section.

Compared with the conventional model, our model can easily decompose the confounding mixed total income effect $\left(\tilde{\alpha}_{1}\right)$ into two part: the direct (conditional) income effect or the intensive margin of calorie consumption $\left(\alpha_{1}\right)$ and the dietary structural change effect or the extensive margin of calorie consumption $\left(\alpha_{2} * \theta_{1}\right)$. The structural change effect $\left(\alpha_{2} * \theta_{1}\right)$ can be also regarded as an indirect effect of income. This is consistent with the Equation (3) of the theoretical framework section. 
Here comes to the proxy variables for dietary structure. Following Jensen \& Miller (2010) and Tian \& Yu (2015), we propose two measures for dietary structure: the calories share of meat products ( calsmeat $_{i}$ ), and the share of meat expenditure on total food expenditure $\left(\right.$ esmeat $\left._{i}\right)$.

\subsection{Data source and descriptive statistics}

We use the China Health and Nutrition Survey (CHNS) dataset for this study. CHNS is a widely recognized long-lasting survey specifically shedding light on nutrition and health issues for Chinese people. It is supported by three institutes: Carolina Population Center of the University of North Carolina at Chapel Hill, the Chinese Center for Disease Control and Prevention and the National Institute of Nutrition and Food Safety. The current project covers more than 7000 households.

The survey starts initially in 1989, but the early surveys cover limited information on the prices of food. As a result, we only make use of data in 2004, 2006, and 2009, since the price information is reported in those three rounds.

The calculation of expenditure share of meat consumption which is an indicator of food structure requires the prices of individual food items. which are reported in the community survey. Then we estimate total food expenditure as well as expenditures for specific food categories. In this way, we finally calculate the expenditure share of meat consumption.

As we have the information each food category consumed by the samples, the calculation of calorie share of meat consumption can be easily realized by multiplying the food consumption quantity by calories contents for each food category. The calories 
contents can be easily obtained from China Food Composition Table 2002 and 2004 (which

are released by the Chinese Center for Disease Control and Prevention).

The definition of the variables of our interests is reported in Table 3.1.

Table 3.1: Summary of descriptions of variables

\begin{tabular}{llll}
\hline Category & Variable name & Unit & Description \\
\hline $\begin{array}{l}\text { Dependent } \\
\text { Variable }\end{array}$ & lncalint & kcal & The natural logarithm of calorie intake \\
Mediator Variables & esmeat & $\%$ & Share of food expenditure spend on meat \\
& calsmeat & $\%$ & Share of calorie absorbed from meat \\
Independent & lnincome & CNY & The natural logarithm of income inflated to the 2004 price level \\
Variable & facility & counts & Number of nearby food facilities \\
& hhage & year & Age of household head \\
& hhagesqr & year^2 & Squared term of household head's age \\
& hhedu & year & Years of household head's education \\
& hhmale & dummy & The gender of household head, if male, it equals 1, or else 0 \\
& share_child & $\%$ & Share of kids younger than or equal to 5 years old \\
& share_old & $\%$ & Share of family members older than 60 \\
& share_madult & $\%$ & Share of male members aged between 19 and 60 \\
\hline
\end{tabular}

As Table 3.1 shows, we follow the common social-economical factors to construct the covariates. We compute food consumption data for each category and each specific food item by calculating the inventory change plus the food away from home. Afterward, we estimate the calorie consumption per capita per day for each member of each family. But it is noticeable that the accuracy of calorie consumption per capita we calculated here may suffer from food waste and the differences in the household size of the survey and real food consumption size of households (Yu and Abler, 2016). 


\section{Table 3.2: Descriptive statistics}

\begin{tabular}{lllll}
\hline Category/mean & Variable & $\begin{array}{l}\text { Whole } \\
\text { sample }\end{array}$ & $\begin{array}{l}\text { Rural } \\
\text { sample }\end{array}$ & $\begin{array}{l}\text { Urban } \\
\text { sample }\end{array}$ \\
\hline Dependent variable & lncalint & 7.639 & 7.649 & 7.618 \\
Mediator variables & esmeat & 0.236 & 0.213 & 0.282 \\
& calsmeat & 0.107 & 0.093 & 0.137 \\
Independent variable & lnincome & 8.497 & 8.326 & 8.853 \\
Covariates & facility & 47.895 & 42.888 & 58.268 \\
& hhage & 54.222 & 53.548 & 55.619 \\
& hhagesqr & 3112.48 & 3036.211 & 3270.475 \\
& hhedu & 7.515 & 7.066 & 8.444 \\
& hhmale & 0.836 & 0.871 & 0.763 \\
& share_child & 0.028 & 0.031 & 0.022 \\
& share_old & 0.199 & 0.175 & 0.25 \\
& share_madult & 0.311 & 0.317 & 0.298 \\
\hline Number of observations & & 11678 & 7876 & 3802 \\
\hline
\end{tabular}

Notice: the sample mean of lncalint is 7.639, while $\mathrm{e}^{\wedge} 7.639=2077.67$. The sample mean of household daily calorie intake per capita is about 2000 to $2100 \mathrm{kcal}$.

Table 3.2 above shows the descriptive statistics of all the variables. After dropping the observations with missing values or outliers, we have 11678 observations staying in the sample. Meat belongs to a high-quality food category and accounts for $24 \%$ of total food expenditure, but only $11 \%$ of the whole calorie consumption. More than $80 \%$ of household heads are males, and the average age of the household head is 54 years old. Meanwhile, around two-thirds of participation families come from rural regions.

We particularly exploit the expenditure share and calorie share for meat products as the indicators of dietary structural change. Yu and Tian (2013) describe that the dietary change in China is represented by the fast preference transformation from the grain intense food to the meat intense food. An increase in meat consumption is a general trend in nutrition transition observed in developing and transition countries.

Besides the variables listed above, we add the county level dummies in regression to control for unobserved regional disparity and the food price differences. 


\section{Figure 3.2: The fitted values of calorie consumption on income}
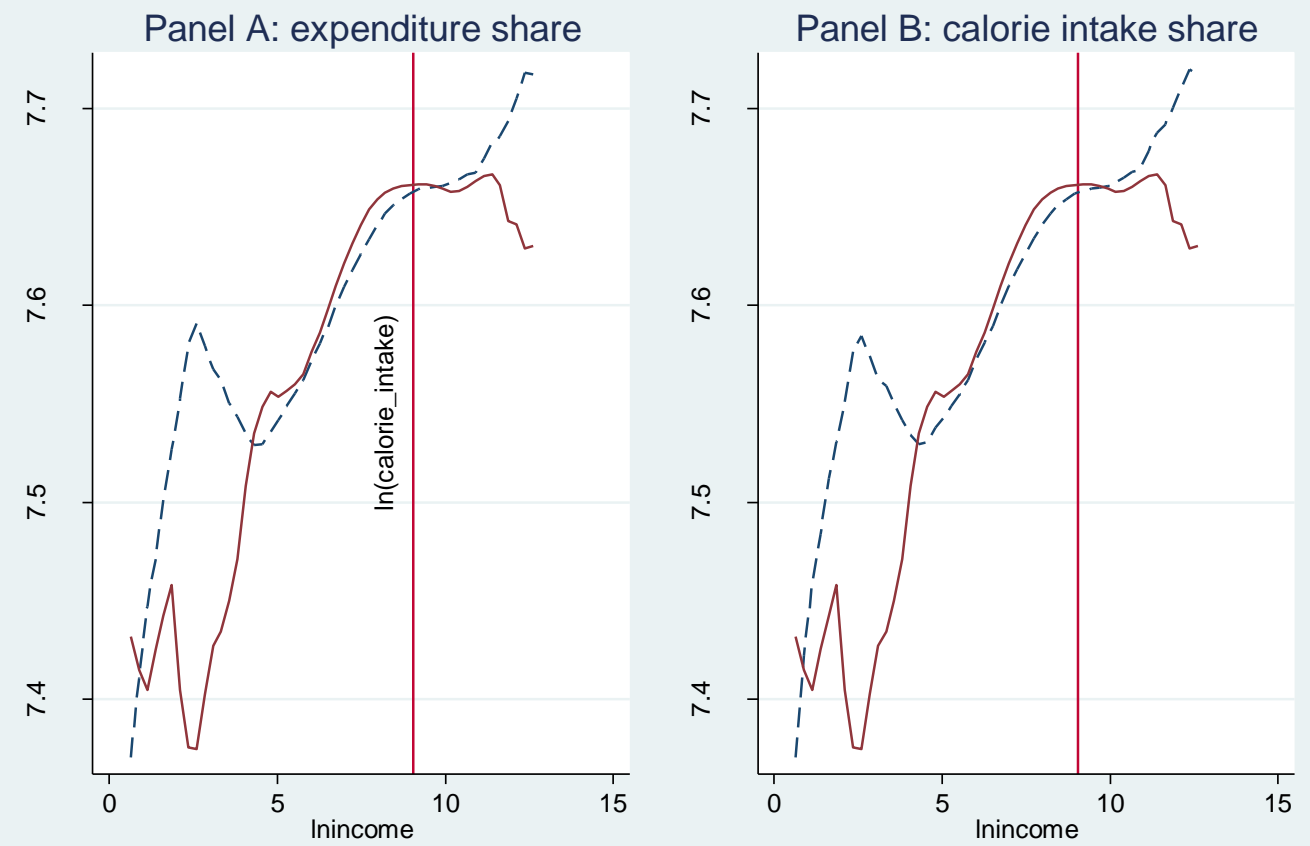

Notice: The dashed line shows the fitted local polynomial smooth values, while the solid line shows the local polynomial smooth of the sample. The vertical line represents the mean income of the sample, 8385.063 CNY per capita per year.

Figure 3.2 straightforwardly shows the relationship between income and household per capita calorie consumption. As we can observe, calorie consumption and income are positively correlated except for very low and very high-income people. Very poor people may tend to be engaged in labor tense heavy work so that they need to consume more calories to support their activities. Similarly, we find that very rich people tend to consume slightly less energy. We argue that rich people can easily obtain enough energy, so they pay more attention to the dietary quality and diversity of food. 


\section{Figure 3.3: Meat consumption and income dynamics}
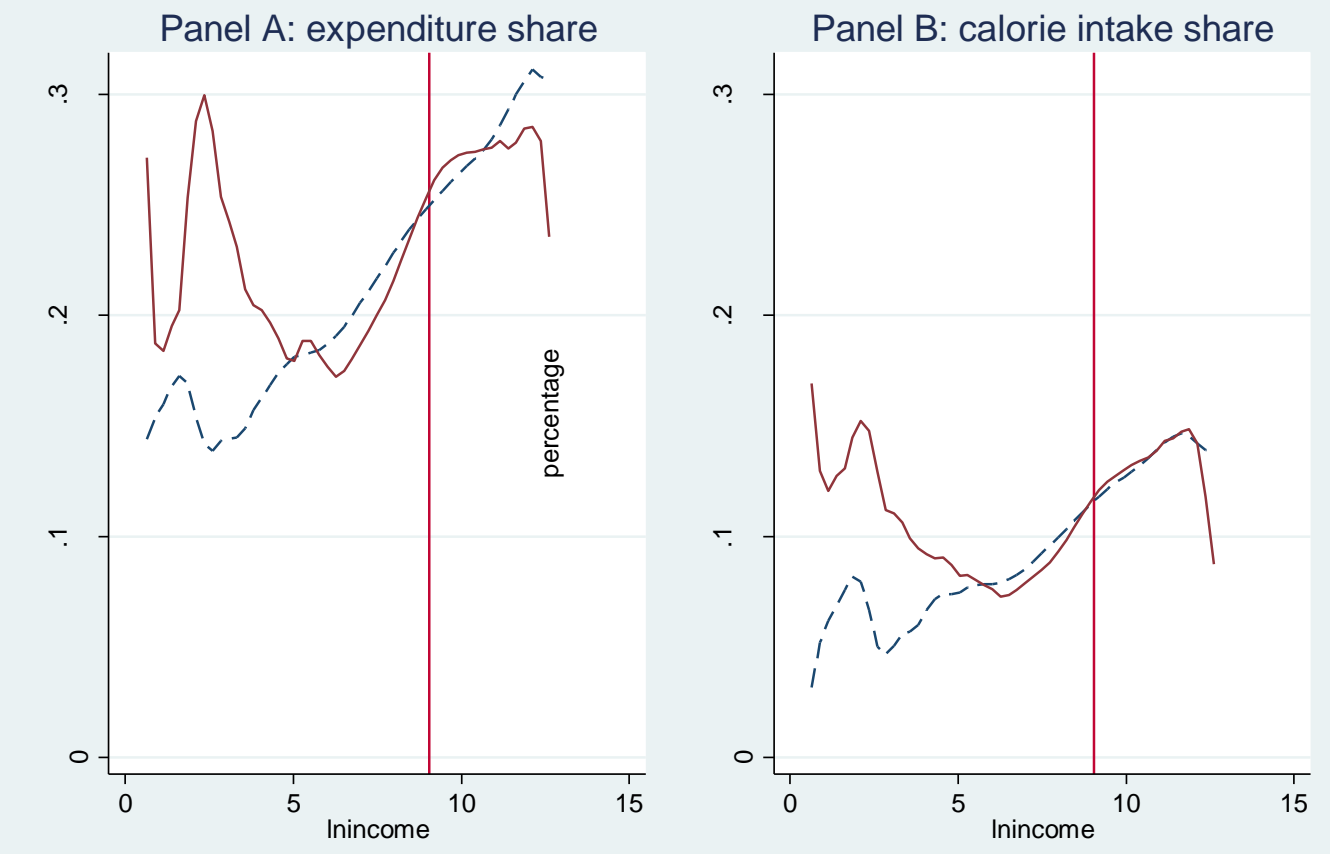

Notice: The dashed line shows the fitted local polynomial smooth values, while the solid line shows the local polynomial smooth of the sample. The vertical line represents the mean income of the sample, 8385.063 CNY per capita per year.

Figure 3.3 shows the relationship between food structure change and income growth without controlling for other factors. Generally speaking, the upward shape of the fitted curve implies that Chinese consumers tend to spend more expenditure on meat when they can afford to, and the percentage of calories obtained from meat also increases with income growth.

\subsection{Empirical results}

- Sobel, Araion and Goodman test

Following MacKinnon et al. (2002), we implement Sobel, Araion, and Goodman test for the hypothetical mediation variables mentioned above: expenditure share and calorie share for meat, and corresponding shares for staple food, before we move to the popular bootstrapping regression approach. 


\section{Table 3.3: Sobel test for mediators}

\begin{tabular}{|c|c|c|c|c|c|}
\hline \multirow{2}{*}{$\begin{array}{l}\text { Independent variable } \\
\text { lnincome }\end{array}$} & & \multicolumn{3}{|c|}{$\mathrm{Z}$ scores for tests } & \multirow[b]{2}{*}{$\begin{array}{l}\text { mediated } \\
\text { proportion }\end{array}$} \\
\hline & & Sobel test & Aroian test & $\begin{array}{l}\text { Goodman } \\
\text { test }\end{array}$ & \\
\hline \multirow[t]{4}{*}{ Mediation variables } & esmeat & $0.004 * * *$ & $0.004 * * *$ & $0.004 * * *$ & $21.0 \%$ \\
\hline & calsmeat & $0.003 * * *$ & $0.003 * * *$ & $0.003 * * *$ & $15.5 \%$ \\
\hline & esstaple & $-0.004 * * *$ & $-0.004 * * *$ & $-0.004 * * *$ & $-20.8 \%$ \\
\hline & calsstaple & $-0.002 * * *$ & $-0.002 * * *$ & $-0.002 * * *$ & $-11.3 \%$ \\
\hline
\end{tabular}

Note: $* * *, * *, *$ denote significant at $1 \%, 5 \%$ and $10 \%$ respectively.

As shown in Table 3.3, all the four potential mediators reject the null hypothesis at the $1 \%$ statistical level, among Sobel test, Aroian test, and Goodman test. The result implies the existence of an indirect dietary structural effect. The estimated proportion of mediation effect over total effect is reported in the table, consistent with intuition: households tend to consume more meat and less staple food when they are getting rich.

- Conditional income effect and dietary structural change

As error terms in equation (4) and (5) might be correlated, the seemingly unrelated regression (SUR) with bootstrapped standard errors could serve the purpose better and obtain a more efficient estimator (Preacher and Hayes, 2008).

\section{Table 3.4: Empirical results}

\begin{tabular}{llll}
\hline Variables & \multirow{2}{*}{$\begin{array}{l}\text { Estimation Method } \\
\text { lncalint }\end{array}$} & \multicolumn{2}{l}{ SUR with Bootstrapped SE } \\
\cline { 3 - 4 } & esmeat & $0.197^{* * *}$ & Calorie share \\
\hline Mediation Variables & & $(0.024)$ & \\
& calsmeat & & $0.282^{* * *}$ \\
& & & $(0.051)$ \\
Independent Variable & lnincome & $0.016^{* * *}$ & $0.017^{* * *}$ \\
& & $(0.004)$ & $(0.004)$ \\
Control Variables & facility & $-0.000^{* * *}$ & $-0.000^{* * *}$ \\
& & $(0.000)$ & $(0.000)$ \\
& hhage & $0.011^{* * *}$ & $0.011^{* * *}$ \\
& & $(0.002)$ & $(0.002)$ \\
& hhagesqr & $-0.000^{* * *}$ & $-0.000^{* * *}$
\end{tabular}




\begin{tabular}{|c|c|c|c|}
\hline & \multirow[t]{2}{*}{ hhedu } & $-0.003 * *$ & $-0.002 *$ \\
\hline & & $(0.001)$ & $(0.001)$ \\
\hline & \multirow[t]{2}{*}{ hhmale } & $0.042 * * *$ & $0.042 * * *$ \\
\hline & & $(0.011)$ & $(0.012)$ \\
\hline & \multirow[t]{2}{*}{ share_child } & $-0.404 * * *$ & $-0.404 * * *$ \\
\hline & & $(0.045)$ & $(0.045)$ \\
\hline & \multirow[t]{2}{*}{ share_old } & -0.039 & $-0.040^{*}$ \\
\hline & & $(0.025)$ & $(0.024)$ \\
\hline & \multirow[t]{2}{*}{ share_madult } & 0.047 & 0.048 \\
\hline & & $(0.029)$ & $(0.030)$ \\
\hline & \multirow[t]{2}{*}{ constant } & $7.032 * * *$ & $7.038 * * *$ \\
\hline & & $(0.070)$ & $(0.070)$ \\
\hline & County Fixed Effect & Yes & Yes \\
\hline & Mediation Variables & Expenditure share & Calorie share \\
\hline \multirow[t]{7}{*}{ Independent Variable } & \multirow[t]{2}{*}{ lnincome } & $0.021 * * *$ & $0.011 * * *$ \\
\hline & & $(0.002)$ & $(0.001)$ \\
\hline & \multirow[t]{2}{*}{ constant } & $0.078 * * *$ & $0.033 * *$ \\
\hline & & $(0.028)$ & $(0.016)$ \\
\hline & Control Variables & Yes & Yes \\
\hline & County fixed effect & Yes & Yes \\
\hline & $\mathrm{N}$ & 11678 & 11678 \\
\hline
\end{tabular}

Note: Standard Errors are reported in brackets. and ***,**, * denote significant at $1 \%, 5 \%$ and $10 \%$ respectively. All the other results estimated are based on the same group of control variables, so we do not list them one by one in other tables.

In Table 3.4, the first column reports the results using the expenditure share of meat consumption $\left(\right.$ esmeat $\left._{i}\right)$ as an indicator for dietary structural change; while the second column reports the results with using the calories share of meat $\left(\right.$ calsmeat $\left._{i}\right)$. For both measures of food structure, all the coefficients of interests, including the parameters of lincome $_{i}$, esmeat $_{i}$ and calsmeat $_{i}$, are positive and statistically significant. It is consistent with our expectations.

Using equation (7), with the estimated coefficients in the first and the second column in hand, the estimated unconditional income elasticity of calorie consumption is $0.017+0.282 * 0.011=0.020$ with meat expenditure share as the measure for the dietary 
structure which is $0.016+0.197 * 0.021=0.020$. The unconditional income elasticities are very close even we utilize different food structure measures.

Consistent with the literature, almost all control variables are statistically significant, such as household head gender, household head age, and household head education, local food facilities, etc. It evidences that the model fits the data very well.

- Staple food ratio as the mediator

An alternative measure for changes in food structure induced by nutrition transition in the developing and emerging economy is the share of expenditure and share of calories on staple food. As we listed in Table 3.5, the results are highly significant and not surprising: when the household becomes rich, the family members tend to consume more food and have higher calorie intake. Meanwhile, they tend to decrease the expenditure and calorie ratio devoted to staple food.

Table 3.5: Empirical results with staple food ratio as a mediator

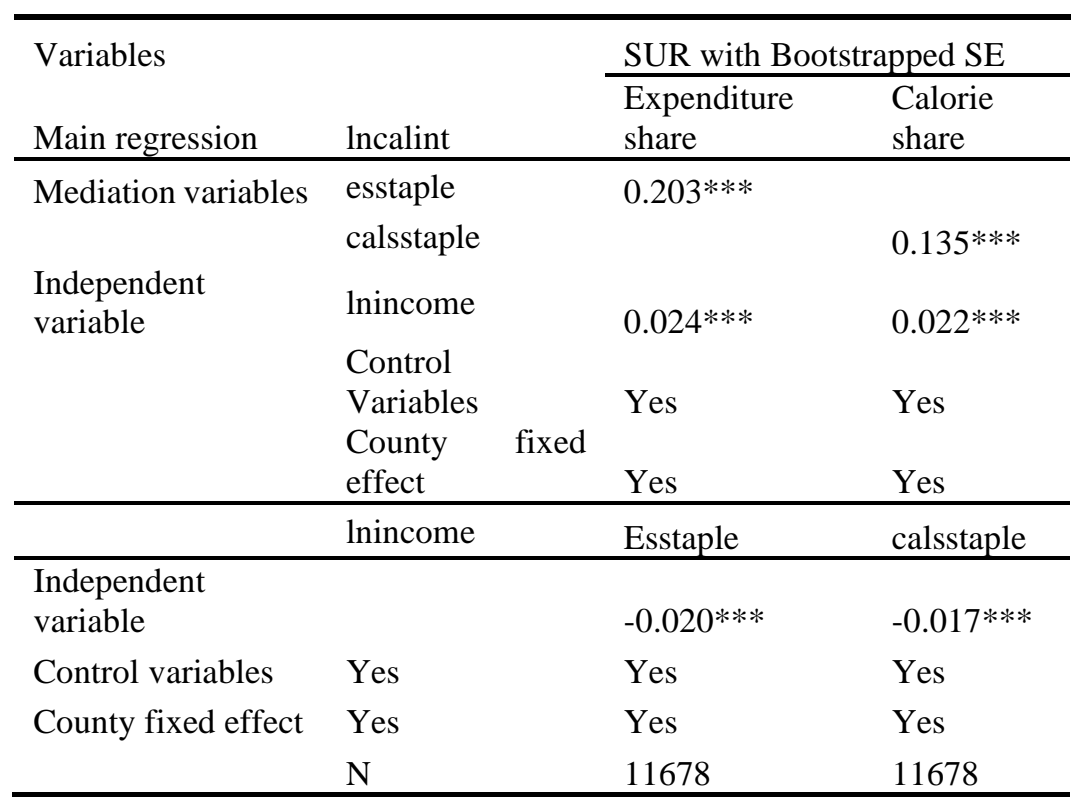


- Robust check

In order to implement a robust check, we conduct estimations separately for each year. The results are reported in Table 3.6. While the conditional income elasticity stays between 0.020 and 0.026 , slightly larger than the counterpart elasticity in the primary results, the importance of structural change effect varies as well. The signs of coefficients in the yearspecific regression are consistent with the primary setting.

Some researchers may concern the rural-urban gap on the dietary change dynamics in China (e.g. Shimokawa 2009; Tian and Yu 2015). Our results in Table 3.7 show that rural consumers have a higher marginal effect of food structure on calorie consumption, but the conditional income elasticities are very close. It implies that different stages of nutrition transition between rural and urban China rests on food structure. Particularly, rural households have space to demand more for dietary quality and food diversity in the future. 
Table 3.6: SUR results for each year

\begin{tabular}{|c|c|c|c|c|c|c|}
\hline \multirow{2}{*}{$\begin{array}{l}\text { Incalint } \\
\text { Year }\end{array}$} & \multicolumn{3}{|c|}{ Expenditure share } & \multicolumn{3}{|c|}{ Calorie share } \\
\hline & 2004 & 2006 & 2009 & 2004 & 2006 & 2009 \\
\hline esmeat & $\begin{array}{l}0.149 * * * \\
(0.038)\end{array}$ & $\begin{array}{l}0.261 * * * \\
(0.044)\end{array}$ & $\begin{array}{l}0.183 * * * \\
(0.047)\end{array}$ & & & \\
\hline calsmeat & & & & $\begin{array}{l}0.175^{*} \\
(0.089)\end{array}$ & $\begin{array}{l}0.460 * * * \\
(0.088)\end{array}$ & $\begin{array}{l}0.296^{* * * *} \\
(0.093)\end{array}$ \\
\hline Inincome & $\begin{array}{l}0.022 * * * \\
(0.007)\end{array}$ & $\begin{array}{l}0.020 * * * \\
(0.006)\end{array}$ & $\begin{array}{l}0.026 * * * \\
(0.007)\end{array}$ & $\begin{array}{l}0.024 * * * \\
(0.007)\end{array}$ & $\begin{array}{l}0.021 * * * \\
(0.006)\end{array}$ & $\begin{array}{l}0.026 * * * \\
(0.007)\end{array}$ \\
\hline facility & $\begin{array}{l}-0.000 \\
(0.000)\end{array}$ & $\begin{array}{l}-0.000 * \\
(0.000)\end{array}$ & $\begin{array}{l}0.001 * * * \\
(0.000)\end{array}$ & $\begin{array}{l}-0.000 \\
(0.000)\end{array}$ & $\begin{array}{l}-0.000^{*} \\
(0.000)\end{array}$ & $\begin{array}{l}0.001 * * * \\
(0.000)\end{array}$ \\
\hline hhage & $\begin{array}{l}0.009 * * \\
(0.004)\end{array}$ & $\begin{array}{l}0.012 * * * \\
(0.004) \\
-\end{array}$ & $\begin{array}{l}0.013 * * \\
(0.005) \\
-\end{array}$ & $\begin{array}{l}0.009 * * \\
(0.004)\end{array}$ & $\begin{array}{l}0.011 * * * \\
(0.004) \\
-\end{array}$ & $\begin{array}{l}0.013 * * \\
(0.005) \\
-\end{array}$ \\
\hline hhagesqr & $\begin{array}{l}-0.000^{* *} \\
(0.000)\end{array}$ & $\begin{array}{l}0.000 * * * \\
(0.000)\end{array}$ & $\begin{array}{l}0.000^{* * *} \\
(0.000)\end{array}$ & $\begin{array}{l}-0.000 * * \\
(0.000)\end{array}$ & $\begin{array}{l}0.000 * * * \\
(0.000)\end{array}$ & $\begin{array}{l}0.000 * * * \\
(0.000)\end{array}$ \\
\hline hhedu & $\begin{array}{l}-0.001 \\
(0.002)\end{array}$ & $\begin{array}{l}0.007 * * * \\
(0.002)\end{array}$ & $\begin{array}{l}0.000 \\
(0.002)\end{array}$ & $\begin{array}{l}-0.001 \\
(0.002)\end{array}$ & $\begin{array}{l}0.007 * * * \\
(0.002)\end{array}$ & $\begin{array}{l}0.001 \\
(0.002)\end{array}$ \\
\hline hhmale & $\begin{array}{l}0.030 \\
(0.020) \\
-\end{array}$ & $\begin{array}{l}0.081 * * * \\
(0.018) \\
-\end{array}$ & $\begin{array}{l}0.019 \\
(0.021) \\
-\end{array}$ & $\begin{array}{l}0.030 \\
(0.020) \\
-\end{array}$ & $\begin{array}{l}0.080 * * * \\
(0.016) \\
-\end{array}$ & $\begin{array}{l}0.019 \\
(0.021) \\
-\end{array}$ \\
\hline share_child & $\begin{array}{l}0.428 * * * \\
(0.078)\end{array}$ & $\begin{array}{l}0.322 * * * \\
(0.074)\end{array}$ & $\begin{array}{l}0.414 * * * \\
(0.082)\end{array}$ & $\begin{array}{l}0.429 * * * \\
(0.078)\end{array}$ & $\begin{array}{l}0.332 * * * \\
(0.074)\end{array}$ & $\begin{array}{l}0.407 * * * \\
(0.082)\end{array}$ \\
\hline share_old & $\begin{array}{l}-0.105^{* *} \\
(0.041)\end{array}$ & $\begin{array}{l}0.105^{* * *} \\
(0.038)\end{array}$ & $\begin{array}{l}0.043 \\
(0.042)\end{array}$ & $\begin{array}{l}0.108 * * * \\
(0.041)\end{array}$ & $\begin{array}{l}0.103 * * * \\
(0.039)\end{array}$ & $\begin{array}{l}0.042 \\
(0.044)\end{array}$ \\
\hline share_madult & $\begin{array}{l}0.037 \\
(0.052)\end{array}$ & $\begin{array}{l}-0.010 \\
(0.038)\end{array}$ & $\begin{array}{l}0.101^{*} \\
(0.061)\end{array}$ & $\begin{array}{l}0.035 \\
(0.050)\end{array}$ & $\begin{array}{l}-0.004 \\
(0.038)\end{array}$ & $\begin{array}{l}0.099 \\
(0.061)\end{array}$ \\
\hline constant & $\begin{array}{l}7.134 * * * \\
(0.123)\end{array}$ & $\begin{array}{l}6.943 * * * \\
(0.117)\end{array}$ & $\begin{array}{l}6.800^{* * *} \\
(0.147)\end{array}$ & $\begin{array}{l}7.139 * * * \\
(0.122)\end{array}$ & $\begin{array}{l}6.941 * * * \\
(0.123)\end{array}$ & $\begin{array}{l}6.801 * * * \\
(0.148)\end{array}$ \\
\hline County Fixed Effect & Yes & Yes & Yes & Yes & Yes & Yes \\
\hline Year & 2004 & 2006 & 2009 & 2004 & 2006 & 2009 \\
\hline Inincome & $\begin{array}{l}0.028 * * * \\
(0.003)\end{array}$ & $\begin{array}{l}0.019 * * * \\
(0.003)\end{array}$ & $\begin{array}{l}0.013 \text { *** } \\
(0.003)\end{array}$ & $\begin{array}{l}0.013 * * * \\
(0.002)\end{array}$ & $\begin{array}{l}0.008 * * * \\
(0.002)\end{array}$ & $\begin{array}{l}0.007 * * * \\
(0.002)\end{array}$ \\
\hline _cons & $\begin{array}{l}0.028 \\
(0.052)\end{array}$ & $\begin{array}{l}0.070 \\
(0.043)\end{array}$ & $\begin{array}{l}0.143^{* * *} \\
(0.049)\end{array}$ & $\begin{array}{l}-0.006 \\
(0.026)\end{array}$ & $\begin{array}{l}0.043^{*} \\
(0.026)\end{array}$ & $\begin{array}{l}0.087 * * * \\
(0.028)\end{array}$ \\
\hline Control Variables & Yes & Yes & Yes & Yes & Yes & Yes \\
\hline County fixed effect & Yes & Yes & Yes & Yes & Yes & Yes \\
\hline 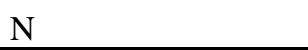 & 3754 & 3896 & 4028 & 3754 & 3896 & 4028 \\
\hline
\end{tabular}




\section{Table 3.7: Rural-urban gap}

\begin{tabular}{|c|c|c|c|c|}
\hline \multirow{2}{*}{$\begin{array}{l}\text { Incalint } \\
\text { Regions }\end{array}$} & \multicolumn{2}{|c|}{ Expenditure share } & \multicolumn{2}{|c|}{ Calorie share } \\
\hline & Rural & Urban & Rural & Urban \\
\hline esmeat & $\begin{array}{l}0.223 * * * \\
(0.030)\end{array}$ & $\begin{array}{l}0.145 * * * \\
(0.040)\end{array}$ & & \\
\hline calsmeat & & & $\begin{array}{l}0.362 * * * \\
(0.067)\end{array}$ & $\begin{array}{l}0.162 * * \\
(0.077)\end{array}$ \\
\hline Inincome & $\begin{array}{l}0.014 * * * \\
(0.005) \\
-\end{array}$ & $\begin{array}{l}0.021 * * * \\
(0.006)\end{array}$ & $\begin{array}{l}0.015 \text { *** } \\
(0.005) \\
-\end{array}$ & $\begin{array}{l}0.022 * * * \\
(0.006)\end{array}$ \\
\hline facility & $\begin{array}{l}0.000 * * * \\
(0.000)\end{array}$ & $\begin{array}{l}-0.000 \\
(0.000)\end{array}$ & $\begin{array}{l}0.000 * * * \\
(0.000)\end{array}$ & $\begin{array}{l}-0.000 \\
(0.000)\end{array}$ \\
\hline hhage & $\begin{array}{l}0.016 * * * \\
(0.003) \\
-\end{array}$ & $\begin{array}{l}0.004 \\
(0.003)\end{array}$ & $\begin{array}{l}0.016 \text { *** } \\
(0.003) \\
-\end{array}$ & $\begin{array}{l}0.003 \\
(0.003)\end{array}$ \\
\hline hhagesqr & $\begin{array}{l}0.000 * * * \\
(0.000)\end{array}$ & $\begin{array}{l}-0.000 * * \\
(0.000)\end{array}$ & $\begin{array}{l}0.000 * * * \\
(0.000)\end{array}$ & $\begin{array}{l}-0.000 * * \\
(0.000)\end{array}$ \\
\hline hhedu & $\begin{array}{l}-0.002 \\
(0.002)\end{array}$ & $\begin{array}{l}-0.004 * * \\
(0.002)\end{array}$ & $\begin{array}{l}-0.001 \\
(0.002)\end{array}$ & $\begin{array}{l}-0.004 * * \\
(0.002)\end{array}$ \\
\hline hhmale & $\begin{array}{l}0.046 * * * \\
(0.016) \\
-\end{array}$ & $\begin{array}{l}0.036 * * \\
(0.017)\end{array}$ & $\begin{array}{l}0.046 \text { *** } \\
(0.017) \\
-\end{array}$ & $\begin{array}{l}0.035 * * \\
(0.016)\end{array}$ \\
\hline share_child & $\begin{array}{l}0.469 * * * \\
(0.052)\end{array}$ & $\begin{array}{l}-0.206 * * \\
(0.080)\end{array}$ & $\begin{array}{l}0.469 * * * \\
(0.049)\end{array}$ & $\begin{array}{l}-0.201 * * \\
(0.087)\end{array}$ \\
\hline share_old & $\begin{array}{l}-0.039 \\
(0.033)\end{array}$ & $\begin{array}{l}-0.029 \\
(0.033)\end{array}$ & $\begin{array}{l}-0.040 \\
(0.033)\end{array}$ & $\begin{array}{l}-0.030 \\
(0.033)\end{array}$ \\
\hline share_madult & $\begin{array}{l}0.021 \\
(0.039)\end{array}$ & $\begin{array}{l}0.091 * * \\
(0.045)\end{array}$ & $\begin{array}{l}0.023 \\
(0.040)\end{array}$ & $\begin{array}{l}0.090 * * \\
(0.044)\end{array}$ \\
\hline constant & $\begin{array}{l}6.914 * * * \\
(0.089)\end{array}$ & $\begin{array}{l}7.455 * * * \\
(0.096)\end{array}$ & $\begin{array}{l}6.915 * * * \\
(0.087)\end{array}$ & $\begin{array}{l}7.476 * * * \\
(0.099)\end{array}$ \\
\hline County Fixed Effect & Yes & Yes & Yes & Yes \\
\hline Regions & Rural & Urban & Rural & Urban \\
\hline lnincome & $\begin{array}{l}0.023 * * * \\
(0.002)\end{array}$ & $\begin{array}{l}0.018 * * * \\
(0.003)\end{array}$ & $\begin{array}{l}0.012 * * * \\
(0.001)\end{array}$ & $\begin{array}{l}0.010 * * * \\
(0.002)\end{array}$ \\
\hline _cons & $\begin{array}{l}0.057 * \\
(0.033)\end{array}$ & $\begin{array}{l}0.231 * * * \\
(0.051)\end{array}$ & $\begin{array}{l}0.033^{*} \\
(0.017)\end{array}$ & $\begin{array}{l}0.074 * * * \\
(0.027)\end{array}$ \\
\hline Control Variables & Yes & Yes & Yes & Yes \\
\hline County fixed effect & Yes & Yes & Yes & Yes \\
\hline $\mathrm{N}$ & 7876 & 3802 & 7876 & 3802 \\
\hline
\end{tabular}

Note: Standard Errors are reported in brackets. and ***,**, * denote significant at $1 \%, 5 \%$ and $10 \%$ respectively. 
Table 3.8: The decomposition of nutrition improvement

\begin{tabular}{|c|c|c|c|c|c|c|}
\hline \multirow[b]{2}{*}{ Sample } & \multicolumn{3}{|c|}{ Expenditure share } & \multicolumn{3}{|c|}{ Calorie share } \\
\hline & $\begin{array}{l}\text { Whole } \\
\text { sample }\end{array}$ & $\begin{array}{l}\text { Rural } \\
\text { Region }\end{array}$ & $\begin{array}{l}\text { Urban } \\
\text { Region }\end{array}$ & $\begin{array}{l}\text { Whole } \\
\text { sample }\end{array}$ & $\begin{array}{l}\text { Rural } \\
\text { Region }\end{array}$ & $\begin{array}{l}\text { Urban } \\
\text { Region }\end{array}$ \\
\hline $\begin{array}{l}\text { Indirect } \\
\text { effect }\end{array}$ & $\begin{array}{l}0.004 * * * \\
(0.001)\end{array}$ & $\begin{array}{l}0.005^{* * *} \\
(0.001)\end{array}$ & $\begin{array}{l}0.003 * * * \\
(0.001)\end{array}$ & $\begin{array}{l}0.003 * * * \\
(0.001)\end{array}$ & $\begin{array}{l}0.004 * * * \\
(0.001)\end{array}$ & $\begin{array}{l}0.002 * \\
(0.001)\end{array}$ \\
\hline Direct effect & $\begin{array}{l}0.016^{* * *} \\
(0.004)\end{array}$ & $\begin{array}{l}0.014 * * * \\
(0.005)\end{array}$ & $\begin{array}{l}0.021 * * * \\
(0.007)\end{array}$ & $\begin{array}{l}0.017 * * * \\
(0.004)\end{array}$ & $\begin{array}{l}0.015^{* * *} \\
(0.005)\end{array}$ & $\begin{array}{l}0.022 * * * \\
(0.006)\end{array}$ \\
\hline Total effect & $\begin{array}{l}0.020 * * * \\
(0.004)\end{array}$ & $\begin{array}{l}0.019 * * * \\
(0.005)\end{array}$ & $\begin{array}{l}0.023 * * * \\
(0.006)\end{array}$ & $\begin{array}{l}0.020 * * * \\
(0.004)\end{array}$ & $\begin{array}{l}0.019 * * * \\
(0.005)\end{array}$ & $\begin{array}{l}0.023 * * * \\
(0.006)\end{array}$ \\
\hline Indirect ratio & $\begin{array}{l}0.210 * * * \\
(0.058)\end{array}$ & $\begin{array}{l}0.266^{* * * *} \\
(0.099)\end{array}$ & $\begin{array}{l}0.112 \\
(0.299)\end{array}$ & $\begin{array}{l}0.155^{* * * *} \\
(0.047)\end{array}$ & $\begin{array}{l}0.216 * * \\
(0.091)\end{array}$ & $\begin{array}{l}0.069 \\
(0.058)\end{array}$ \\
\hline Direct ratio & $\begin{array}{l}0.790 * * * \\
(0.058)\end{array}$ & $\begin{array}{l}0.734 * * * \\
(0.099)\end{array}$ & $\begin{array}{l}0.888 * * * \\
(0.299)\end{array}$ & $\begin{array}{l}0.845^{* * *} \\
(0.047)\end{array}$ & $\begin{array}{l}0.784 * * * \\
(0.091)\end{array}$ & $\begin{array}{l}0.931 * * * \\
(0.058)\end{array}$ \\
\hline $\mathrm{N}$ & 11678 & 7876 & 3802 & 11678 & 7876 & 3802 \\
\hline
\end{tabular}

Note: Standard Errors are reported in brackets. and $* * *, * * *$ denote significant at $1 \%, 5 \%$ and $10 \%$ respectively.

- Decomposition

Table 3.8 reports the decomposition of unconditional income effect into a direct (conditional) income effect and structural change effect. We already calculated that the unconditional (total) income elasticity of calorie consumption is 0.02 . It means that a $1 \%$ improvement in income will increase per capita calorie consumption by $0.02 \%$. However, given such a small income elasticity, the contribution rates of dietary structural change (indirect effect of income) are estimated at $15.5 \%$ (calculated based on the calorie share) to $21 \%$ (calculated based on the expenditure share) in the whole sample, the rest $74.5 \%$ to $79 \%$ is still attributed to the food quantity expansion driven by direct income growth.

Meanwhile, the rural-urban gap should not be ignored. Early study shows that high income correlates with obesity and high in fat food patterns especially in urban China. (Popkin et al., 1993). In our case, more than $20 \%$ of the total income effect can be attributed to a dietary structural change in rural China, while only $7 \%$ to $11 \%$ can be attributed to a dietary structural change in urban China. One possible explanation is that consumers in 
rural China still have more room to improve their dietary quality and food diversity, while the food demand for urban consumers is much closer to a saturation point.

\subsection{Conclusion}

Nutrition transition has been widely studied in the literature. Food structure is known to play important roles in nutrition improvements, but its effect has not quantitatively examined. In order to fill in the research gap in the literature, this study proposes a simple but innovative method to empirically decompose the total income effect on nutrition improvement into direct (conditional) income effect and dietary structural change effect. With the use of the China Health and Nutrition Survey (CHNS) data, we find that unconditional income elasticity of calorie consumption is 0.02 : a $1 \%$ increment in income will boost per capita calorie consumption by $0.02 \%$ within a family. It is evident that Chinese consumers have been released from the hunger stage so that the total marginal effect of income on calorie consumption is very small.

By decomposition, we find that about $16 \%$ to $21 \%$ of the calorie consumption uprising is driven by the dietary structural change, while the remaining part is attributed to the direct income effect. This implies that dietary structural change plays an important role in nutrition improvement.

The importance of dietary structure is found to be different between rural and urban areas. Specifically, the dietary structural change effect is more prominent in the rural region, which implies a rural-urban gap in the diet.

These findings imply that reaching broader awareness of the regional disparities and rural-urban food structure gap is essential for nutrition transition and dietary structural 
change in emerging countries. According to our estimation, $22 \%$ to $27 \%$ of the total income effect can be attributed to a dietary structural change in rural China, while only $7 \%$ to $11 \%$ in urban China. The increasing meat consumption is expected in rural China.

One policy implication is that global demand for meat is expected to be driven by the high demand for animal source products as households' increasing demand in rural China. It is wise to make predictions and bridge the gap in advance to avoid unnecessary market frictions and deal with the food security issue. Given China's enormous population, this is not only a local food security issue, but a challenge for global meat producers and the environment as the high carbon emission of meat product compared with other categories of food. 


\section{Chapter 4 Food Facility, Dietary Patterns, and Obesity}

\section{in China}

The location of food facilities has an impact on nutritional outcomes by influencing food availability and forming the food environment. Utilizing the propensity score matching method and the instrumental variable method, we investigate the impact of the different types and the location of the food facility on food patterns and nutritional outcomes of residence in China. Based on the household survey data in China, we find that the existence of the food facility leads to dynamics of body weight index and food pattern choices, but the effect varies from different types of food facilities. Moreover, food facility plays a role in explaining the obesity of community residence. Compared with the Westernstyle fast food facility and outdoor food outlet, the Chinese restaurant has a larger effect on inducing unfavored nutritional outcomes and contributing to the prevalence of obesity.

\subsection{Introduction}

Global status for the widespread obesity (Ng et al., 2014) causing a high cost of economic and social capital, as a fact that overweight and obesity are one of the main contributors to NCDs (non-commutable diseases). The global prevalence rate of adult overweight and obesity has reached 39\% and 13\% in 2016 respectively, as estimated in the WHO report. According to a pioneering study, the social cost of overweight and obesity could rise to around 500 million US dollars annually if the trend of obesity prevalence continued. (Wang et al., 2011). As for China, the indirect economic cost of obesity could be up to $8.73 \%$ of GNP in 2025 (Popkin et al., 2006), and the medical cost is up to 24.35 billion CNY (Chinese Yuan) annually from 2000 to 2009 (Qin and Pan, 2015).To curb the 
popularity of obesity, it is more efficient to regulate the food industry rather than change the preference of consumers (Alston, 2016). Except for the disparity of lifestyle, activity intensity, and genetics, the choice of dietary patterns and knowledge on diet play an important role in determining the outcome of obesity. Furthermore, the location of the food facility has an impact on the dietary intake and hence the level of obesity for residents, from the perspective of Behavioral Economics and Urban Economics.

Along with rapid economic growth, China is facing the popularity of obesity. Transformation of the classical high in fiber and carbohydrate staple food intense dietary pattern to a high in refined sugar and animal source product dietary pattern (Tian and $\mathrm{Yu}$, 2013; Batis et al., 2014; Tian and Yu, 2015; Chang et al., 2018) has an impact on the nutritional outcome of Chinese people. As a result, the trend shows that the increasing prevalence of obesity in low-income families implies the health and nutritional cost of obesity-related non-communicate diseases towards poor families (Dearth-Wesley et al., 2008). Recent literature also supports the trend for the prevalence of obesity based on 2004 to 2010 data (Jiang et al. 2015).

Given the increasing prevalence rate of obesity, accompanying the acceleration of urbanization in the last two decades in China, we aim to gauge the drift of dietary patterns dynamics and its outcome on the health condition that is driven by the location of the food facility.

According to a classical research (Lytle and Myers, 2017), the food environment is composed with physical, social, and person-centered environment, and it has huge impact on food availability, food accessibility, and food affordability. The location of the food facility affects dietary choices through food accessibility and thus food environment 
(Gordon-Larsen, 2014). Literature shows that both the types and the location of food facilities influence the time opportunity cost (shoe-leather cost) and food environment for FAFH (food away from home) behavior (Bai et al., 2012), and the FAFH has an impact on Chinese adult obesity (Ma et al., 2006), we expect that the location of food facility correlates with the prevalence of obesity and food patterns of residents. Several kinds of literature show the density of restaurants nearby has a significant impact on the BMI of adults in rural China(Du et al., 2014), and the effect varies for the different types of restaurants (Tian et al. 2016). The type of meals may imply different FAFH consumption patterns as well. An early study shows FAFH behavior varies for different types of meals: nearly $40 \%$ of households have FAFH for breakfast and almost $75 \%$ of households have lunch or dinner away from home in two-survey-weeks in 1992 and 1993 in the U.S.(Jensen and Yen, 1996).

Several studies (Asfaw,2008; Schipmann and Qaim 2011; Chege et al., 2015; Kimenju et al. 2015, Khonje and Qaim 2019) show that fast food venues and supermarkets (with food stalls nearby) in developing countries could affect the quality of food (Yu and Abler, 2009), dietary patterns and the obesity status of residents. Location of food outlets in supermarket influence the food decision making process of consumers by forming food accessibility and food availability (Hawkes, 2008). One study in Southeast Asia shows that the nutrition of children from the household with high-income levels suffers from over-nutrition induced by increasing the use of the supermarket.

Obesity for adults, children, and adolescence may vary in the driving forces. The number of children in the household has an impact on the obesity risk of children and adolescence. One study in Canada (Gillis, 2002) shows that meat servings, SSBs (sugar- 
sweetened beverages) consumption, and FAFH are all correlated with high body fat for adolescents. Adult obesity has nearly tripled from 1991 to 2009, and education has a different effect on the obesity of males and females (Gordon-Larsen et al., 2014). One study (Zhang et al., 2016) shows that the child in the one-child family tended to consume a diet with a high density of sugar, fat, and protein, and face a higher chance to be overweight and obese. Thus, the one-child policy enhanced the popularity of adolescent obesity in China.

Limit our topic to the nutritional outcome of the food facility. There is no consensus on how different types of food facilities affect the nutritional status of residents, especially in the emerging economy. One recent study already shows that the consumption of fast food is positively correlated with food availability (Jekanowski et al., 2014). As described by recent literature (Gordon-Larsen, 2014), the correlation of food environment of neighborhood and food availability nearby with food patterns and obesity outcomes are mixed. Meanwhile, early literature (McCracken and Brandt, 1987) claims that the impact of the conventional restaurant, fast food facility, and other food establishments on FAFH and food expenditure varies. One study in Portland in the U.S. proves that the density of neighborhood fast-food outlets correlates with unhealthy food patterns and low physical activity levels and even high obesity risk for senior citizens ( $\mathrm{Li}$ et al., 2009).

To fill in the research gap between food environment represented by the location of food facility and the nutritional status of residents, this study aims to investigate: (1) whether the food facility contributes to the prevalence of obesity in an emerging economy like China; (2) How the food facility affects the dietary patterns of nearby 
residents. To avoid the self-selection bias, we use a propensity score matching method to make sure that the location of the food facility is rather exogenous to the residents.

\subsection{Methodology}

Ideally, we would use a randomized experiment to identify the treatment effect of the food facility on the dietary patterns and the long-term health outcome of residents in the community. However, it is economically too expensive to keep track of the non-short record on the dietary patterns and even health situations. As the alternative, we use secondary data that already covered the food choice in questionnaires and the location information of the food facility gave us a chance to conduct an observational investigation. The propensity score matching (PSM) method is preferred in our study given we have access to secondary data CHNS using a pooled regression with the demographics, dietary knowledge, physical activity intensity information, and year dummies.

In implicating the PSM, since the PSM is a tool to assess the average treatment effect, two extra assumptions are necessary: unconfoundedness and overlap. The former makes sure that after controlling for the covariates, the choice of treatment variable should be independent of the potential outcome variable. The latter guarantees the region of common support to obtain the identification. The advantages of PSM are as follows: first, compared with regression, PSM eliminates the endogeneity problem by reducing the selection bias that is based on the observed control variables and controlling for the measurement errors of self-reported variables. Second, PSM constructs the onedimension propensity score to avoid the "the curse of dimensionality" match the given 
that the number of confounders is rather large. Meanwhile, PSM has several

disadvantages: First, in terms of efficiency, PSM requires a bigger sample size. Second, a rather big common support is preferred, or else the representativeness of the sample is violated. Third, PSM reducing the selection bias based on the observed control variables but not dealing with other sources of endogeneity.

In practice, we apply a PSM method to investigate the effect of different types of food facilities in three steps. In the first step, we construct a propensity score function $\mathrm{P}(\mathrm{X})$ from logistic regression, which is the estimated probability of the home of a participant is close to specific types of the food facility. In our case, they are Chinese restaurants, Western-style fast-food restaurants, and outdoor food stalls. The functional form of the propensity score could be shown as follows:

$$
P\left(X_{i}\right)=F\left(X_{i}^{\prime} \beta\right)=\frac{\exp \left(X_{i}^{\prime} \beta\right)}{1+\exp \left(X_{i}^{\prime} \beta\right)}
$$

Where $P\left(X_{i}\right)$ is the propensity score, and $X_{i}$ is the covariates. Specifically, the covariates for propensity function $X_{i}$ includes the educational attachment, age, gender, natural log of income, marital status, smoking indicator, drinking indicator, the intensity level of physical activity, employed or not, supermarket nearby or not, and the year dummies.

In the second step, we choose three matching algorithms, specifically, nearest neighbor, kernel matching, and radius matching, to match the treated units with untreated participants based on the propensity score function calculated in the first step. 
In the third step, we calculate the ATT (average treatment effect on the treated) of food facility availability on nutritional outcome variable Y using matched observations of participants with food facility nearby participants without food facility nearby.

$$
\tau_{a t t, i}=E\left(Y_{i}(1)-Y_{i}(0) \mid P\left(X_{i}\right), T_{i}=1\right)
$$

For comparison, the analysis framework for multiple treatments has been adopted. Fllowing McCaffrey et. al (2013), we estimate the propensity scores in each treatment group based on multinomial logistic regression, check for the common support, calculate the inverse propensity score weights, and obtain the treatment effect by calculating the difference in the weight means.

After that, we use the Instrumental Variable (IV) method to estimate the marginal effect where the instrument for food facility location is the distance to the nearest specific types of food facility. As shown below, we utilize a typical linear model and a two-stage procedure to depict the causality of food facilities located on the nutritional outcome of residents.

$$
\begin{aligned}
& C_{i}=\rho Z_{i}+X_{i}{ }^{\prime} \gamma+u_{i} \\
& Y_{i}=\theta \widehat{C}_{\imath}+X_{i}{ }^{\prime} \delta+v_{i}
\end{aligned}
$$

Equation (3) is the description of stage 1 . The instrumental variable $Z_{i}$ is a variable that is correlated with the treatment variable (whether there is a specific type of food facility nearby or not), but not correlated with the error term $v_{i}$ of stage 2 as described in equation (4). Based on the estimation of stage one with the introduction of the instrument $Z_{i}$, we then implement a regression using the predicted treatment participation (here it is the probability of the existence for the specific type of food facility nearby) $\widehat{C}_{l}$ and the covariates $X_{i}$ in the second stage 
which represented in equation (4). Notice that the $\rho$ and $\theta$ are the parameters for instrument and predicted treatment, while $\gamma$ and $\delta$ are the vectors of parameters for covariates.

\subsection{Data}

We utilize the secondary data from CHNS, specifically for subjects who take the survey in 2004, 2006, 2009, and 2011. We choose those waves because both the information of the dietary knowledge and the food facility-related questions at the community level are accessible at this period.

The raw data are drawn from several surveys of CHNS. Specifically, the community level data, household-level data, and the individual level data for the food at home and food away from home (FAFH) for the three conservative days, and the 24-hour diet recall investigation is being combined in our analysis.

Descriptive statistics for the sample are shown in Table 4.1. 
Table 4.1: Descriptive and the variable definitions

\begin{tabular}{|c|c|c|c|}
\hline Variable & Obs & Mean & Definition \\
\hline \multicolumn{4}{|l|}{ Outcome Variable } \\
\hline bmi & 9553 & 23.33 & body mass index \\
\hline obese & 9553 & 0.09 & bmi $>=28$ \\
\hline overweight & 9553 & 0.30 & $28>$ bmi $>=24$ \\
\hline ssb & 2532 & 2.08 & weekly sugar-sweetened beverage consumption \\
\hline fafh & 9553 & 7.98 & counted times of food away from home in 3 days \\
\hline \multicolumn{4}{|l|}{ Treatment Variable } \\
\hline chinese_res & 4908 & 0.95 & Chinese restaurant in $5 \mathrm{~km}$ radius \\
\hline western_fast_food & 9483 & 0.23 & Western-style fast food restaurant in the village/community \\
\hline food_stall & 4852 & 0.82 & food stall within $5 \mathrm{~km}$ radius \\
\hline \multicolumn{4}{|l|}{ Control Variable } \\
\hline primary & 9553 & 0.20 & primary school diploma \\
\hline middle & 9553 & 0.36 & junior high school diploma \\
\hline high & 9553 & 0.22 & senior high / secondary technical school / vacational school \\
\hline college & 9553 & 0.07 & college diploma and above \\
\hline age & 9553 & 50.14 & age \\
\hline female & 9553 & 0.05 & participant is female \\
\hline lnincome & 9553 & 9.35 & $\log$ (income), inflated to 2015 level \\
\hline married & 9553 & 0.95 & ever married \\
\hline smoking & 9553 & 0.87 & currently smoking \\
\hline drinking & 9553 & 0.67 & drink an alcoholic beverage in the last 365 days \\
\hline moderate_act & 9553 & 0.17 & job with moderate physical intensity \\
\hline heavy_act & 9553 & 0.42 & job with intensive physical activity \\
\hline employed & 9553 & 0.78 & participant is working \\
\hline supermkt & 9553 & 0.58 & supermarket approachable in 30 mins bus riding \\
\hline year & 9553 & 2007.85 & survey year, ranged from 2004 to 2011 \\
\hline dis_western & 2066 & 1.73 & distance to the nearest Western-style fast food restaurant \\
\hline dis_chinese & 4978 & 1.00 & distance to the nearest Chinese restaurant \\
\hline dis_stall & 4281 & 0.78 & distance to the nearest food stall \\
\hline
\end{tabular}

- Dependent Variables

To account for the general health outcome, we use several types of dependent variables: BMI (body mass index) for general health outcome and the intake of various 
types of food as the indicator for dietary patterns dynamics induced by the food facility

location. Apart from that, we put the frequency of FAFH into consideration since it is widely used in early literature. Other than that, we also utilize the frequency of SSBs consumption (sugar-sweetened beverages) as an indicator of food patterns.

BMI is calculated using the height (in $\mathrm{cm}$ ) of the participants divided by the squared term of weight (in $\mathrm{kg}$ ). Unlike the other socio-economic surveys, CHNS does not record the self-reported height and weight information but rather reports the results measured by well-trained medical staff with uniformly calibrated measuring equipment. To guarantee the consistency of our findings, we also use the overweight and obese dummies as the dependent variable. It is noticeable that we adapt the lower standard proposed by the China Obesity Working Group: for Chinese, 24, and 28 are the cutoff points for overweight and obesity.

A direct channel that the food facility impact on the dietary patterns of residents is that it pushes up the frequency of food away from home (FAFH). In our study, FAFH is the variable that we counted for 4 meals (breakfast, lunch, dinner, and snacks) that the subject enjoyed in the 3 consecutive recorded days.

The reason that we use SSBs (sugar-sweetened beverages) consumption as a food pattern indicator is that SSB is ultra-processed food and not available in a conventional meal. Although the channels are not concrete, SSB consumption is marked as the primary factor for obesity, especially for children and adolescents, by obesity researchers and public health activists(Pereira, 2006).

- Treatment Variable 
In accordance with the design of the CHNS questionnaire, we classify all the food facilities in the community into three groups: Chinese restaurants, Western-style fastfood restaurants, and food stalls. Specifically, the number of each type of food facility located in (for Western-style fast-food restaurant) or close to (5km radius) the community is the treatment variable.

\section{- Covariates}

As listed in Table 4.1, control variables include logarithms of income, the intensity of physical activity, lifestyle controls, and other demographics.

We use demographics, health status, and intensity of physical activity level (those are all self-reported) to build the propensity score. Specifically, age, gender, educational attainment, household income, marital status, number of kids in the family, household size, working status, self-reported drinking and smoking behavior, and intensity of labor activity level are covered.

\subsection{Results}

To start with propensity score matching analysis, we need to specify a functional form of the propensity score function. We choose the logistic form and put all the covariates as controls.

Our study concentrates on the nutritional outcome, so both the BMI and prevalence of overweight and obesity should be discussed.

Before we start our analysis of the results based on PSM, we need to check the validation of matching and hence examine the common support. We choose a logistic form to estimate the propensity score function. 
Table 4.2: Common supports for the choice of treatment variables

\begin{tabular}{|c|c|c|c|c|}
\hline & psmatch2: & $\begin{array}{l}\text { psmatch } \\
\text { Commor }\end{array}$ & 2: & \\
\hline \multirow[t]{2}{*}{$\begin{array}{l}\text { Choice } \\
\text { Treatments }\end{array}$} & $\begin{array}{l}\text { treatment } \\
\text { assignment }\end{array}$ & $\begin{array}{l}\text { Off } \\
\text { support }\end{array}$ & $\begin{array}{l}\text { On } \\
\text { support }\end{array}$ & Total \\
\hline & Untreated & 0 & 246 & 246 \\
\hline \multirow[t]{3}{*}{ chinese_res } & Treated & 208 & 4,454 & 4,662 \\
\hline & Total & 208 & 4,700 & 4,908 \\
\hline & Untreated & 7 & 7,323 & 7,330 \\
\hline \multirow[t]{3}{*}{ western_fast_food } & Treated & 6 & 2,147 & 2,153 \\
\hline & Total & 13 & 9,470 & 9,483 \\
\hline & Untreated & 0 & 864 & 864 \\
\hline \multirow[t]{2}{*}{ food_stall } & Treated & 18 & 3,970 & 3,988 \\
\hline & Total & 18 & 4,834 & 4,852 \\
\hline
\end{tabular}

As shown in Table 4.2, there are not many observations off support and hence the choice of propensity score function is applicable. To explicitly show the heterogeneity of distribution for the treated group (with food facility nearby) and untreated group (without food facility nearby), we draw Figure 4.1. 


\section{Figure 4.1: Balancing test for propensity scores on different treatment variables}
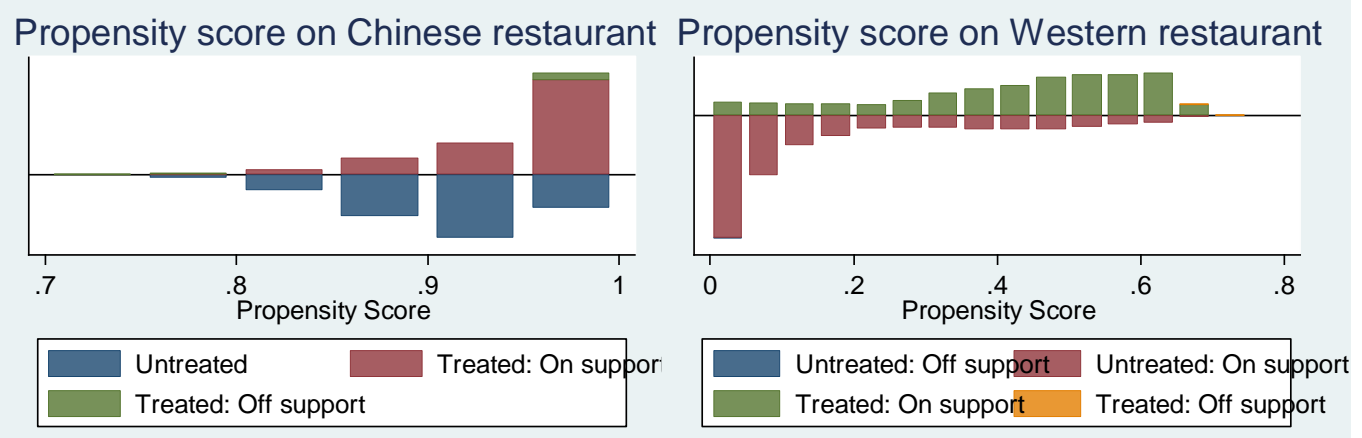

Propensity score on food stall

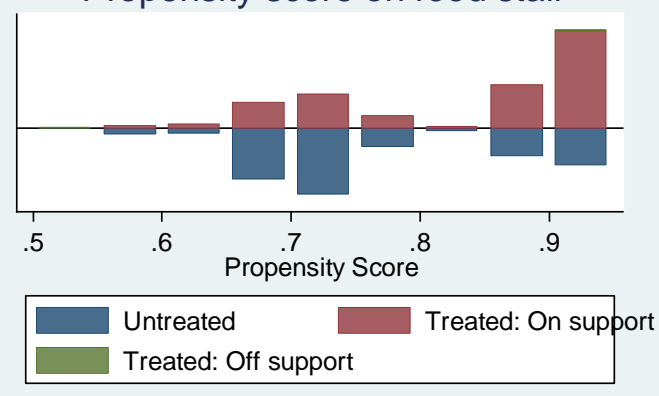

As shown above in Figure 4.1, although the propensity score distributions of the two groups are not exactly balanced, they appear in each interval of the propensity score. Generally speaking, the choice of propensity score function is acceptable.

With regard to the choices of matching methods, we use three classical approaches: nearest neighbor matching, radius matching, and kernel matching, following the suggestion from the literature (Becker and Ichino, 2002). 
Table 4.3: Propensity score function

\begin{tabular}{|c|c|c|c|c|c|c|c|c|c|c|c|}
\hline \multirow{2}{*}{\multicolumn{3}{|c|}{$\begin{array}{c}\text { Treatment variable: chinese_res } \\
\text { Mean }\end{array}$}} & \multicolumn{9}{|c|}{ Treatment variable: western_fast_food } \\
\hline & & & & & & & Mean & & & & \\
\hline Variable & Treated & Control & $\%$ bias & $\mathrm{p}>\mathrm{t}$ & $\mathrm{V}(\mathrm{T}) / \mathrm{V}(\mathrm{C})$ & Variable & Treated & Control & $\%$ bias & $\mathrm{p}>\mathrm{t}$ & $\mathrm{V}(\mathrm{T}) / \mathrm{V}(\mathrm{C})$ \\
\hline primary & 0.19 & 0.21 & $\begin{array}{l}-4.20 \\
-\end{array}$ & 0.28 & . & primary & 0.12 & 0.23 & -28.60 & 0.00 & \\
\hline middle & 0.37 & 0.48 & 23.90 & 0.00 & . & middle & 0.30 & 0.38 & -16.00 & 0.00 & . \\
\hline high & 0.22 & 0.10 & 34.80 & 0.00 & . & high & 0.32 & 0.18 & 31.40 & 0.00 & . \\
\hline college & 0.09 & 0.03 & 26.10 & 0.00 & . & college & 0.18 & 0.05 & 42.50 & 0.00 & . \\
\hline age & 51.12 & 50.85 & 1.90 & 0.64 & $0.92 *$ & age & 52.18 & 49.95 & 16.10 & 0.00 & 1.07 \\
\hline female & 0.05 & 0.06 & -2.00 & 0.57 & . & female & 0.05 & 0.05 & 0.00 & 1.00 & . \\
\hline Inincome & 9.69 & 9.50 & $\begin{array}{l}16.10 \\
-\end{array}$ & 0.00 & $0.77 *$ & lnincome & 9.99 & 9.59 & 36.30 & 0.00 & $0.60 *$ \\
\hline married & 0.96 & 0.99 & $\begin{array}{l}12.80 \\
-\end{array}$ & 0.00 & . & married & 0.97 & 0.95 & 6.70 & 0.03 & . \\
\hline smoking & 0.87 & 0.94 & 22.10 & 0.00 & . & smoking & 0.84 & 0.89 & -16.30 & 0.00 & . \\
\hline drinking & 0.67 & 0.62 & 10.30 & 0.01 & . & drinking & 0.67 & 0.67 & -0.90 & 0.79 & \\
\hline moderate_act & 0.18 & 0.10 & 23.20 & 0.00 & . & moderate_act & 0.17 & 0.18 & -3.60 & 0.26 & . \\
\hline heavy_act & 0.37 & 0.67 & 62.90 & 0.00 & . & heavy_act & 0.09 & 0.50 & -98.10 & 0.00 & . \\
\hline employed & 0.77 & 0.85 & 18.00 & 0.00 & . & employed & 0.67 & 0.82 & -34.40 & 0.00 & . \\
\hline supermkt & 0.60 & 0.50 & 21.00 & 0.00 & . & supermkt & 0.94 & 0.45 & 120.40 & 0.00 & . \\
\hline year & 2010.20 & 2009.80 & 33.30 & 0.00 & 0.99 & year & 2010.30 & 2010.10 & 9.90 & 0.00 & $0.90 *$ \\
\hline
\end{tabular}

Treatment variable: food_stall

Mean

\begin{tabular}{llllll}
\multicolumn{7}{c}{ Mean } & & & & \\
\hline Variable & Treated & Control & $\%$ bias & $\mathrm{p}>\mathrm{t}$ & $\mathrm{V}(\mathrm{T}) / \mathrm{V}(\mathrm{C})$ \\
primary & 0.19 & 0.19 & -0.60 & 0.79 &. \\
middle & 0.37 & 0.34 & 7.10 & 0.00 &. \\
high & 0.23 & 0.23 & 0.10 & 0.96 &. \\
& & & - & & \\
college & 0.09 & 0.12 & 12.70 & 0.00 &. \\
age & 51.18 & 50.61 & 4.20 & 0.07 & $0.90^{*}$ \\
female & 0.05 & 0.05 & -0.60 & 0.75 &. \\
lnincome & 9.70 & 9.81 & -9.40 & 0.00 & 1.03 \\
married & 0.96 & 0.96 & 1.10 & 0.63 &. \\
smoking & 0.87 & 0.86 & 2.80 & 0.23 &. \\
drinking & 0.68 & 0.67 & 1.50 & 0.50 &. \\
moderate_act & 0.18 & 0.18 & 1.60 & 0.48 &. \\
heavy_act & 0.35 & 0.35 & -1.80 & 0.41 &. \\
employed & 0.77 & 0.75 & 3.70 & 0.11 &. \\
supermkt & 0.65 & 0.65 & 0.00 & 1.00 &. \\
year & 2010.20 & 2010.30 & - & & \\
\hline
\end{tabular}


Notice that the definitions for these 3 types of food facility are slightly different: where the treatment variable is western_fast_food, it represents whether there is any Western-style fast food restaurant exactly within the community while the treatment variables for other two types of food facilities are counted if there is any within $5 \mathrm{~km}$ radius.

\section{Table 4.4: Empirical results on BMI}

\begin{tabular}{llrrr}
\hline \multirow{3}{*}{ PSM } & Treatment & & & \\
\hline Nearest & Variable & Coefficient & SE & T-test \\
Neighbor & chinese_res & 0.46 & 0.50 & 0.92 \\
& western_fast_food & 0.12 & 0.16 & 0.74 \\
Radius & food_stall & $-0.34^{*}$ & 0.21 & -1.59 \\
& chinese_res & $0.64^{* *}$ & 0.28 & 2.29 \\
& western_fast_food & 0.14 & 0.11 & 1.27 \\
Kernel & food_stall & -0.12 & 0.17 & -0.71 \\
& chinese_res & $0.57^{* *}$ & 0.28 & 1.99 \\
& western_fast_food & 0.13 & 0.11 & 1.26 \\
OLS & food_stall & -0.11 & 0.17 & -0.64 \\
& chinese_res & $0.36^{*}$ & 0.25 & 1.44 \\
& western_fast_food & $0.15^{*}$ & 0.10 & 1.53 \\
& food_stall & 0.03 & 0.15 & 0.2 \\
\hline
\end{tabular}

Note: $* * *, * *, *$ denote significant at $1 \%, 5 \%$ and $10 \%$ respectively.

The main results are reported in Table 4.4. Although the literature shows that (Western-style) fast food consumption could increase the risk for obesity and type 2 diabetes (Pereira et al., 2015), there is little literature comparing the nutritional outcome of Western-style fast food consumption with Chinese style restaurant food consumption. Notice that the Chinese restaurant has the highest and significant impact (except for the model approached by nearest neighbor) on BMI among the 3 types of food facilities, which is, however, violates the myth that Chinese restaurants should be nutritionally preferred since they accommodate the healthier conventional Chinese recipe. One possible explanation is that the excessive use of cooking oil for enhancing the taste and color of food is rather common in a Chinese restaurant. Another possible reason is that Western- 
style fast food restaurant has stricter food standard and tougher implication of uniformed and standardized receipt. The third reason could be that most of the recipes in Chinese restaurants are newly invented or newly-revised along with the richness of raw material maintained by modern food supply chains but not the conventional ones.

Besides, the outdoor food stall could even contribute to the lower BMI of the community, and the effect is statistically significant in the nearest neighbor setting. One plausible explanation is that outdoor food stall serves fiber intensive and low-in-energydensity food.

Table 4.5: Empirical results on overweight and obesity

\begin{tabular}{|c|c|c|c|c|}
\hline Overweight & $\begin{array}{l}\text { Treatment } \\
\text { Variable }\end{array}$ & Coefficient & $\mathrm{SE}$ & T-test \\
\hline Nearest & chinese_res & $0.10 *$ & 0.06 & 1.67 \\
\hline \multirow[t]{2}{*}{ Neighbor } & western_fast_food & $0.03 *$ & 0.02 & 1.75 \\
\hline & food_stall & -0.03 & 0.03 & -0.98 \\
\hline \multirow[t]{3}{*}{ Radius } & chinese_res & $0.08 * * *$ & 0.03 & 2.47 \\
\hline & western_fast_food & $0.04 * * *$ & 0.01 & 2.53 \\
\hline & food_stall & -0.01 & 0.02 & -0.61 \\
\hline \multirow[t]{3}{*}{ Kernel } & chinese_res & $0.08 * *$ & 0.03 & 2.31 \\
\hline & western_fast_food & $0.04 * * *$ & 0.01 & 2.51 \\
\hline & food_stall & -0.01 & 0.02 & -0.53 \\
\hline \multirow[t]{3}{*}{ OLS } & chinese_res & 0.02 & 0.03 & 0.69 \\
\hline & western_fast_food & $0.05 * * *$ & 0.01 & 3.62 \\
\hline & food_stall & -0.01 & 0.02 & -0.51 \\
\hline Obese & $\begin{array}{l}\text { Treatment } \\
\text { Variable }\end{array}$ & Coefficient & $\mathrm{SE}$ & T-test \\
\hline \multirow{3}{*}{$\begin{array}{l}\text { Nearest } \\
\text { Neighbor }\end{array}$} & chinese_res & 0.03 & 0.03 & 0.82 \\
\hline & western_fast_food & 0.01 & 0.01 & 0.73 \\
\hline & food_stall & -0.01 & 0.02 & -0.67 \\
\hline \multirow[t]{3}{*}{ Radius } & chinese_res & 0.02 & 0.02 & 0.90 \\
\hline & western_fast_food & 0.01 & 0.01 & 0.58 \\
\hline & food_stall & 0.00 & 0.01 & -0.24 \\
\hline \multirow[t]{2}{*}{ Kernel } & chinese_res & 0.02 & 0.02 & 0.82 \\
\hline & western_fast_food & 0.01 & 0.01 & 0.60 \\
\hline
\end{tabular}




\begin{tabular}{clrrr}
\hline \multirow{2}{*}{ OLS } & food_stall & 0.00 & 0.01 & -0.16 \\
& chinese_res & 0.02 & 0.02 & 1.14 \\
& western_fast_food & 0.00 & 0.01 & 0.33 \\
& food_stall & 0.01 & 0.01 & 0.84 \\
\hline
\end{tabular}

Note: $* * * * *, *$ denote significant at $1 \%, 5 \%$ and $10 \%$ respectively.

As shown in Table 4.5, the Chinese restaurant, followed by the western-style fast food store, has the largest impact on the overweight status of the community. It could boost 8 to 10 percentage of the probability of residents being overweight. The Western-style fast food store increases the probability of 3 to 4 percentage probability of being overweight. Besides, the outdoor food stalls show no significant effect on the prevalence of overweight.

None of any single type of food facility has a significant direct effect on the prevalence of obesity. Intuitively, people tend to consume more calories than they needed when they live in a community with fancy food facilities nearby, and hence face a higher probability of being overweight. But the self-awareness of body weight from the resident may be hedging down the probability of being obese.

Table 4.6: Empirical results on FAFH

\begin{tabular}{llrrr}
\hline \multirow{3}{*}{ PSM } & Treatment & & & \\
\hline Nearest & Variable & Coefficient & SE & T-test \\
Neighbor & chinese_res & -0.31 & 0.28 & -1.13 \\
& western_fast_food & 0.02 & 0.10 & 0.23 \\
Radius & food_stall & -0.09 & 0.13 & -0.73 \\
& chinese_res & $-0.47 * * *$ & 0.16 & -3.03 \\
& western_fast_food & -0.03 & 0.07 & -0.38 \\
Kernel & food_stall & -0.09 & 0.10 & -0.91 \\
& chinese_res & $-0.46^{* * *}$ & 0.16 & -2.88 \\
& western_fast_food & -0.03 & 0.07 & -0.37 \\
OLS & food_stall & -0.10 & 0.10 & -1.03 \\
& chinese_res & $-0.24 *$ & 0.15 & -1.57 \\
& western_fast_food & -0.07 & 0.06 & -1.17 \\
& food_stall & -0.11 & 0.09 & -1.23 \\
\hline
\end{tabular}

Note: $* * *, * * *$ denote significant at $1 \%, 5 \%$ and $10 \%$ respectively. 
As for FAFH (food away from home), we find all the types of food facilities have no positive impact on the frequency of FAFH. Specifically, as listed in Table 4.6, only Chinese restaurants have a significant negative effect (but not significant under the nearest neighbor setting). Here, it means that the existence of a Chinese restaurant nearby could decrease the frequency of FAFH by 0.31 to 0.47 for the total 12 meals (breakfast, lunch, dinner, and snacks) in the three consecutive days. It contradicts with intuition. One possible explanation is that the potential endogeneity issue that originates from measurement error or missing important control variables.

\section{- Multiple treatments framework}

So far, our results are based on the single treatment framework. While the multiple treatment framework could be a better alternative since it allows mixed results and synergy among the three types of food facilities.

Following Wooldridge (2008 and 2010), since we have 3 types of facilities, which means 3 binary indicators for treatments, that generates $2^{\wedge} 3=8$ treatment states in total under the multiple treatments framework: Chinese restaurant nearby $(\mathrm{CN})$, Western-style fast food store nearby (WFF), outdoor food stall nearby (OF), Chinese restaurant + Western-style fast food store nearby $(\mathrm{CN}+\mathrm{WFF})$, Chinese restaurant nearby + outdoor food stall nearby $(\mathrm{CN}+\mathrm{OF})$, Western-style fast food store + outdoor food stall nearby $(\mathrm{WFF}+\mathrm{OF})$, all of the three types of food facility nearby $(\mathrm{CN}+\mathrm{WFF}+\mathrm{OF})$, and none of the food facility nearby. Assuming that we take the state of the participants without any food facilities nearby as the control group, there will be 7 treatment groups. 
Our estimation strategy follows generalized boosted models (GBM) for propensity score weights proposed by McCaffrey et. al (2013) and developed by Cefalu \& Buenaventura (2017).

The total number of observations is 9553 , and more than half of the participants live in the community with no food facility nearby (in a $5 \mathrm{~km}$ radius). The results for BMI and obesity situation based on GBM and PSM for multiple treatments approach (McCaffrey et. al, 2013) are shown below.

Table 4.7: Food facility on BMI under multiple treatments framework

\begin{tabular}{rrrr}
\hline $\begin{array}{r}\text { Treatment } \\
\text { groups }\end{array}$ & ATT & SE & T-test \\
\hline $\mathrm{CN}$ & 0.07 & 0.17 & 0.44 \\
$\mathrm{OF}$ & -0.60 & 0.45 & -1.35 \\
$\mathrm{WFF}$ & 0.65 & 0.73 & 0.89 \\
$\mathrm{CN}+\mathrm{OF}$ & $0.37 * * *$ & 0.09 & 4.13 \\
$\mathrm{CN}+\mathrm{WFF}$ & $2.62 * * *$ & 0.42 & 6.24 \\
$\mathrm{CN}+\mathrm{WFF}+\mathrm{OF}$ & $0.77 * * *$ & 0.27 & 2.85 \\
cons & 23.04 & 0.05 & 489.09 \\
\hline
\end{tabular}

Note: Standard Errors are reported in brackets. and $* * *, * * *$ denote significant at $1 \%, 5 \%$ and $10 \%$ respectively. The control group is the group with no food facility nearby. There is no observation in WFF+OF group. 
Table 4.8: Food facility on Obesity under multiple treatments framework

\begin{tabular}{|c|c|c|c|}
\hline $\begin{array}{l}\text { Overweight } \\
\text { Treatment } \\
\text { groups }\end{array}$ & ATT & SE & T-test \\
\hline $\mathrm{CN}$ & 0.02 & 0.02 & 0.91 \\
\hline $\mathrm{OF}$ & 0.07 & 0.11 & 0.60 \\
\hline WFF & -0.05 & 0.11 & -0.42 \\
\hline $\mathrm{CN}+\mathrm{OF}$ & 0.01 & 0.01 & 1.22 \\
\hline $\mathrm{CN}+\mathrm{WFF}$ & $0.27 * * *$ & 0.09 & 2.96 \\
\hline $\mathrm{CN}+\mathrm{WFF}+\mathrm{OF}$ & $0.1 * * *$ & 0.04 & 2.64 \\
\hline cons & 0.28 & 0.01 & 43.52 \\
\hline $\begin{array}{l}\text { Obese } \\
\text { Treatment } \\
\text { groups } \\
\end{array}$ & ATT & SE & T-test \\
\hline $\mathrm{CN}$ & -0.01 & 0.01 & -0.47 \\
\hline $\mathrm{OF}$ & $0.06^{* * *}$ & 0.01 & -5.20 \\
\hline WFF & 0.00 & 0.06 & -0.06 \\
\hline $\mathrm{CN}+\mathrm{OF}$ & $0.02 * * *$ & 0.01 & 3.03 \\
\hline $\mathrm{CN}+\mathrm{WFF}$ & 0.05 & 0.03 & 1.40 \\
\hline $\mathrm{CN}+\mathrm{WFF}+\mathrm{OF}$ & 0.02 & 0.02 & 1.10 \\
\hline _cons & 0.07 & 0.00 & 19.80 \\
\hline
\end{tabular}

Note: Standard Errors are reported in brackets. and $* * *, * *, *$ denote significant at $1 \%, 5 \%$ and $10 \%$ respectively. The control group is the group with no food facility nearby. There is no observation in WFF+OF group.

It is noticeable that any treatment group with a single type of food facility nearby shows no statistically significant differences from the control group, while the combination of the Chinese restaurant with any one of the two other types of food facilities has a negative health influence on the residents. Specifically, residents with both Chinese restaurant and Western fast food store nearby takes the largest BMI. That implies the potential synergy of different types of food facilities. The single treatment framework may overestimate the unhealthy outcome of the Chinese restaurant. Interestingly, for the ones who keep the weight, the outdoor food stall could be a good option when enjoying a FAFH meal, compared with Chinese restaurants and Western fast food stores. 
As for the prevalence of overweight, the two combination stands up: Chinese restaurants plus Western fast food store show the largest impact, while the all the three types of food facility nearby boost the probability of being overweight slightly lower. Again, when there are already unhealthy recipes suppliers nearby, it is better to have a meal in the outdoor food stall. Finally, the outdoor food stall could reduce the probability of being obese for the resident. But the combination of Chinese restaurants and outdoor food stalls could boost the prevalence of obesity.

\subsection{Robustness Check}

To account for the impact of the location of the food facility on the sugar-sweetened beverage (SSB) consumption of residents, again we conduct a matching method and regression as shown in Table 4.9 .

Table 4.9: Empirical results on SSB consumption

\begin{tabular}{lrrr}
\hline Treatment & & & \\
Variable & Coefficient & SE & \multicolumn{1}{c}{ T-test } \\
\hline chinese_res & 0.33 & 0.38 & 0.88 \\
western_fast_food & $0.32 * *$ & 0.17 & 1.87 \\
food_stall & -0.08 & 0.30 & -0.28 \\
chinese_res & 0.26 & 0.32 & 0.81 \\
western_fast_food & $0.28^{* *}$ & 0.13 & 2.19 \\
food_stall & -0.25 & 0.20 & -1.27 \\
chinese_res & 0.24 & 0.32 & 0.76 \\
western_fast_food & $0.28^{* *}$ & 0.13 & 2.24 \\
food_stall & -0.24 & 0.20 & -1.20 \\
chinese_res & 0.26 & 0.28 & 0.92 \\
western_fast_food & $0.26^{* * *}$ & 0.11 & 2.38 \\
food_stall & -0.07 & 0.16 & -0.47 \\
\hline
\end{tabular}


It is not surprising that only western fast food store show significant influence on the frequency of SSB consumption for resident, since the most of the western-style fast food accommodate SSB, while the other two food facility has no such the convention.

Which type of restaurant is healthier in terms of calorie intake and body weight gain contribution, Western diets, or Chinese style diets? Literature (Johar et al., 2017) proposed that the Western-style fast food restaurant could be one main contributor to the growing BMI in China. While our results show the Chinese restaurant may induce worse nutritional outcomes in China.

To control for unobserved heterogeneity, we also implement an instrumental regression for comparison.

Table 4.10: Instrumental variables regression for the nutritional outcome of Chineses restaurant and food stall

\begin{tabular}{lllllll}
\hline Types of facility & \multicolumn{2}{l}{ Chinese restaurant } & \multicolumn{4}{l}{ Outdoor food stall } \\
\hline Outcome & Coefficient & SE & T-test & Coefficient & SE & T-test \\
\hline bmi & $3.88^{* *}$ & 1.91 & 2.03 & -0.11 & 0.43 & -0.26 \\
overweight & 0.18 & 0.23 & 0.79 & -0.07 & 0.05 & -1.33 \\
obese & 0.19 & 0.15 & 1.26 & 0.01 & 0.03 & 0.25 \\
fafh & -1.19 & 1.13 & -1.05 & $0.45^{*}$ & 0.26 & 1.75 \\
\hline
\end{tabular}

Notice using distance as an instrumental variable is not available for Western fastfood restaurants because of collinearity, we only report results for Chinese restaurants and food stalls. Again, the Chinese restaurant has the largest and most significant impact on the BMI of Chinese adults even if we take the endogeneity issue into account. Other than that, the outdoor food stall could boost the frequency of FAFH while without boosting up the BMI of residents or the prevalence of obesity in the community. One possible explanation is that the recipes accommodated in the outdoor food stall are close to the homemade meals. 


\subsection{Conclusions}

We check if the different types of food facilities have a significant impact on nutritional outcomes and dietary pattern choices. Given the food facility as a proxy indicator for food availability and food environment, we contribute to the literature by extending the channel of food availability on the food patterns and health outcomes. We argue that the combination of the Chinese restaurant and the Western fast food store has the largest impact on the BMI of residents.

With the use of CHNS 2004 to 2011 data, we implement both a propensity matching method and an instrumental variable method to deal with potential endogeneity issues like self-selection and omitted variables. This study shows that given the Chinese restaurant nearby if there are any other two types of food facility could have a significant positive effect on the popularity of obese and overweight for the residents. We find no evidence that the location of the food facility has an impact on the choice of food at home or food away from home. Nevertheless, we find the location of the food facility indeed changes the choices of food patterns such as by increasing the SSB consumption.

One policy implication of our study is to enhance the public awareness of nutrition outcomes of food patterns and dietary structure. For policymakers, it is possible to legislate a stricter food quality control standard such as making the food ingredients and calories visible to the consumers or promote a healthy diet habit following a specific standard like Dietary guidelines for Chinese residents for the community. 


\section{Chapter 5 General Conclusion}

As an emerging economy with the largest population, China has undergone rapid economic growth in the last decades. As a result, food patterns and dietary structure in typical Chinese household has changed drastically. A traditional high in fiber, low in fat food has been replaced by high in sugar and fat, high in energy-dense food. As described as nutrition transition, the nutritional outcome of household income growth attracts the attention of researchers.

However, how the lifestyle, food patterns and dietary structure, food availability, and nutritional outcome linked with each other in the emerging economy remains unclear. We contribute to the literature by investigating three topics covering those aspects.

\subsection{Conclusions}

For the first paper, we study the impact of the golden week policy for the National Day holiday on body weight and obesity since 2000 in the short run and long run. Based on the secondary observational data, we use a regress discontinuity design to deal with the jump in the BMI before and after the National Day holiday. The results show Chinese adults tend to gain $1.561 \mathrm{~kg}$ during the National Day holiday. The weight gain shrinks to insignificant $0.491 \mathrm{~kg}$ when we turn to the one-month level analysis.

For the second paper, we decompose the result of income growth on calorie consumption into conditional income effect and partial effect mediated by change on the dietary structure. Based on household survey data in China, we find that 16 to $21 \%$ of the increase is due to dietary structural change, while the rest part is attributed to the conditional income effect. On top of that, we find regional disparity that the dietary 
structural change effect is more important in rural China. For policymakers, they could estimate the slowdown in increasing demand for meat in urban China but may an uprising demand in rural China.

For the third paper, we check the food availability on the nutritional outcome by checking the location of different food facilities on BMI, obesity status of residents, and checking the FAFH frequency and SSB consumption frequency. Unlike the institutional thinking that the Western-style food facility has a larger effect on inducing unhealthy food patterns compared with a Chinese restaurant, we find that the Chinese restaurant has the largest positive impact on BMI and prevalence of obesity. Not surprisingly, the Western fast-food restaurants increase the frequency of SSB consumption. The conventional outdoor food stall could be the good option for residents, since we do not observe any significant unfavored nutritional outcome. For policymakers, it is possible to spread dietary knowledge to reduce the hazard caused by highly processed food. Meanwhile, it is possible to make the regulation on marking the food content and total calories of meals to enhance the nutritional awareness for the residence.

\subsection{Policy implication}

The relationship between obesity and nutrition transition attracts the attention of researchers. All of these three papers in this dissertation deal with some facets of nutrition transition. According to the estimate by recent study (Wang et al. 2021), the current policies was inadequate to curb the trend of obesity epidemic, thus government, community, and the household should realize the severe situation and take action. 
When dealing with the policy implication on the public holiday, we argue that even the week-long public holiday induces behavior and lifestyle change of the public and influences the prevalence of overweight and obesity. We should not ignore the fact that the golden-week national Day holiday, although boosting the travel industry, could help people gain body weight both in the short run and middle run.

When evaluating the effect of income growth on nutritional improvement, generally speaking, we argue that 20 percent of improvement could be attributed to the change in dietary structure and food patterns. To be specific, getting rich and having meat is correlated especially in rural China since the corresponding number is $22 \%$ to $27 \%$.

The food demand is dynamic, people have incentives to change their dietary structure when they get a higher income. This is essential for correction on the food demand prediction and formulating agricultural or food policies, as well as food security in the long run.

When dealing with food availability and food facility, we make one counterintuitive argument that among all the food facilities, Chinese restaurants rather than Western-style fast-food restaurants have a larger effect on malnutrition and prevalence of overweight and obesity, and the synergy of these two types of food facility greatly enhance the risks. Different from Western-style fast-food restaurants in chain operation, the Chinese restaurant has hardly a uniform standard in ingredients such as fat and oil. Thus, to prevent the prevalence of obesity, it is possible to enhance public awareness about food content and nutritional composition of the meals when they are having food at a non-standardized restaurant. The government could compulsory nutrition fact labelling for the food facilities. 
The improvement on the built environment could also help reduce the obesity risks by increasing the physical activity of residents (Townshend and Lake, 2017).

\subsection{Limitation and future research}

For sure we have some limitations in those 3 topics. In Chapter 2, we only use the data for several years rather than all years after the golden week policy was implemented in 2000 because of the availability of data from CHNS. On top of that, we impose a strong assumption of random sampling, that is, there is no systematic difference between the participants who record health exam results before the National Day holiday, and the participants report their height and weight after the holiday in terms of everything other than BMI. Further, our conclusion about the holiday is rather case-specific. We must admit that the conclusion of body weight gain during the National Day holiday in China may not able to extend to other public holidays and other countries.

In Chapter 3, we use household inventory change data to estimate food consumption and the dietary structure. Those calculated data for food consumption may induce measurement error. Meanwhile, Food waste is not being considered.

In Chapter 4, we use no exact location information such as GPS data but rather the self-reported $5 \mathrm{~km}$ radius as the standard for the availability of food facilities.

To have a research outlook, we could conduct a survey to obtain the primary data rather than utilizing the secondary data which limits the scope of our topic in the future. Endogeneity is not considered especially in Chapter 3, thus we would search for a valid instrument or considering the specific econometric tools such as the control function method to eliminate the potential bias that may be caused by endogeneity. We also limit 
our topic in the aggregate or the categorical data for a different type of food, and in-depth product-by-product analysis is possible in the future study. 


\section{Bibliography}

Achadi, E., Ahuja, A., Bendech, M. A., Bhutta, Z. A., De-Regil, L. M., Fanzo, J., Fracassi, P., Grummer-Strawn, L. M., Haddad, L. J. \& Hawkes, C. (2016), Global nutrition report 2016: from promise to impact: ending malnutrition by 2030, International Food Policy Research Institute.

Alston, J. M., MacEwan, J. P., \& Okrent, A. M. (2016). "The economics of obesity and related policy". Annual Review of Resource Economics, 8, 443-465.

An R, He L, Shen MJ. Impact of neighbourhood food environment on diet and obesity in China: a systematic review. Public Health Nutr 2020; 23: 457-73.

Asfaw, A. (2008). "Does supermarket purchase affect the dietary practices of households? Some empirical evidence from Guatemala". Development Policy Review, 26(2), 227-243.

Bai, J., Zhang, C., Qiao, F., \& Wahl, T. (2012). "Disaggregating household expenditures on food away from home in Beijing by type of food facility and type of meal". China Agricultural Economic Review, 4(1), 18-35.

Batis, C., Sotres-Alvarez, D., Gordon-Larsen, P., Mendez, M. A., Adair, L., \& Popkin, B. (2014), "Longitudinal analysis of dietary patterns in Chinese adults from 1991 to 2009", British Journal of Nutrition, 111(8), 1441-1451.

Becker, S. O., \& Ichino, A. (2002), "Estimation of average treatment effects based on propensity scores", The Stata Journal, 2(4), 358-377.

Chang, X., DeFries, R. S., Liu, L., \& Davis, K. (2018). "Understanding dietary and staple food transitions in China from multiple scales". PloS One, 13(4), e0195775.

Chavas, Jean-Paul (1983), "Structural change in the demand for meat", American Journal of Agricultural Economics. 65, no. 1: 148-153. 
Chege, C. G., Andersson, C. I., \& Qaim, M. (2015). "Impacts of supermarkets on farm household nutrition in Kenya". World Development, 72, 394-407.

Chen D., D. Abler, D. Zhou, X. Yu, and W. Thompson (2016), "A Meta-Analysis of Food Demand Elasticities for China", Applied Economics Perspective and Policy. Vol. 38(1):50-72.

Dawson, Philip J.(1997), "The demand for calories in developing countries", Oxford Development Studies.25, no. 3: 361-369.

Dearth-Wesley, T., Wang, H., \& Popkin, B. (2008). "Under-and overnutrition dynamics in Chinese children and adults (1991-2004) ". European Journal of Clinical Nutrition, 62(11), 1302.

Díaz-Zavala, R. G., Castro-Cantú, M. F., Valencia, M. E., Álvarez-Hernández, G., Haby, M. M., \& Esparza-Romero, J. (2017). "Effect of the holiday season on weight gain: a narrative review". Journal of Obesity, 2017.

Du, S., Lu, B., Zhai, F., \& Popkin, B. M. (2002), "A new stage of the nutrition transition in China", Public Health Nutrition, 5(1a), 169-174.

Du, W., Su, C., Wang, H., Wang, Z., Wang, Y., \& Zhang, B. (2014). "Is density of neighbourhood restaurants associated with BMIin rural Chinese adults? A longitudinal study from the China Health and Nutrition Survey". BMJ Open, 4(4), e004528.

Hasiner E. and X. Yu (2016), "Meat Consumption and Democratic Governance: A Cross National Analysis", China Economic Review, Vol. 59: 100950

Gillis, L. J., \& Bar-Or, O. (2003). "Food away from home, sugar-sweetened drink consumption and juvenile obesity". Journal of the American College of Nutrition, 22(6), 539-545.

Gordon-Larsen, P. (2014). "Food availability/convenience and obesity". Advances in Nutrition, 5(6), 809-817. 
Gordon-Larsen, P., Wang, H., \& Popkin, B. M. (2014). "Overweight dynamics in Chinese children and adults". Obesity Reviews, 15, 37-48.

Hausman, C., \& Rapson, D. S. (2018). "Regression discontinuity in time: Considerations for empirical applications". Annual Review of Resource Economics, 10, 533-552.

Hawkes, C. (2008). "Dietary implications of supermarket development: a global perspective". Development Policy Review, 26(6), 657-692.

Helander, E. E., Wansink, B., \& Chieh, A. (2016), "Weight gain over the holidays in three countries". New England Journal of Medicine, 375, 1200-1202.

Hull, H. R., Radley, D., Dinger, M. K., \& Fields, D. A. (2006). "The effect of the Thanksgiving holiday on weight gain". Nutrition Journal, 5, 29.

Jekanowski, M. D., Binkley, J. K., \& Eales, J. S. (2001). "Convenience, accessibility, and the demand for fast food". Journal of Agricultural Resource Economics, 26(1835-2016-148749), 5874.

Jensen, H. H., \& Yen, S. T. (1996). "Food expenditures away from home by type of meal". Canadian Journal of Agricultural Economics, 44(1), 67-80.

Jensen, Robert T., and Nolan H. Miller (2010), "A revealed preference approach to measuring hunger and undernutrition", No. w16555. National Bureau of Economic Research

Jiang, Y., Xu, Y., Bi, Y., Wang, L., Zhang, M., Zhou, M., . . Wang, T. (2015). "Prevalence and trends in overweight and obesity among Chinese adults in 2004-10: data from three nationwide surveys in China". The Lancet, 386, S77.

Johar, M., Maruyama, S., \& Truong, J. (2017). "The contribution of Western fast food to fastgrowing body mass in China". Applied Economics, 49(8), 797-811. 
Khonje, M. G., \& Qaim, M. (2019). "Modernization of African food retailing and (un) healthy food consumption". Sustainability, 11(16), 4306.

Kimenju, S. C., Rischke, R., Klasen, S., \& Qaim, M. (2015). "Do supermarkets contribute to the obesity pandemic in developing countries? " Public health nutrition, 18(17), 3224-3233.

Lee, D. S., \& Lemieux, T. (2010), "Regression discontinuity designs in Economics". Journal of Economic Literature, 48, 281-355.

Li, F., Harmer, P., Cardinal, B. J., Bosworth, M., \& Johnson-Shelton, D. (2009). "Obesity and the built environment: does the density of neighborhood fast-food outlets matter?" American Journal of Health Promotion, 23(3), 203-209.

Lytle L, Myers A. Measures registry user guide: food environment. Washington, DC: National Collaborative on Childhood Obesity Research, 2017

Ma, H., Huang, J., Fuller, F., \& Rozelle, S. (2006). "Getting rich and eating out: consumption of food away from home in urban China". Canadian Journal of Agricultural Economics, 54(1), 101-119.

McCracken, V. A., \& Brandt, J. A. (1987). "Household consumption of food-away-fromhome: total expenditure and by type of food facility". American Journal of Agricultural Economics, 69(2), 274-284.

Min, S., Wang, X., \& Yu, X. (2020). "Does dietary knowledge affect household food waste in the developing economy of China?". Food Policy, 101896.

Ng, M., Fleming, T., Robinson, M., Thomson, B., Graetz, N., Margono, C., . . Abera, S. F. (2014). "Global, regional, and national prevalence of overweight and obesity in children and adults during 1980-2013: a systematic analysis for the Global Burden of Disease Study 2013". The Lancet, 384(9945), 766-781. 
Ogden, C. L., Carroll, M. D., Fryar, C. D., \& Flegal, K. M. (2015). "Prevalence of obesity among adults and youth: United States", 2011-2014, NCHS Data Brief, 1-8.

Pan, X. F., Wang, L., \& Pan, A. (2021). Epidemiology and determinants of obesity in China. The Lancet Diabetes \& Endocrinology, 9(6), 373-392.

Pereira, M. A., Kartashov, A. I., Ebbeling, C. B., Van Horn, L., Slattery, M. L., Jacobs Jr, D. R., \& Ludwig, D. S. (2005). "Fast-food habits, weight gain, and insulin resistance (the CARDIA study): 15-year prospective analysis". The Lancet, 365(9453), 36-42.

Popkin, Barry M., Bing Lu, and Fengying Zhai (2002), "Understanding the nutrition transition: measuring rapid dietary changes in transitional countries", Public Health Nutrition. 5, no. 6a: 947953.

Popkin, B. M., Keyou, G., Zhai, F., Guo, X., Ma, H., \& Zohoori, N. (1993), "The nutrition transition in China: a cross-sectional analysis", European Journal of Clinical Nutrition, 47(5), 333346.

Popkin, B. M., Kim, S., Rusev, E. R., Du, S., \& Zizza, C. (2006). "Measuring the full economic costs of diet, physical activity and obesity-related chronic diseases". Obesity Reviews, 7(3), 271293.

Popkin, Barry M., Linda S. Adair, and Shu Wen Ng (2012), "Global nutrition transition and the pandemic of obesity in developing countries." Nutrition Reviews, 70, no. 1: 3-21.

Preacher, Kristopher J., and Andrew F. Hayes(2008), "Asymptotic and resampling strategies for assessing and comparing indirect effects in multiple mediator models."Behavior Research Methods. 40, no. 3: 879-891.

Qin, X., \& Pan, J. (2016). "The medical cost attributable to obesity and overweight in China: Estimation based on longitudinal surveys". Health Economics, 25(10), 1291-1311. 
Roberts, S. B. (2000). "Holiday weight gain: fact or fiction?". Nutrition Reviews, 58, 378-379.

Schipmann, C., \& Qaim, M. (2011). "Modern food retailers and traditional markets in developing countries: comparing quality, prices, and competition strategies in Thailand". Applied Economic Perspectives and Policy, 33(3), 345-362.

Schoeller, D. A. (2014). "The effect of holiday weight gain on body weight". Physiology \& Behavior. 134, 66-69.

Shimokawa, Satoru.(2010). "Asymmetric Intrahousehold Allocation of Calories in China". American Journal of Agricultural Economics, 92, no. 3: 873-888.

Shimokawa, Satoru (2015). "Sustainable Food Consumption in China". Journal of Integrative Agriculture, 14(6): 1023-1032.

Sturm, R., Patel, D., Alexander, E., \& Paramanund, J. (2016). "Seasonal cycles in food purchases and changes in BMIamong South Africans participating in a health promotion programme". Public Health Nutrition, 19, 2838-2843.

Subramanian, Shankar, and Angus Deaton. (1996). "The demand for food and calories". Journal of Political Economy 104, no. 1: 133-162.

Tian, X., \& Yu, X. (2013). "The demand for nutrients in China". Frontiers of Economics in China, 8(2), 186-206.

Tian, X., \& Yu, X. (2015). "Using semiparametric models to study nutrition improvement and dietary change with different indices: The case of China". Food Policy, 53, 67-81.

Tian, X., Zhong, L., von Cramon-Taubadel, S., Tu, H., \& Wang, H. (2016). "Restaurants in the neighborhood, eating away from home and BMIin China". PloS One, 11(12), e0167721. 
Townshend T, Lake A. Obesogenic environments: current evidence of the built and food environments. Perspect Public Health 2017; 137: 38-44.

Umberger, W. J., He, X., Minot, N., \& Toiba, H. (2015). "Examining the relationship between the use of supermarkets and over-nutrition in Indonesia". American Journal of Agricultural Economics, 97(2), 510-525.

Wagner, D. R., Larson, J. N., \& Wengreen, H. (2012), "Weight and body composition change over a six-week holiday period", Eating and Weight Disorders-Studies on Anorexia, Bulimia and Obesity, 17, e54-e56.

Wang, Y. C., McPherson, K., Marsh, T., Gortmaker, S. L., \& Brown, M. (2011). "Health and economic burden of the projected obesity trends in the USA and the UK". The Lancet, 378(9793), $815-825$.

Wang, Y., Zhao, L., Gao, L., Pan, A., \& Xue, H. (2021). Health policy and public health implications of obesity in China. The Lancet Diabetes \& Endocrinology.

Wang, Zhi-Hong, Feng-Ying Zhai, Shu-Fa Du, and Barry Popkin (2008), "Dynamic shifts in Chinese eating behaviors", Asia Pacific Journal of Clinical Nutrition 17, no. 1 (2008): 123-130.

Whitney, E., \& Rolfes, S. R. (2016), Understanding Nutrition. 14e, Canada.

W.H.O., "Obesity and overweight fact sheets 2014", available at:

http://www.who.int/mediacentre/factsheets/fs311/en/ (accessed 16 April 2020).

Xu H, Short SE, Liu T. Dynamic relations between fast-food restaurant and body weight status: a longitudinal and multilevel analysis of Chinese adults. J Epidemiol Community Health 2013; 67: $271-79$. 
Yanovski, J. A., Yanovski, S. Z., Sovik, K. N., Nguyen, T. T., O'Neil, P. M., \& Sebring, N. G. (2000). "A prospective study of holiday weight gain". New England Journal of Medicine, 342, 861-867.

Yu X. (2015), "Meat consumption in China and its impact on international food security: Status quo, trends, and policies", Journal of Integrative Agriculture, Vol. 14(6):989-994.

Yu, Xiaohua, and David Abler (2009), "The demand for food quality in rural China", American Journal of Agricultural Economics, 91, no. 1 (2009): 57-69.

Yu X. and D. Abler (2016), "Matching food with mouths: A statistical explanation to the abnormal decline of per capita food consumption in rural China", Food Policy, Vol.63:36-43.

Zeng Q. and X. Yu (2019) . "Overweight and obesity standards and subjective well-being: evidence from China". Economics and Human Biology, Vol. 33: 144-148.

Zhang, B., Zhai, F., Du, S., \& Popkin, B. M. (2014). "The China Health and Nutrition Survey, 1989-2011". Obesity Reviews, 15, 2-7.

Zhang, J., Xu, P., \& Liu, F. (2016). "One-child policy and childhood obesity". China Economic Review, 100938.

Zhao Q and X. Yu (2019). "Parental nutrition knowledge, iron deficiency and children anemia in rural China". forthcoming in Journal of Development Studies.

Zhou D. , X. Yu and T. Herzfeld (2015), "Dynamic food demand in urban China", China Agricultural Economic Review, Vol.7(1):27-44.

Zhou, De, and Xiaohua Yu (2015), "Calorie elasticities with income dynamics: evidence from the literature", Applied Economic Perspectives and Policy.37, no. 4 (2015): 575-601. 
Zhou, De, Xiaohua Yu, David Abler, Danhong Chen (2017), "Projecting meat and cereals demand for China based on a meta-analysis of income elasticities", China Economic Review, 101135 


\section{Curriculum Vitae}

\section{Personal Information}

Name: Hengrong Luo

Email: hengrong.luo(at)agr.uni-goettingen.com

Tel: +49-(0)5513920213

Address: Heinrich-Düker-Weg 12, 37073 Göttingen, Germany

Place of birth: Sichuan province, China

\section{Position}

3/2017-3/2020 Ph.D. student and research associate in Agricultural Economics

RTG 1666: Transformation of Global Agri-Food Systems

University of Göttingen, Germany

\section{Education}

2009-2013 Bachelor of Business Administration, Southwestern University of Finance and Economics, Chengdu, China

2013-2016 Master of Economics, Southwestern University of Finance and Economics, Chengdu, China

2017-present Ph.D. student in Agricultural Economics, University of Göttingen, Göttingen, Germany (Supervisor: Prof. Xiaohua Yu Ph.D.)

\section{Publications}

Peer-reviewed publications or book chapters

Yu, X., H. Luo, H. Wang, J. H. Feil (2020). Climate Change and Agricultural Trade in Central Asia: Evidence from Kazakhstan. Forthcoming in Ecosystem Health and Sustainability. https://doi.org/10.1080/20964129.2020.1766380 
Luo, H., X. Yu (2020), "National Day Holiday and Weight Gain in China: Evidence from CHNS Surveys", Forthcoming in Applied Economic Letters. https://doi.org/10.1080/13504851.2020.1861184

Other publications

Luo, H., X. Yu (2020), "Holiday and Weight Gain: Evidence from the National Day Holiday in China", GlobalFood Discussion Paper. University of Goettingen.

Luo, H., X. Yu (2020), "Meat Consumption, Dietary Structure and Nutrition Transition in China", GlobalFood Discussion Paper. University of Goettingen.

\section{Conference presentations}

2017, The $9^{\text {th }}$ CAER-IFPRI Annual Conference, Beijing, China

Presented paper: Holiday and weight gain, evidence from National Day holiday in China 2019, The $11^{\text {th }}$ CAER-IFPRI Annual Conference, Hangzhou, China

Presented paper: Meat consumption, dietary structure and nutrition transition in China 